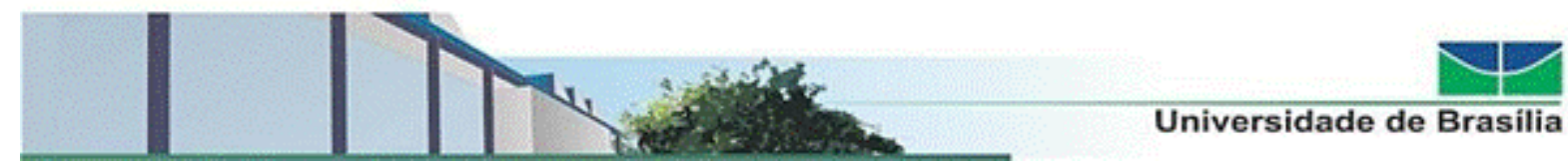

UNIVERSIDADE DE BRASÍLIA

FACULDADE DE ECONOMIA, ADMINISTRAÇÃO E CONTABILIDADE - FACE DEPARTAMENTO DE CIÊNCIAS CONTÁBEIS E ATUARIAIS - DCCA PROGRAMA DE PÓS-GRADUAÇÃO EM CIÊNCIAS CONTÁBEIS - PPGCONT

AVALIAÇÃO NA SAÚdE PÚBLICA: UM OLHAR SOBRE O DESEMPENHO DOS MUNICÍPIOS BRASILEIROS NA SUBFUNÇÃO ATENÇÃO BÁSICA À SAÚDE

Marina de Freitas Prieto

BRASÍLIA, DF 


\section{Professora Doutora Márcia Abrahão Moura}

Reitora da Universidade de Brasília

\section{Professor Doutor Enrique Huelva Unternbäumen}

Vice-reitor da Universidade de Brasília

\section{Professora Doutora Helena Eri Shimizu}

Decana de Pesquisa e Pós-graduação

Professor Doutor Eduardo Tadeu Vieira

Diretor da Faculdade de Economia, Administração e Contabilidade

Professor Doutor José Antônio de França

Chefe do Departamento de Ciências Contábeis e Atuariais

Professor Doutor César Augusto Tibúrcio Silva Coordenador de Pós-Graduação em Ciências Contábeis 
MARINA DE FREITAS PRIETO

AVALIAÇÃO NA SAÚDE PÚBLICA: UM OLHAR SOBRE O DESEMPENHO DOS MUNICÍPIOS BRASILEIROS NA SUBFUNÇÃO ATENÇÃO BÁSICA À SAÚDE

Dissertação apresentada ao Programa de PósGraduação em Ciências Contábeis da Universidade de Brasília (PPGCont) como requisito para a obtenção do título de Mestre em Ciências Contábeis.

Linha de pesquisa: Impactos da Contabilidade no Setor Público, nas Organizações e na Sociedade.

Orientadora: Profa. Dra. Mariana Guerra.

Brasília, DF 
Ficha catalográfica elaborada automaticamente, com

os dados fornecidos pelo(a) autor(a)

PRIETO, Marina de Freitas.

Avaliação na saúde pública: um olhar sobre o desempenho dos municípios brasileiros na subfunção atenção básica à saúde. / Marina de Freitas Prieto. Brasília, 2018.

91f.

Dissertação apresentada a Universidade de Brasília, como parte dos requisitos exigidos para a Conclusão do Curso de Mestrado em Ciências Contábeis.

Orientador: Prof. ${ }^{\text {a }}$ Dra. Mariana Guerra.

1. Atenção básica 2. Eficiência. 3. SUS 4. Eficiência 5. Avaliação. Município.

I. GUERRA, Mariana (Orientadora) II. Título. 

MARINA DE FREITAS PRIETO

\title{
AVALIAÇÃO NA SAÚDE PÚBLICA: UM OLHAR SOBRE O DESEMPENHO DOS MUNICÍPIOS BRASILEIROS NA SUBFUNÇÃO ATENÇÃO BÁSICA À SAÚDE
}

Dissertação apresentada como requisito parcial à obtenção do título de Mestre em Ciências Contábeis do Programa de Pós-Graduação em Ciências Contábeis da Universidade de Brasília.

Aprovada em:

Comissão Avaliadora:

\section{Prof. Dra. Mariana Guerra}

Programa de Pós-Graduação em Ciências Contábeis - PPGCont

(Presidente da Banca)

\section{Prof. Dr. André Nunes}

Programa de Pós-Graduação em Ciências Contábeis - PPGCont

(Membro Examinador Interno)

\section{Prof. Dr. Márcio Augusto Gonçalves}

Programa de Pós-Graduação em Ciências Contábeis - FACE - UFMG

(Membro Examinador Externo)

\author{
BRASÍLIA, DF
}


À Deus, meus pais, minha vó, minha tia e amigos por me apoiarem quando achei que não conseguiria. 


\section{AGRADECIMENTOS}

À Deus.

À Prof. Dra. Mariana Guerra, orientadora deste trabalho, que me aceitou como orientanda no meio do caminho e que me auxiliou ao longo de um ano não deixando desistir. Obrigada pela sua paciência, compreensão e dedicação. Muito obrigada, professora!

À Sara e a Inez pela presteza e dedicação que tiveram ao longo desses dois anos comigo. À minha família pela ajuda e apoio.

Aos membros da banca avaliadora pelas contribuições.

Que Deus os abençoe. Muito obrigada! 
"Aprendi o silêncio com os faladores, a tolerância com os intolerantes, a bondade com os maldosos; $e$, por estranho que pareça, sou grato a esses professores".

Khalil Gibran 


\section{RESUMO}

A avaliação como componente da gestão em saúde tem hoje um reconhecimento que se traduz na existência de múltiplas iniciativas voltadas para a consolidação e aprimoramento do Sistema Único de Saúde (SUS) no Brasil. Com o objetivo de avaliar a eficiência na Atenção Primária em Saúde (APS) nos municípios brasileiros, além de averiguar possíveis disparidades regionais, de fatores socioeconômicos e de características do sistema de saúde, foi utilizada a metodologia proposta por Varela et al (2012). Utilizou-se, portanto, análise envoltória de dados e regressão multivariada, para analisar os municípios brasileiros, entes responsáveis pela subfunção atenção básica à saúde. A população composta inicialmente era de 5.560, sendo excluídos os municípios com informações ausentes ou inconsistentes para as bases de dados utilizadas, quais sejam: o Sistema de Informações Ambulatoriais - SIA, o Sistema de Informações da Atenção Básica SIAB e o Sistema de Informações sobre Orçamentos Públicos em Saúde - SIOPS. Os resultados validam a metodologia utilizada e confirmam que as variáveis densidade populacional e número de habitantes idosos determinam a eficiência no gasto municipal com APS no Brasil.

Palavras-chave: Atenção Básica. Eficiência. SUS. Avaliação. Município. 


\begin{abstract}
The evaluation as a component of health management has now been recognized that there are multiple initiatives aimed at consolidating and improving the Unified Health System (SUS) in Brazil. The methodology proposed by Varela et al (2012) was used to assess the efficiency of Primary Health Care in Brazilian municipalities, as well as to investigate possible regional disparities and socioeconomic factors and characteristics of the health system. Data and multivariate regression analysis were used to analyze the Brazilian municipalities, which are responsible for the basic health subfunction. The population initially comprised 5560, excluding municipalities with missing or inconsistent information for the databases used, namely: the Outpatient Information System - SIA, the Basic Attention Information System - SIAB and the Information System on Public Budgets in Health - SIOPS. The results validate the methodology used and confirm that the variables population density and number of elderly inhabitants determine the efficiency in municipal spending with basic care in Brazil.
\end{abstract}

Keywords: Basic Attention. Efficiency. SUS. Evaluation. County. 


\section{LISTA DE FIGURAS}

Figura 1 - Contribuições dos estudos seminais da Visão Baseada em Recursos ....................26

Figura 2 - Pacto da saúde: uma estratégia para viabilizar a equidade em saúde no Brasil.......40

Figura 3 - Etapas para implementar a modelagem por DEA................................................49

Figura 4 - Variáveis de input discricionário e outputs do modelo de eficiência técnica ..........51

Figura 5 - Pressupostos do modelo de regressão para as 17 DMUS eficientes - normalidade dos

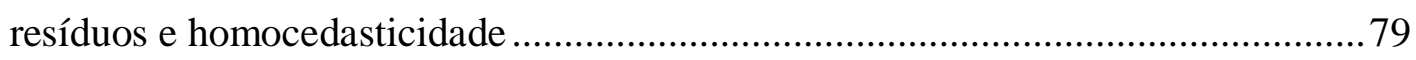

Figura 6 - Pressupostos do modelo de regressão - normalidade dos resíduos e homocedasticidade utilizando todas as variáveis não controláveis, para as DMUs

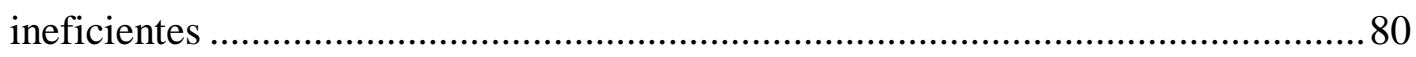

Figura 7 - Pressupostos do modelo de regressão - normalidade dos resíduos e homocedasticidade utilizando todas as variáveis não controláveis, para as DMUs ineficientes resultantes do Primeiro Estágio ........................................................ 80

Figura 8 - Intervalo de Confiança variável DD no modelo de Regressão para os 116 municípios

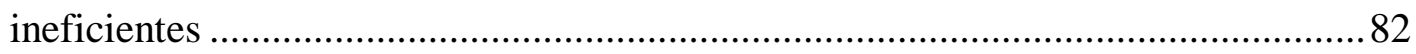

Figura 9 - Intervalo de Confiança da variável RS no modelo de Regressão para os $116 \ldots \ldots . . . .83$

Figura 10 - Valores preditivos com base modelo de regressão para os 16 municípios

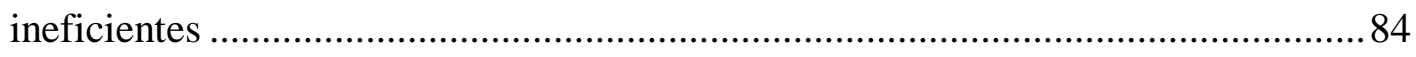




\section{LISTA DE QUADROS}

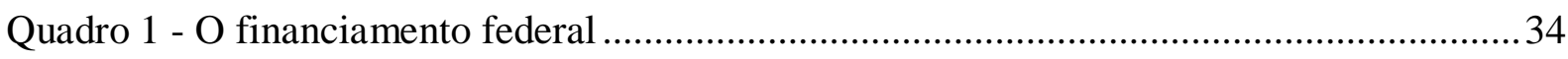

Quadro 2 - Princípios da Atenção Primária à Saúde nas Redes de Atenção à Saúde ..............38

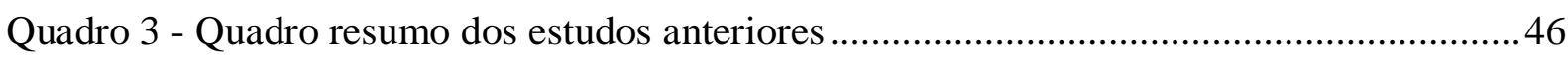

Quadro 4 - Variáveis não controláveis do modelo de eficiência dos municípios.....................54 


\section{LISTA DE TABELAS}

Tabela 1 - Escores de eficiência no primeiro para DMUS com eficiência padrão > 10\% .......55

Tabela 2 - Escores de eficiência para DMUS com eficiência padrão < 10\% ............................57

Tabela 3 - Modelo de Regressão Múltipla utilizando todas as variáveis não controláveis, para

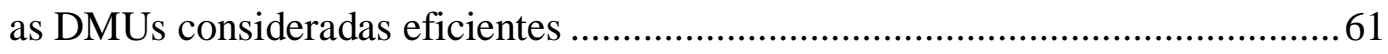

Tabela 4 - Modelo de Regressão Múltipla para os 116 municípios ineficientes .....................62 Tabela 5 - Modelo de Regressão Múltipla utilizando todas as variáveis não controláveis, para as DMUs eficientes ............................................................... 79

Tabela 6 - ANOVA do modelo de Regressão Múltipla para os 116 municípios ineficientes ..80

Tabela 7 - Gasto Per Capita por municípios considerados eficientes .................................... 85

Tabela 8 - Gasto Per Capita por municípios considerados ineficientes..................................85 


\section{LISTA DE ABREVIATURAS E SIGLAS}

ABS

ACS

AIS

APS

CAPES

CER

CNPJ

COAP

CONASS

COSEMSRN

DD

DEA

DMU

EC

ESF

FDH

FNS

GM

IBGE

IDEAB

IDSUS

INAMPS

LDO

LOA

MMQ

MS

NASF

NOAS

NOBs

OCDE
Atenção Básica à Saúde

Agentes Comunitários de Saúde

Ações Integradas de Saúde

Atenção Primária em Saúde

Coordenação de Aperfeiçoamento de Pessoal de Nível Superior

Compensação das Especificidades Regionais

Cadastro Nacional de Pessoa Jurídica

Contrato Organizativo da Ação Pública em Saúde

Conselho Nacional de Secretários de Saúde

Conselho de Secretarias Municipais de Saúde do Estado do Rio Grande do Norte

Densidade demográfica

Data Envelopment Analysis

Decision Making Units

Emenda Constituicional

Equipes de Saúde da Família

Free Disposal Hull

Fundo Nacional de Saúde

Gabinete do Ministro

Instituto Brasileiro de Geografia e Estatística

Indicador de Eficiência da prestação de serviços de saúde da Atenção

Básica

Índice de Desempenho do Sistema Único de Saúde

Instituto Nacional de Assistência Médica da Previdência Social

Lei de Diretrizes Orçamentárias

Lei Orçamentária Anual

Método de mínimos quadrados

Ministério da Saúde

Núcleo de Apoio a Saúde da Família

Normas Operacio-nais de Assistência à Saúde

Normas Ope-racionais Básicas

Organização para a Cooperação e Desenvolvimento Econômico 
OMS

OPAS

$\mathrm{PAB}$

PAB fixo

$\mathrm{PAB}$ variável

PAC

PACS

PCA

PIB

PMAQ

PNAB

PPA

PSDB

PSE

PSF

PT

RAG

SAMU

SES

SIA

SIAB

SIAD

SIOPS

SSN

SUS

TCG

UBS

UPA $24 \mathrm{H}$

VBR
Organização Mundial de Saúde

Organização Pan-americana da Saúde

Pisos da Atenção Básica

Pisos da Atenção Básica fixo

Pisos da Atenção Básica variável

Programa de Aceleração do Crescimento

Programa de Agentes Comunitários de Saúde

Principal Component Analysis

Produto Interno Bruto

Programa Nacional de Melhoria do Acesso e da Qualidade

Política Nacional de Atenção Básica

Plano Plurianual

Partido da Social Democracia Brasileira

Programa Saúde na Escola

Programa de Saúde da Família

Partido dos Trabalhadores

Relatório Anual de Gestão

Serviço de Atendimento Móvel de Urgência

Secretaria de Estado de Saúde

Sistema de Informações Ambulatoriais

Sistema de Informações da Atenção Básica

Sistema Integrado de Apoio à Decisão

Sistema de Informações sobre Orçamentos Públicos em Saúde

Sistema de Saúde Nacionais

Sistema Único de Saúde

Termo de Compromisso de Gestão

Unidades Básicas de Saúde

Unidades de Pronto Atendimento

Visão Baseada em Recursos 


\section{SUMÁRIO}

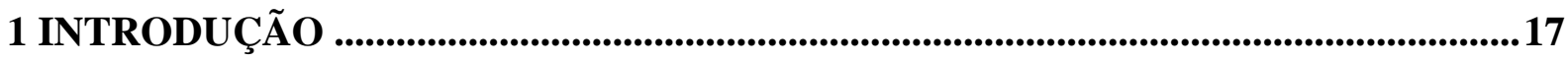

1.1 Contextualização.............................................................................................17

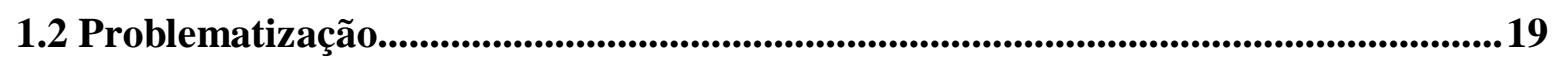

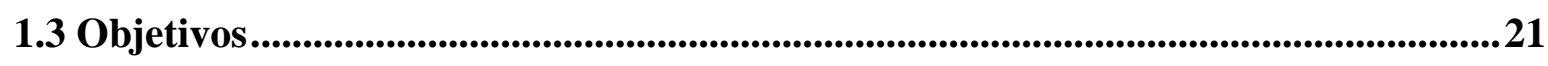

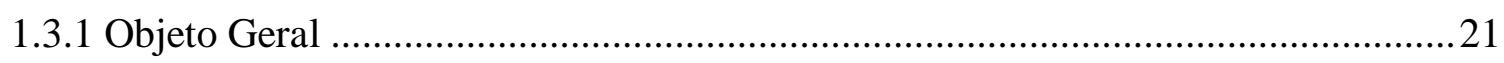

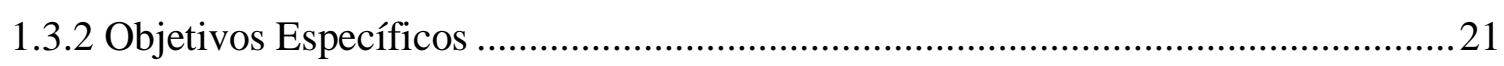

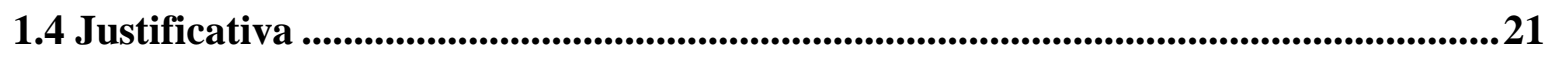

1.5 Estrutura do trabalho ..............................................................................................23

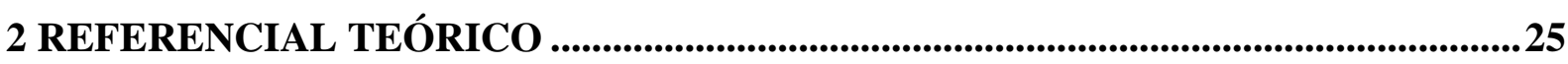

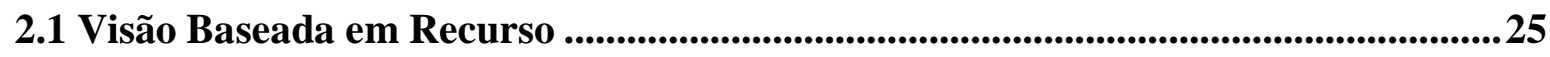

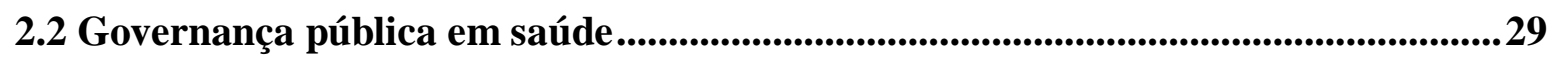

2.3 Financiamento e os blocos de financiamentos federais ............................................30

2.4 O SUS e a atenção básica no Brasil ...................................................................34

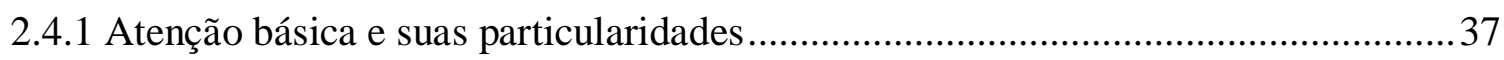

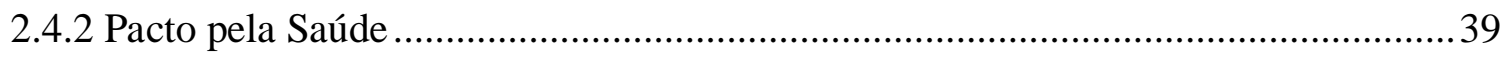

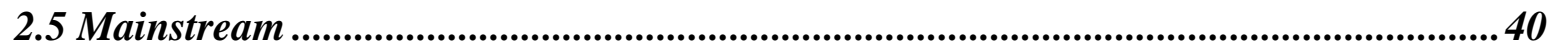

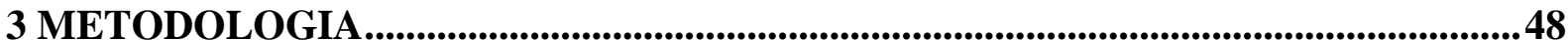

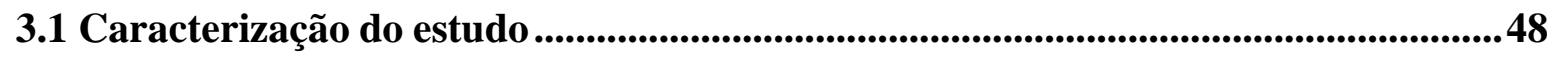

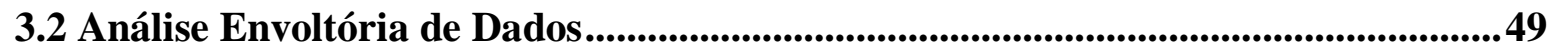

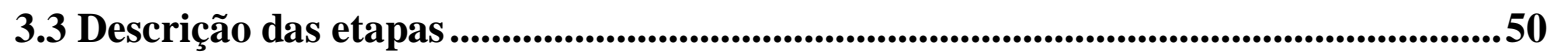

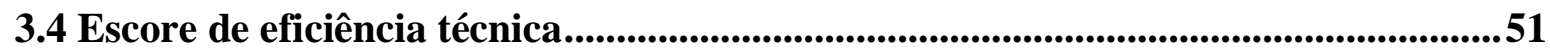

3.5 Modelagem em dois estágios ............................................................................52

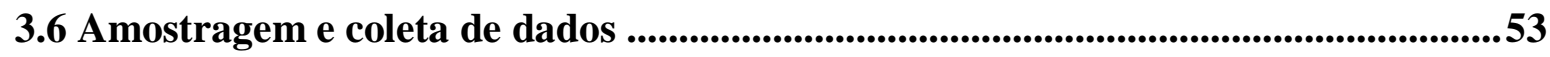

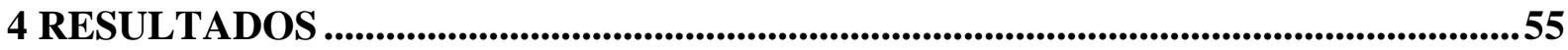

4.1 Primeiro estágio ......................................................................................................................55

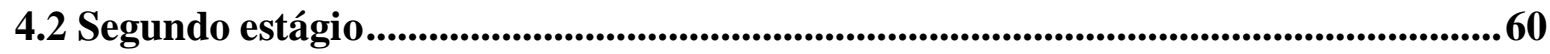

4.2.1 Regressão para DMUs eficientes no primeiro estágio.............................................60

4.2.2 Regressão para DMUs ineficientes no primeiro estágio .......................................62

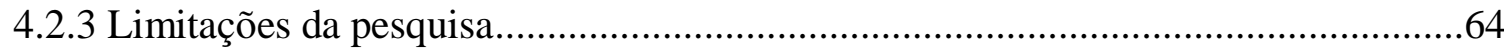

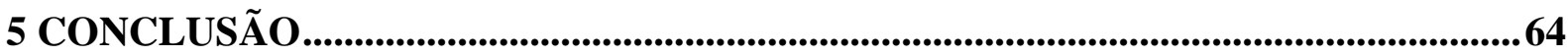

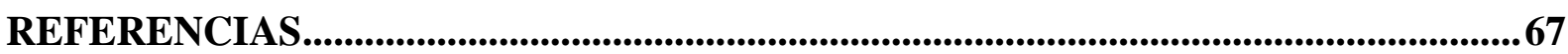

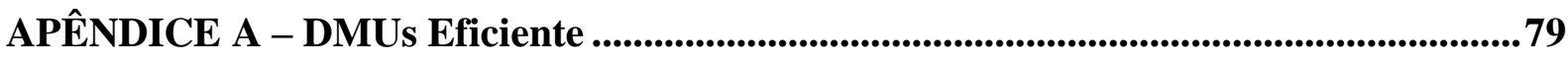

APÊNDICE B - DMUs Ineficientes ............................................................................................88 
APÊNDICE C - Gasto Per Capita …...............................................................................................85

MODELO DE REGRESSÃO LINEAR MÚLTIPLA.......................................................89 


\section{INTRODUÇÃO}

\subsection{Contextualização}

Com a promulgação da Constituição Federal em 1988, os cidadãos brasileiros passaram a ter o direito à atenção à saúde de forma universal e integral, sendo a organização dos serviços de responsabilidade do Sistema Único de Saúde (SUS). Entretanto, a existência de desigualdades em relação, sobretudo, aos componentes da oferta desses serviços e na ineficiência da aplicação dos recursos públicos, têm gerado disparidades e afetado a qualidade de vida da população.

Por caracterizar-se como uma política pública historicamente importante, no sentido de se configurar como uma conquista social, mas de abrangência e complexidade singulares, o processo de avaliação e financiamento tem-se constituído uma preocupação permanente dos gestores e de todos os envolvidos com a consolidação desse sistema de saúde (KROTH, 2017). Chesnais (2005) destaca que, desde sua criação do SUS até os dias atuais, garantir a universalidade e integralidade diante de um cenário de restrições orçamentárias e financeiras e alocar recursos de forma equânime em um país de desigualdades sociais e regionais têm- se transformado em um grande desafio para os gestores públicos da saúde (HECKMAN et al., 2014).

A avaliação, como componente da gestão em saúde, tem hoje um reconhecimento que se traduz na existência de múltiplas iniciativas voltadas para sua implementação nas diversas dimensões do SUS (Ministério da Saúde - MS, 2005). Com o objetivo principal de dar suporte aos processos decisórios na esfera do sistema de saúde, deve subsidiar a identificação de problemas e a mudança de ações e serviços desenvolvidos, avaliar a incorporação de novas práticas sanitárias na rotina dos profissionais e mensurar o impacto das ações implementadas pelos serviços e programas sobre o estado de saúde da população.

Para Silva (2005), a avaliação de políticas, programas e projetos pode ter como enfoque os diferentes níveis do sistema de saúde. E, embora a avaliação de políticas frequentemente envolva a avaliação de programas, a distinção entre essas duas dimensões pode ser necessária para fins analíticos. Nesse sentido, a institucionalização da avaliação constitui-se em um dos desafios mais importantes para os sistemas de saúde na atualidade. Para Hartz (2002, p. 419): 
[...] institucionalizar a avaliação deve ter o sentido de integrá-la em um sistema organizacional no qual está seja capaz de influenciar o seu comportamento, ou seja, um modelo orientado para a ação ligando necessariamente as atividades analíticas às de gestão das intervenções programáticas.

Assim sendo, enfrentam-se aspectos (i) técnicos - definição de critérios, indicadores e instrumentos, (ii) culturais-organizacionais - referentes ao modus operandi de como as instituições desenvolvem suas práticas de avaliação e (iii) políticos - relacionados às relações de poder que se estabelecem entre as esferas de gestão e os diferentes atores envolvidos nas práticas de saúde (MEDINA; AQUINO, 2002).

No que se referem-se aos serviços abrangidos pelo Sistema, cumpre destacar que, desde o estabelecimento do SUS, prevalece o enfoque de um modelo voltado para a Atenção Básica, sendo as demais modalidades (i.e., média e alta complexidade) caracterizadas como seletivas (NORONHA et al., 2012). Além disso, essa política de saúde esteve, historicamente, muito ligada à emissão de Normas Operacionais que tinham o intuito de ordenar o SUS. Por conseguinte, no primeiro momento, após à adoção do SUS, a política de saúde no Brasil apresentava uma natureza mais centralizada, isto é, a maioria das ações e dos programas de saúde, bem como seu financiamento, estava subordinada ao Ministério da Saúde sob tutela do Instituto Nacional de Assistência Médica da Previdência Social (INAMPS).

A atuação do Estado se materializa por meio de planos, políticas, programas e ações de governo, sendo relevante analisá-los quando se quer estimar a necessidade de financiamento. $\mathrm{Na}$ área de saúde, em especial, são muitas as ações do Estado, tais como: Promoção, Prevenção e Vigilância à Saúde, Atenção Básica em Saúde, Serviço de Atendimento Móvel de Urgência (SAMU) e suas Centrais de Regulação Médica das Urgências, Sala de Estabilização, Força Nacional de Saúde do SUS, unidades de Pronto Atendimento (UPA 24 HORAS) e o conjunto de serviços de urgência 24 horas, Hospitalar e Atenção Domiciliar (BRASIL, 2017).

De forma geral, há relevância em discutir avaliação da saúde por sua abrangência enquanto serviço público. Compreende-se que a saúde é um fator primordial para garantir o desenvolvimento econômico de uma sociedade. Aliado a isso, as mudanças relacionadas ao perfil demográfico (envelhecimento da população), epidemiológico (maior incidência de doenças crônicas e degenerativas) e de preços da tecnologia médica vêm pressionando para o aumento das despesas com saúde em nível mundial (MCKEOWN, 2009; XU; SAKSENA; HOLLY, 2011).

Corroborando o consenso entre os especialistas acerca da importância da saúde para o desenvolvimento econômico, a questão da avaliação e financiamento das políticas em saúde 
tem assumido um papel importante no debate, ao considerar-se a restrição orçamentária contemporânea dos governos e a sustentabilidade dos gastos no tempo (GERDTHAM; JONSSON, 2000; ORGANIZAÇÃO PARA A COOPERAÇÃO E DESENVOLVIMENTO ECONÔMICO - OCDE, 2015b). De forma geral, os pesquisadores e formuladores de política têm demonstrado preocupação em como tornar os sistemas de saúde mais eficientes (KROTH, 2017).

No cenário brasileiro, o aprimoramento da política de saúde tem sido considerado um dos principais desafios do SUS (BRASIL, 2006; CONSELHO NACIONAL DE SECRETÁRIOS DE SAÚDE - CONASS, 2011; PIOLA et al., 2009). O SUS vem consolidando, desde sua institucionalização em 1988, a operacionalização de um sistema abrangente que contempla cinco pilares: universal, integral, descentralizado, regionalizado e com controle social (BRASIL, 1988, art. 198).

Contudo, o SUS ainda se confronta com a insuficiência de recursos e a ineficiência da prestação de serviços de saúde (OCKÉ-REIS, 2009; PIOLA et al., 2009). Alguns dos principais problemas referem-se a oferta limitada de serviços, baixa resolutividade e insatisfação dos usuários, resultando na exclusão do acesso à saúde de boa parte da população do país.

Para Kroth (2017), ao considerar a importância da saúde para o desenvolvimento econômico e também o potencial de crescimento das despesas com cuidados de saúde no Brasil, emerge a necessidade e a relevância de se encontrar alternativas de gestão e financiamento, garantindo ao mesmo tempo maior resultado de saúde a menor custo de produção. Ressalta-se ainda a relevância das pesquisas direcionadas a temas da atenção básica (ou primária), que é considerada a porta de entrada preferencial para o sistema público e potencial ordenadora dos cuidados em saúde.

\subsection{Problematização}

No âmbito da Atenção Básica, em 2006 foi lançado o Pacto pela Saúde, que buscava alcançar o fortalecimento desse nível de cuidado (SIMÃO; ALBUQUERQUE; ERDMANN, 2007) a partir de três diretrizes: Pacto pela Vida, Pacto em Defesa do SUS e Pacto de Gestão (ver Subseção 2.4.2). Com diversos objetivos traçados, a primeira meta visava, entre outros, ao fortalecimento da Atenção Básica; a segunda, a regulamentação da Emenda Constitucional n. 29, de 2000 (BRASIL, 2000); e a terceira estabelecia as diretrizes de financiamento e pretendia nortear a alocação dos recursos financeiros para a saúde (BRASIL, 2006). 
Com a implementação do Pacto, os recursos repassados deixaram de ser atrelados a programas específicos e se vincularam aos respectivos blocos [“temáticos”] de financiamento (MENDES; MARQUES, 2014). Dessa forma, de acordo com o Ministério da Saúde, a Atenção Básica passou a se caracterizar, como o próprio nome diz, como a etapa mais básica da promoção da saúde, a qual abrange ações de prevenção, atendimento, tratamento de doenças etc. em nível local (i.e., municipal) (ARANTES et al., 2011).

Haddad et al. (2008) ressaltam que mais investimento na Atenção Básica (ou Atenção Primária à Saúde - APS) acarretam em menos gasto nos níveis mais complexos, pois impede que casos simples se agravem. Para Silva (2011), o nível da Atenção Básica deve servir como facilitador e ordenador do acesso aos demais níveis de saúde pela população. Nesse sentido, é relevante se questionar se os recursos públicos estão sendo aplicados da melhor forma, a fim de garantir melhorias na prestação dos serviços da atenção básica à saúde. Em outras palavras, os entes federativos no Brasil, em especial os municípios - responsáveis pela gestão e financiamento da APS, têm alocados recursos orçamentários de maneira a melhor atender a demanda por serviços básicos de saúde? Há relação entre despesas orçamentária e desempenho na APS?

Varela et al. (2012) desenvolveram um estudo a fim de responder questões semelhantes as aqui problematizadas. Especificamente, os autores buscaram avaliar o desempenho dos municípios do Estado de São Paulo, no que refere a eficiência técnica na aplicação de recursos públicos nas ações de atenção básica à saúde. Para tanto, analisaram a influência de variáveis não controláveis no processo de geração e prestação de serviços em saúde. O presente trabalho busca, de forma semelhante, desenvolve um estudo avaliando a eficácia na APS, ampliando a metodologia de Varela et al. (2012) a todos os municípios brasileiros.

Nesse sentido, cumpre salientar que a eficácia alocativa relaciona-se à aplicação dos recursos públicos via execução orçamentária para cumprimento dos objetivos do SUS junto a APS. Dentre os fatores que podem impactar a análise dessa eficácia, tem-se a escassez de recursos e às ilimitáveis necessidades sociais da população. Dado o conflito entre a escassa disponibilidade de meios e a multiplicidade crescente de necessidades a atender, não basta que os recursos estejam empregados segundo padrões de máxima eficiência produtiva - este é um requisito necessário, mas não suficiente (KROTH, 2017). Além dele, coloca-se a questão da eficácia alocativa, que diz respeito à escolha dos bens e serviços finais, de consumo e de acumulação, que a economia produzirá.

A função alocativa do Estado decorre da necessidade de corrigir as falhas de mercado. Uma vez que os recursos de cada bloco, no Pacto da Saúde, são destinados somente ao custeio 
de ações e serviços de saúde relativos ao próprio bloco (GUERRA, 2013), é possível avaliar a eficácia da aplicação dos recursos orçamentários-financeiros, e comparar os diferentes níveis.

Segundo Varela et al. (2012), há, entretanto, dificuldades em se avaliar a atenção básica dos municípios, especificamente quando se trata dos recursos consumidos (inputs) e dos serviços e/ou produtos gerados (outputs). Sendo assim, validar a metodologia sugerida pelos referidos autores, e base para o desenvolvimento do presente estudo, ganha relevância pelas variáveis consideradas em um modelo não paramétrico. Ainda segundo os mesmos autores, analisar uma área tão peculiar como a saúde e analisar a eficiência dos municípios lança luz sobre as possibilidades de transpassar as abordagens tradicionais da controladoria, aplicadas apenas nas empresas do setor privado, trazendo essa prática para as organizações governamentais.

\subsection{Objetivos}

\subsubsection{Objeto Geral}

Avaliar a eficiência alocativa dos municípios brasileiros na aplicação de recursos na subfunção atenção básica à saúde.

\subsubsection{Objetivos Específicos}

- Compreender a lógica de financiamento da saúde básica no Brasil e quais resultados esperados dessa política.

- Identificar a eficiência relativa entre os municípios na alocação de recursos a atenção básica.

- Identificar as variáveis determinantes dessa eficiência alocativa.

- Avaliar a influência de outras variáveis exógenas (e.g., demográficas, sociais e ambientais) na produtividade da saúde pública municipal.

- Validar a metodologia de Varela et al. (2012) para um número abrangente de municípios de diferentes estados brasileiros.

\subsection{Justificativa}

A Organização Mundial de Saúde (OMS) e a Organização para a Cooperação e Desenvolvimento Econômico (OCDE) apresentam dois elementos primordiais para a melhoria 
da eficiência dos sistemas de saúde (OMS, 2000, 2008; OCDE, 2010b). O primeiro refere-se à tecnologia de produção de saúde, ou seja, à maneira de se prestar os serviços de saúde à população; e o segundo, a governança em saúde. Nesse âmbito, há modelos que preveem (i) que a prestação de serviços de saúde deva ser intensiva em práticas curativas ou médicohospitalares, isto é, voltadas basicamente para a reabilitação de enfermidades e traumas; e (ii) outros que enfatizam práticas promotoras da saúde e/ou preventivas, voltadas para evitar problemas de saúde. Esse segundo grupo é tido como mais custo-eficiente (STARFIELD, 2002; PAIM, 2012).

O segundo elemento de eficiência preconizado pela OMS e OCDE, a governança em saúde, compreende as ações de formulação e coordenação de políticas, alocação de recursos, gestão e planejamento da prestação de serviços de saúde e a regulação. De acordo com o Banco Mundial (2007), governança refere-se a maneira pela qual o poder é exercido na administração dos recursos sociais e econômicos do país, objetivando o desenvolvimento e a capacidade dos governantes de planejar, formular e programar políticas e cumprir funções. Assim sendo, a boa governança refere-se à elaboração de políticas previsíveis através de processos democráticos e transparentes (KROTH, 2017).

Nos estudos que avaliam os componentes de eficiência (tecnologia de produção de saúde e governança), evidenciam-se que as despesas em saúde geram maiores resultados em países com boa governança, ou seja, em países nos quais a formulação de orçamento, a execução e o monitoramento são efetivos (RAJKUMAR; SWAROOP, 2008), e que a sustentabilidade das despesas em saúde não compromete a prestação dos serviços, desde que instrumentos adequados de política sejam adotados (OCDE, 2015b).

Nesse contexto, o presente estudo concentra-se a avaliação dos resultados obtidos em nível municipal, no que se refere aos serviços de saúde da atenção básica. Ao se traçar um comparativo de desempenho dos municípios brasileiros, é possível identificar os pontos fracos de uma gestão e traçar um paralelo entre os diversos municípios, transformando em aprendizado as diversidades de experiências (VARELA et al., 2012).

No presente estudo, utilizou-se como metodologia a proposta de Varela et al. (2012), que avaliaram o desempenho dos municípios do Estado de São Paulo, no que refere a eficiência técnica na aplicação de recursos públicos nas ações de atenção básica à saúde. Como mencionado, os autores analisaram a influência de variáveis não controláveis no processo de geração e prestação de serviços em saúde. Salienta-se que a eficiência técnica é um dos parâmetros de avaliação de desempenho dos gestores públicos, refletindo a capacidade de uma entidade obter máximos outputs com o menor consumo de inputs. 
A escolha por essa metodologia deve-se ao fato de que o Índice de Desempenho do Sistema Único de Saúde (IDSUS), um conjunto de indicadores que buscavam fazer uma aferição contextualizada do desempenho do SUS quanto ao cumprimento de seus princípios e diretrizes, deixou de ser calculado e publicado pelo Ministério da Saúde desde 2014.

Inicialmente, o IDSUS tinha uma proposta de avaliar o desempenho do SUS no que se refere à universalidade do acesso, integralidade, igualdade, resolubilidade e equidade da atenção, descentralização com comando único por esfera de gestão, responsabilidade tripartite, regionalização e hierarquização da rede de serviços de saúde, identificar e avaliar problemas e deficiências do SUS, subsidiando a superação destes e sendo uma referência para a construção de pactos de compromissos entre gestores do SUS (BRASIL, 2017).

Optando pela metodologia de Varela et al. (2012), de forma alternativa, entende-se ser possível apresentar adequadamente, por características de grupos de municípios, um comparativo da prestação de serviços de saúde (outputs) em todo o país.

\subsection{Estrutura do trabalho}

Esta pesquisa está estruturada em cinco capítulos, a partir dessa introdução. O referencial teórico encontra-se no Capítulo 2, em que se apresenta a aplicabilidade da Visão Baseada em Recurso com teoria base para o desenvolvimento do presente trabalho. Buscou-se na subseção 2.1, explicitar o uso dessa teoria, originalmente atrelada a avaliação de organizações privadas, no contexto de serviços públicos. A partir da VBR, passou-se à apresentação das principais características sobre governança pública em saúde (subseção 2.2), referencial necessário para suportar a discussão sobre a oferta de serviços públicos. O Referencial Teórico segue na subseção 2.3, em que se aborda mais especificamente as particularidades do financiamento da saúde, que se dá hoje por blocos 'temáticos'. A subseção 2.4 trata do SUS e a atenção básica no Brasil, detalhando ainda mais as especificidades em se discutir gestão da saúde básica no país. A última subseção apresenta os estudos anteriores publicados sobre a temática eficiência dos serviços de saúde e saúde pública no Brasil, de maneira geral.

A metodologia, por sua vez, é apresentada no Capítulo 3, subdividido em: (subseção 3.1) caracterização do estudo, (subseção 3.2) Análise Envoltória de Dados (Data Envelopment Analysis - DEA), (subseção 3.3) descrição das etapas, (subseção 3.4) escore de eficiência técnica, (subseção 3.5) análise de componentes principais, (subseção 3.6) amostragem e coleta de dados e (subseção 3.7) limitações da pesquisa. 
Os resultados estão evidenciados no Capítulo 4 e subdividem-se em: (subseção 4.1) Primeiro estágio de aplicação do Modelo e (subseção 4.2) segundo estágio, no qual são apresentadas a regressão para DMUs eficientes no primeiro estágio e a regressão para DMUs ineficientes no primeiro estágio. Por fim, no Capítulo 5, encontram-se as considerações finais do estudo, com sugestões de pesquisas futuras, seguidas das referências e os apêndices da pesquisa. 


\section{REFERENCIAL TEÓRICO}

Como mencionado, o presente estudo concentra-se na avaliação dos resultados obtidos em nível municipal, no que se refere aos serviços de saúde da atenção básica. Para tanto, em um nível macro, utiliza-se como referencial teórico aspectos da governança pública em saúde, limitando-se ao histórico de criação e atual situação do SUS, bem como as especificidades da atenção primária no Brasil e o pacto pela saúde. Ainda para contextualizar a discussão proposta, apresenta-se histórico e particularidades do financiamento da saúde e o Pacto da Saúde no Brasil. Por fim, a discussão de eficiência alocativa tem como embasamento a perspectiva da visão baseada em recurso.

\subsection{Visão Baseada em Recurso}

A Visão Baseada em Recursos (VBR), uma das perspectivas teóricas mais utilizadas na gestão estratégica, fundamenta a concepção de que diferentes recursos, e a maneira que estes são configurados, afetam o desempenho organizacional (LEE; WHITFORD, 2013). Não obstante à sua ampla utilização nas organizações privadas, a gestão pública dispõe de poucos estudos que relatem o emprego bem-sucedido da VBR (SZYMANIEC-MLICKA, 2014). Visto que os entes públicos são criados para o cumprimento de responsabilidades do governo, desenvolvimento de políticas e prestações de serviços para a população em geral, torna-se interessante o emprego de teorias de gestão estratégica com o intuito se buscarem melhorias nestes serviços (MATTHEWS; SHULMAN, 2005).

O objetivo da VBR é o de desenvolver algumas ferramentas econômicas simples para analisar a posição de recursos de uma empresa e olhar para algumas opções estratégicas sugeridas em sua análise, aplicando particularmente a relação entre rentabilidade e recursos, bem como formas de gerir a posição de recursos da empresa ao longo do tempo (BROGNOLLI, 2017). Nesse sentido, cumpre salientar que, apesar de a VBR não ter sido utilizada no presente estudo por sua abordagem estratégica, entendeu-se que a apropriação de alguns entendimentos tidos a partir de tal teoria pudesse dar suporte a problematização da eficiência alocativa na saúde pública - em especial, a ênfase nos recursos escassos e na necessidade de melhor aplicação no processo de prestação de serviços.

A VBR conta com um considerado número de autores responsáveis pelo avanço e disseminação na literatura. Penrose (1959) desenvolveu em seu trabalho seminal, chamado de 
The theory of the growth of the firm, a ideia de que a organização deveria ser olhada como um conjunto de recursos, os quais atribuem desempenhos diferentes devido a suas configurações distintas. Nesse ponto, tomando-se os municípios brasileiros como nível de análise no presente estudo, entende-se que diferentes fatores locais (i.e., municipais) poderiam explicar os resultados obtidos na saúde básica.

Alguns autores que seguiram os pressupostos de Penrose (1959), também contribuíram para a introdução da teoria na área da estratégica. Como exemplo desses seguidores, Rubin (1973) que corroborou com o conceito de uma organização formada por recursos e acrescentou a ideia de que existe uma taxa de crescimento ideal para essa (FOSS, 1997). A partir de então, seguiram-se autores que trouxeram subsídios primordiais para a constituição da teoria, como, por exemplo, Wernerfelt (1984), que alegava que os produtos da organização demandavam muitos recursos, assim como, os diversos recursos eram intrínsecos para a formação do produto.

O responsável por formalmente transformar a VBR em uma teoria foi Barney (1991), que apresentou o conceito de recursos estrategicamente significativos, divergindo de Wernerfelt (1984), que julgava que todos os recursos da organização eram dessa determinada maneira. A esses autores, acrescentaram-se outros que também contribuíram para a consolidação da teoria (Figura 1): Dierickx e Cool (1989), Grant (1991), Mahoney e Pandian (1992) e Peteraf (1993).

Figura 1 - Contribuições dos estudos seminais da Visão Baseada em Recursos

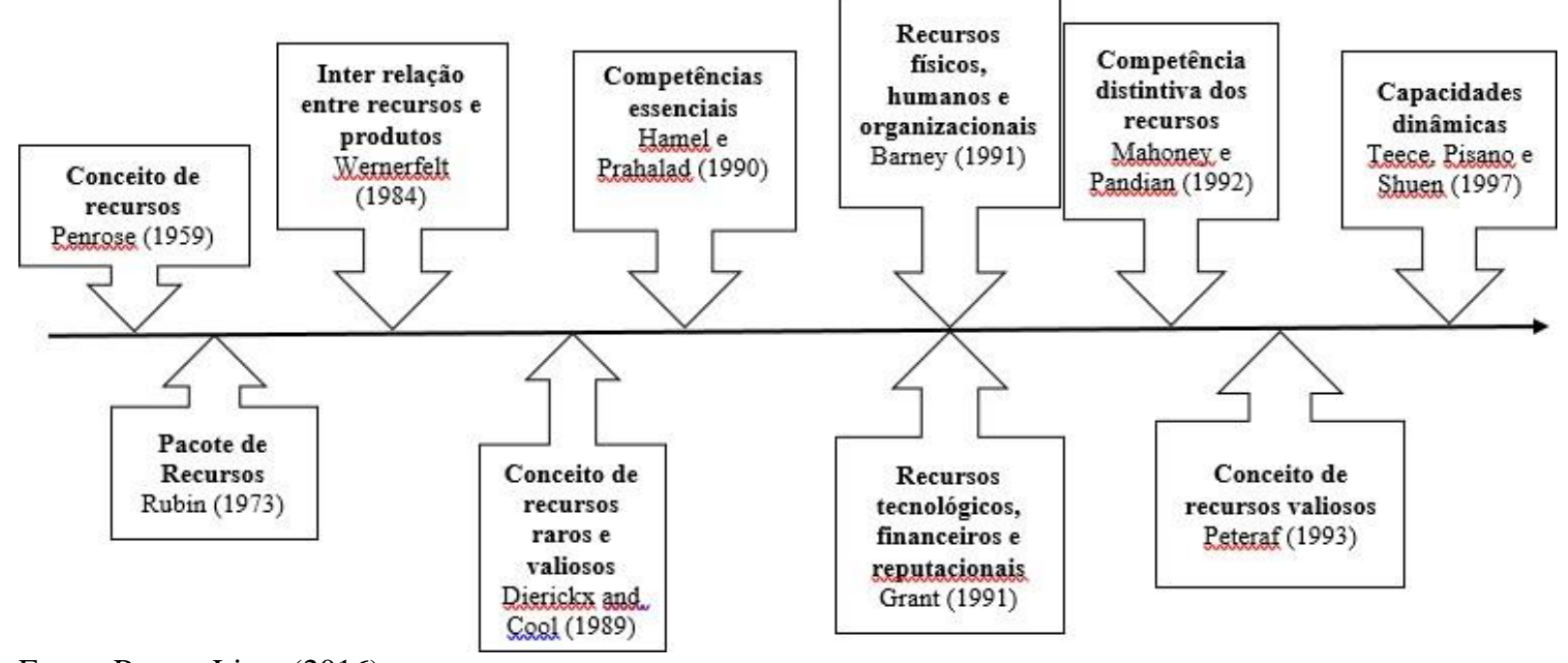

Fonte: Rosa e Lima (2016).

A VBR tornou-se importante metodologia de análise comparativa das organizações. Por exemplo, em pesquisas internacionais, a investigação de Stankiewicz (2012) busca elaborar um modelo de competitividade entre fronteiras para organizações de saúde, também, utilizando a 
VBR. Seus resultados estão relacionados à competitividade de sistemas de saúde entre nações.

Os autores propuseram que era mais relevante, para a vantagem competitiva sustentável, a capacidade da organização de reunir e ordenar os recursos de diferentes maneiras, do que o próprio recurso. As capacidades dinâmicas também foram tópico da pesquisa de Eisenhardt e Martin (2000), que citaram como exemplos: desenvolvimento de produtos, estratégia de tomada de decisões e alianças.

O trabalho de Xia e Li (2013), sobre a teoria da dependência de recursos em organizações públicas, aproxima parcialmente este estudo da proposta em pauta, quando procura explicar a dependência mútua entre as unidades organizacionais por meio das condições externas e internas da dependência de recursos de outros agentes governamentais. O estudo revela que a dependência mútua e o aumento do poder das subunidades ampliam a sua relevância no conjunto das unidades envolvidas em seu processo decisório.

No Brasil, a pesquisa de Santos, Gonçalves e Figueiredo (2013), com base na VBR, analisa o desempenho de municípios da região Sudeste na alocação de recursos na atenção básica da saúde, de 2007 a 2010. Foi feita uma análise de cluster para agrupar os municípios semelhantes, bem como foram utilizados os índices de eficiência técnica do DEA para a análise de desempenho. Os resultados apontam que os escores de eficiência obtidos deixaram evidentes as disparidades na alocação de recursos, fato que poderia ser justificado na ausência de procedimentos de comparação relativa entre estes dados e o modelo adotado no país.

O estudo de Cobaito (2012) analisa a experiência de um Plano Diretor de Melhoria da Gestão Hospitalar utilizando a VBR nas ações dos diversos serviços prestados pelas áreas internas hospitalares. E comprova ser possível hospitais com natureza jurídica de Fundação sem fins lucrativos, através de melhorias nos arranjos organizacionais e práticas de gerenciamento de seus processos internos, enquanto recursos, serem convertidos em centros de maior eficácia e obterem o reconhecimento público. Ainda, como resultado, verificou-se ser possível a formulação de uma estratégia de sucesso no segmento de saúde hospitalar.

A seguir, destacam-se os fundamentos para a aplicação da abordagem da VBR de modo adaptado à avaliação proposta no presente estudo, dessa maneira, procurando explicar os determinantes da eficiência alocativa nos municípios brasileiros.

Uma vez decididos, segundo Barney (1992, 1994, 1996), Barney e Hesterly (1996) e Wernerfelt (1984), os recursos aqui tratados como inputs são vinculados de forma continua à organização, assim, não podem ser transferidos a outra sem custos e isso a capacita a conceber e executar estratégias de modo a obter e/ou manter certa posição em sua capacidade de gerar valor, que nesse caso, são os outputs - como, por exemplo, o atendimento de saúde básico. 
Na construção do conceito de recurso, Barney (1997, p. 143), recorre a Daft (1983, p. 37), afirmando que:

os recursos organizacionais são todos os bens, capacidades, competências, processos organizacionais, atributos organizacionais, informação, conhecimento e outros tantos que são controlados pela organização e que possibilitam a empresa conceber e implementar estratégias que aprimorem sua eficiência e eficácia.

Mais recentemente, Barney (1997, p. 190) propõe a divisão dos recursos em quatro categorias:

(a) recursos financeiros, ou todos os tipos de recursos financeiros que as empresas podem utilizar para conceber e implementar estratégias; (b) recursos físicos, ou capital físico, que correspondem à tecnologia física usada na empresa, a planta organizacional, seus equipamentos, localização geográfica e acesso a matérias primas; (c) recursos de capital humano incluindo o treinamento, experiência, julgamento, inteligência, relacionamentos, bem como os insights dos gerentes e trabalhadores de uma empresa e, (d) recursos institucionais que constituem os atributos da coletividade organizacional - a estrutura organizacional, sistemas de controle e coordenação, a própria cultura da organização, sua reputação, bem como as relações informais entre grupos dentro da própria empresa, ou entre a empresa e seu ambiente.

Grant (1991) apresenta uma proposta diferente de categorização dos recursos que, além dos recursos elencados por Barney (1997), inclui reputação e recursos tecnológicos, ao que denomina de forma ampla de recursos organizacionais. Já Kay (1996, p. 76) apresenta quatro capacidades diferenciadoras como sendo características importantes do relacionamento de uma organização com outras empresas:

(a) a arquitetura organizacional vista como uma rede de contratos em que se podem estabelecer relacionamentos com ou entre seus empregados - arquitetura interna -, com seus fornecedores e clientes - arquitetura externa - ou entre um grupo de empresas engajadas em atividades correlatas - redes; (b) a inovação ou capacidade da empresa de oferecer novos produtos ao mercado; (c) a reputação ou mecanismo utilizado para transmitir informações aos consumidores e que se refere a associação que esta faz da organização com os atributos do produto e; (d) os ativos estratégicos que se relacionam ao domínio ou posição da empresa no mercado.

A arquitetura organizacional foi acrescentada a fim de ressaltar a necessidade de parcerias entre as organizações, introduzindo-se o conceito de articulação de recursos como forma de efetivar tais parcerias. Mascarenhas e Vasconcelos (2004, p. 8) acrescentam, ainda, que as teorias de estratégia que partem dessa discussão defendem então que as organizações não devem se preocupar só com o que se fez bem ontem e se faz bem hoje, mas também com o que podem fazer bem no futuro. 
No presente estudo, a DEA e os fundamentos da VBR relacionam-se com a gestão dos entes públicos, pois esses tem responsabilidades de desenvolvimento de políticas e prestações de serviços para a população em geral. Nesse sentido, podem possibilitar a obtenção de melhorias na eficiência e como um método de avaliação destes serviços (MATTHEWS; SHULMAN, 2005)

Para compreensão dos aspectos da avaliação e financiamento da saúde pública no Brasil a nível da atenção básica, a próxima seção apresenta as principais características do setor saúde e suas relações com o desenvolvimento e implementação do SUS do país.

\subsection{Governança pública em saúde}

Sobre os indicadores de financiamento e de resultados de saúde no Brasil, observam-se dois movimentos da política de saúde nacional nos últimos anos: a descentralização dos recursos para os entes federados e o foco na Atenção Básica, com a Lei n. 142 de 1990 e Portarias Ministério da Saúde n. 399 de 2006 e n. 2.488 de 2011 (BRASIL, 1990, 2006, 2011).

No que tange à descentralização, a Norma Operacional do SUS de 1996 (BRASIL, 1996) deu aos municípios maior responsabilidade na oferta de serviços de saúde, assim como mais transferências diretas de recursos da União (CONASS, 2011). Ademais, os próprios municípios também ampliaram a quantidade de recursos próprios para a área da saúde (PIOLA et al., 2013).

Se o maior protagonismo dos municípios na condução da política de saúde enseja, por um lado, o alcance da diretriz da descentralização dos SUS e de maior proximidade com as preferências e realidade de saúde local, por outro lado, gera preocupações com a capacidade técnica e de transparência (accountability) na governança e supervisão da política de saúde pelos municípios, principalmente, entre os menores (OATES, 2005; SALTMAN; VRANBAEK, 2007).

Desde a conquista do SUS até o presente momento, a Atenção Básica passou por algumas interpretações diferenciadas. Evoluiu da ideia de atenção seletiva (programa destinado a populações pobres), com nível primário de atenção (organização e funcionamento como porta de entrada), para a estratégia de organização do sistema de atenção à saúde (KROTH, 2017). Entende-se que a Atenção Básica permite apropriar, recombinar e reordenar os recursos do sistema condizentes com a necessidade e a demanda da população (MENDES, 2012).

A partir das décadas de 1970 e 1980, a descentralização passou a ser um princípio ordenador das reformas no setor público em diversos países, e passou a figurar como diretriz 
inscrita na Constituição Federal de 1988 (FELICIANO et al., 2017). Já ao longo das décadas de 1990, foram criados os instrumentos jurídicos estruturadores do SUS. Dentre esses, a Lei n. 8.080 de 1990 que vincula a descentralização à municipalização e a Lei n. 8.142 de 1990, a qual confere maior capacidade gerencial aos estados e municípios (BRASIL, 1990a, b). Além dessas leis, as Normas Operacionais Básicas (NOBs), as Normas Operacionais de Assistência à Saúde (NOAS), o Pacto pela Saúde, a Emenda Constitucional n. 29 de 2000, a Lei Complementar n. 141 de 2012 e o Decreto n. 7.508 de 2012, dentre outros instrumentos jurídicos normativos, progressivamente, ampliaram a base normativa estruturadora do processo de implementação do SUS (BRASIL, 2011).

É conjunto ao início de mudanças importantes, a dinâmica do desenvolvimento do setor de saúde no Brasil. Movimentos para sistemas descentralizados de saúde do setor público, dentre outros motivos, foram realizados por causa da insatisfação com a eficiência da prestação centralizada de serviços públicos. Muitas ineficiências estavam ligadas às dificuldades de coordenar grandes conjuntos de atividades em localizações dispersas a partir de um ponto centralizado (ALMEIDA, 2002). Isso porque o processo de descentralização gera uma maior autonomia no processo de tomada de decisões pelos governos locais ou pelos agentes estaduais, pois o governo remove camadas de burocracia, diminuiu custos de informação associados a deseconomias de escala e o tempo no processo de tomada de decisões (DILLINGER, 1999a; SHAH, 1998; SILVERMAN, 1990).

Segundo Kroth (2017), um ponto muito discutido na literatura quando se refere a descentralização em saúde é sobre o federalismo fiscal, pois a descentralização pode melhorar a eficiência alocativa no que se refere a diversidade no fornecimento de serviços públicos, proporcionando maior margem para conhecendo preferências heterogêneas para bens públicos. Outros autores (BANCO MUNDIAL, 1987) citaram os ganhos de eficiência por meio da descentralização associados a um conjunto de reformas do setor da saúde, incluindo a expansão de cobertura de risco, cobrança de tarifas de usuários para serviços de saúde privados entre aqueles capaz de pagá-los e melhor uso de recursos privados e não governamentais.

\subsection{Financiamento e os blocos de financiamentos federais}

O financiamento público da saúde no Brasil, ao longo do tempo, tem sido caracterizado por insuficiências dos recursos próprios estaduais e municipais e por modificações profundas nos critérios dos repasses financeiros aos municípios (MENDES; MARQUES, 2014). Apesar de haver regulamentação a respeito do financiamento do SUS, há uma série de impasses na 
gestão e na origem desses recursos que permanecem desde 1988.

Considerado como um financiamento tripartite, o SUS é de responsabilidade das esferas governamentais: União, Estados e Municípios (CONASS, 2015). No modelo , a União é a responsável por distribuir a maior parte dos recursos financeiros os demais entes da federação, incluindo ao Distrito Federal (MENDES; MARQUES, 2014).

Esta distribuição ocorre por meio da chamada "transferência fundo a fundo", na qual os recursos do Fundo Nacional de Saúde (FNS) são direcionados para os Fundos Estaduais e Municipais de Saúde. O valor dos repasses é definido de acordo com as condições de gestão, certificação e qualificação nos programas do Ministério da Saúde e tetos financeiros (MACHADO; LIMA; BAPTISTA, 2011).

Mais especificamente, a União transfere, fundo a fundo, aos municípios os recursos financeiros por meio do bloco de financiamento da atenção primária, que é constituído pelos Pisos da Atenção Básica (PAB): (i) fixo (PAB fixo), composto por recurso per capita; e (ii) variável (PAB variável), composto por recursos destinados à implantação de estratégias prioritárias (PIOLA et al., 2009). Os Estados, por sua vez, transferem também fundo a fundo, recursos financeiros aos municípios também por meio do bloco de financiamento.

Por fim, o Município aplica recursos próprios para financiar os cuidados primários (DAVID; SHIMIZU; SILVA, 2015). Para Rodrigues Neto et al. (2014), a expansão da atenção primária tem sido significativa. Entretanto, apesar desses avanços, o seu financiamento tem sido problemático, sobretudo porque ainda é insuficiente (MENDES; MARQUES, 2014).

Os recursos de destinação Federal são determinados para as ações e aos serviços de saúde que passam a ser organizados e transferidos na forma de blocos de financiamento, conforme Portaria Gabinete do Ministro do MS n. 204 de 2002 (BRASIL, 2002):

\footnotetext{
Os recursos federais destinados as ações e aos serviços de Saúde são organizados e transferidos na forma de blocos de financiamento que são constituídos por componentes, conforme as especificidades de suas ações e dos Serviços de Saúde pactuados, sendo:

I - Atenção Básica;

II - Atenção de Média e Alta Complexidade Ambulatorial e Hospitalar;

III - Vigilância em Saúde;

IV - Assistência Farmacêutica;

V - Gestão do SUS; e,

VI - Investimento. (BRASIL, 2002)
}

Os recursos federais que compõem cada bloco de financiamento são transferidos aos demais entes federativos, por meio do repasse fundo a fundo, em conta única e específica para cada bloco de financiamento, observados os atos normativos específicos e devem ser aplicados 
nas ações e serviços de Saúde relacionados ao próprio bloco (BRASIL, 2007). Para a aplicação de qualquer recurso na área da Saúde, as ações a que esses se destinam devem estar registradas no Plano de Saúde (MENDES; MARQUES, 2014).

No âmbito federal, o montante e recursos financeiros destinados à viabilização de ações de atenção básica à saúde compõe o Bloco de Financiamento de Atenção Básica (Bloco $\mathrm{AB}$ ) e parte do Bloco de Financiamento de Investimento. Seus recursos deverão ser utilizados para financiamento das ações de atenção básica descritas na RENASES e nos planos de saúde do estado, município e do Distrito Federal (DAVID; SHIMIZU; SILVA, 2015). O Quadro 1, adiante, sintetiza as informações sobre fonte dos recursos, bem como a destinação destes.

Os municípios deverão remeter, por via eletrônica, o processamento da produção de serviços referentes ao Bloco AB ao Ministério da Saúde, de acordo com o cronograma pactuado (GUERRA, 2013). As Secretarias Municipais de Saúde e do Distrito Federal devem enviar as informações ao DATASUS, observando o cronograma estabelecido pelo Ministério da Saúde (MENDES; MARQUES, 2014).

Cada esfera do governo deve assegurar o aporte regular de recursos à Saúde de acordo com a Lei Complementar 141 de 2012 (BRASIL, 2012). As transferências, regulares ou eventuais, da União para estados, municípios e Distrito Federal estão condicionadas à contrapartida destas esferas de governo, em conformidade com as normas legais vigentes (Lei de Diretrizes Orçamentárias, dentre outras) (PIOLA et al., 2013). Segundo Silva (2011), as transferências frequentes contemplam, ainda, os pagamentos diretos a prestadores de serviços e beneficiários cadastrados de acordo com os valores e condições estabelecidas por meio das Portarias do Ministério da Saúde.

Para cumprir os preceitos do financiamento do SUS, o gestor tem de estar seguro quanto a algumas questões legais, tais como: Gasto em Saúde que verifica os recursos da saúde e esses só podem ser empregados em ações e serviços de Saúde definidos nas Leis n. 808 de 1990 e n. 8142 de 1990, Lei Complementar n. 141 de 2012 e na Constituição Federal artigo 200, que diz:

\footnotetext{
Art. 200. Ao sistema único de saúde compete, além de outras atribuições, nos termos da lei:

I - controlar e fiscalizar procedimentos, produtos e substâncias de interesse para a saúde e participar da produção de medicamentos, equipamentos, imunobiológicos, hemoderivados e outros insumos;

II - executar as ações de vigilância sanitária e epidemiológica, bem como as de saúde do trabalhador;

III - ordenar a formação de recursos humanos na área de saúde;

IV - participar da formulação da política e da execução das ações de saneamento básico;

V - incrementar, em sua área de atuação, o desenvolvimento científico e tecnológico e a inovação;
} 
VI - fiscalizar e inspecionar alimentos, compreendido o controle de seu teor nutricional, bem como bebidas e águas para consumo humano;

VII - participar do controle e fiscalização da produção, transporte, guarda e utilização de substâncias e produtos psicoativos, tóxicos e radioativos;

VIII - colaborar na proteção do meio ambiente, nele compreendido o do trabalho (BRASIL, 1988).

No município, o gestor não pode realizar gastos com ações ou serviços que não estejam previamente previstos no Plano Municipal de Saúde e que sejam aprovados pelo Conselho Municipal de Saúde e nas respectivas Leis Orçamentárias (Plano Plurianual - PPA, Lei de Diretrizes Orçamentárias - LDO e Lei Orçamentária Anual - LOA) (ARANTES et al., 2007; BARBOSA, 2013). No que se refere aos Recursos da Saúde a Lei Complementar n. 141 de 2012 (BRASIL, 2012) estabelece o quantitativo mínimo que as esferas cada de governo devem investir em saúde:

1) a União deve investir o que foi empenhado no ano anterior, corrigido com o percentual de variação nominal do PIB [Produto Interno Bruto];

2) os Estados, $12 \%$, no mínimo, do montante de impostos recolhidos;

3) os Municípios, no mínimo, $15 \%$ de sua receita com impostos.

Já sobre a Administração dos recursos da Saúde, esses devem ser administrados em um "Fundo de Saúde", sob responsabilidade do Secretário de Saúde, que deve ser o único ordenador de despesas (PIOLA, 2011). No Fundo Municipal de Saúde, devem estar depositados todos os recursos do SUS (transferências da União e do Estado e os recursos próprios municipais). Nenhum recurso da Saúde pode ser administrado em outra conta da Prefeitura que não componham o Fundo Municipal de Saúde, e além disso, não podem estar fora de aplicações financeiras quando não estiverem sendo utilizados (CONSELHO DE SECRETARIAS MUNICIPAIS DE SAÚDE DO ESTADO DO RIO GRANDE DO NORTE - COSEMSRN, 2015).

O gestor deve dar publicidade às contas do Fundo, com o objetivo de garantir a participação dos conselheiros e cidadãos. Anualmente deve ser elaborado o Relatório Anual de Gestão (RAG), instrumento de prestação de contas, parte do processo de planejamento, que deve ser submetido ao Conselho de Saúde e este homologará a aprovação através de resolução específica (PIOLA et al, 2013).

Os Pressupostos essenciais de financiamento do SUS devem estar sustentado nos seguintes quesitos: Responsabilidade das três esferas de gestão: União, estados e municípios, Redução das iniquidades macrorregionais, estaduais e regionais, a ser contemplada na metodologia de alocação de recursos, considerando as dimensões étnico-racial e social, Repasse fundo a fundo, definido como modalidade preferencial 
de transferência de recursos entre os gestores e Financiamento de custeio com recursos federais constituídos, organizados e transferidos em blocos de recursos, o uso dos recursos fica restrito a cada bloco, atendendo as especificidades previstas nos mesmos, conforme regulamentação específica (COSEMSRN, 2015).

Quadro 1 - O financiamento federal

\begin{tabular}{|c|c|}
\hline Financiamento Federal & Destinação \\
\hline A) Recursos per capita. & $\begin{array}{l}\text { Será transferido mensalmente, de forma regular e } \\
\text { automática, do Fundo Nacional de Saúde aos } \\
\text { Fundos Municipais de Saúde e do Distrito } \\
\text { Federal com base num valor multiplicado pela } \\
\text { população do município. }\end{array}$ \\
\hline $\begin{array}{l}\text { B) Recursos para projetos específicos, tais como os } \\
\text { recursos da Compensação das Especificidades Regionais } \\
\text { (CER), do Programa de Requalificação das Unidades } \\
\text { Básicas de Saúde, recursos de investimento/estruturação } \\
\text { e recursos de estruturação na implantação. }\end{array}$ & $\begin{array}{l}\text { Estão incluídos os recursos da CER, do Programa } \\
\text { de Requalificação das Unidades Básicas de Saúde } \\
\text { e recursos de estruturação. }\end{array}$ \\
\hline C) Recursos de investimento. & $\begin{array}{l}\text { São recursos destinados à estruturação dos } \\
\text { serviços e ações da atenção básica que podem ser } \\
\text { repassados aos municípios/Estados fundo a fundo } \\
\text { ou por meio de convênio. }\end{array}$ \\
\hline $\begin{array}{l}\text { D) Recursos que estão condicionados à implantação de } \\
\text { estratégias e programas prioritários, tais como os } \\
\text { recursos específicos para os municípios que implantarem } \\
\text { as equipes de Saúde da Família, de Saúde Bucal, de } \\
\text { agentes comunitários de saúde, dos Núcleos de Apoio à } \\
\text { Saúde da Família, dos Consultórios na Rua, de Saúde da } \\
\text { Família Fluviais e Ribeirinhas, de Atenção Domiciliar, } \\
\text { Programa Saúde na Escola (PSE), microscopistas e } \\
\text { Academia da Saúde. }\end{array}$ & $\begin{array}{l}\text { Na implantação das equipes de Saúde da Família, } \\
\text { de Saúde Bucal e dos NASF, os municípios e/ou } \\
\text { o Distrito Federal receberão recursos específicos } \\
\text { para estruturação das Unidades Básicas de Saúde, } \\
\text { visando à melhoria da infraestrutura física e de } \\
\text { equipamentos para o trabalho das equipes. Esses } \\
\text { recursos serão repassados na competência } \\
\text { financeira do mês posterior à implantação das } \\
\text { equipes. }\end{array}$ \\
\hline $\begin{array}{l}\text { E) Recursos condicionados a resultados e avaliação do } \\
\text { acesso e da qualidade, tal como o do Programa Nacional } \\
\text { de Melhoria do Acesso e da Qualidade (PMAQ). }\end{array}$ & Tal como o do PMAQ. \\
\hline
\end{tabular}

Fonte: Brasil (2012).

Desde o final da década de 1990, o Ministério da Saúde induz a adesão dos municípios brasileiros a programas que visam ampliar a resolutividade da Atenção Básica, com a oferta de serviços por meio da Estratégia Saúde da Família, da Saúde Bucal, dos Núcleos de Apoio à Saúde da Família, entre outros (RIZZOTTO, 2014).

\subsection{O SUS e a atenção básica no Brasil}

Segundo Gil (2006), as expressões “atenção primária” e "atenção básica” são frequentemente usadas como sinônimos no Brasil. Ainda não se fez um estudo teórico aprofundado para determinar qual a acepção mais adequada (FARIA, 2013). Já na literatura internacional é mais comum "atenção primária". A esse respeito, o Ministério da Saúde, através da Portaria n. 2.488 de outubro de 2012, delimitou: “A Política Nacional de Atenção Básica 
considera os termos "atenção básica" e "Atenção Primária à Saúde - APS", nas atuais concepções, como termos equivalentes. Associa a ambos: os princípios e as diretrizes definidos neste documento" (BRASIL, 2012, p. 22).

A atenção primária é o primeiro nível de atenção do SUS, a porta de entrada e o contato preferencial do usuário com o sistema e as redes de atenção (MENDES, 2009). O Ministério da Saúde utiliza o termo "atenção básica" para se referir a esse conjunto de serviços de elevada complexidade e baixa densidade tecnológica, cujas ações são organizadas " [...] sob a forma de trabalho em equipe, dirigidas a populações de territórios definidos, pelas quais assume responsabilidade sanitária, considerando a dinamicidade existente no território em que vivem essas populações" (BRASIL, 2012, p. 19).

No Brasil a atenção primária ou básica é feita em Unidades Básicas de Saúde (UBS) e a Saúde da Família é sua estratégia prioritária, conforme determina a Política Nacional de Atenção Básica (PNAB) (BRASIL, 2012). Dessa forma, cada UBS, com ou sem Equipe Saúde da Família, deve se organizar para atender a um público-alvo, representado, em síntese, por um conjunto de famílias agregadas geograficamente (FARIA, 2013).

Internacionalmente tem-se apresentado APS como uma estratégia de organização da atenção à saúde voltada para responder de forma regionalizada, contínua e sistematizada à maior parte das necessidades de saúde de uma população, integrando ações preventivas e curativas, bem como a atenção a indivíduos e comunidades. Esse enunciado procura sintetizar as diversas concepções e denominações das propostas e experiências que se convencionaram chamar internacionalmente de APS (MATTA; MOROSINI, 2006).

No Brasil, a APS incorpora os princípios da Reforma Sanitária, levando o SUS a adotar a designação Atenção Básica à Saúde (ABS) para enfatizar a reorientação do modelo assistencial, a partir de um sistema universal e integrado de atenção à saúde (BRASIL, 2000).

Segundo Matta e Morosini (2006) historicamente, a ideia de atenção primária foi utilizada como forma de organização dos sistemas de saúde pela primeira vez no chamado Relatório Dawnson, em 1920. O referido relatório organizava o modelo de atenção em centros de saúde primários e secundários, serviços domiciliares, serviços suplementares e hospitais de ensino. Os centros de saúde primários e os serviços domiciliares deveriam estar organizados de forma regionalizada, onde a maior parte dos problemas de saúde deveriam ser resolvidos por médicos com formação em clínica geral (STARFIELD, 2002).

Os casos que o médico não tivesse condições de solucionar com os recursos disponíveis nesse âmbito da atenção deveriam ser encaminhados para os centros de atenção secundária, onde haveria especialistas das mais diversas áreas, ou então, para os hospitais, quando existisse 
indicação de internação ou cirurgia. Essa organização caracteriza-se pela hierarquização dos níveis de atenção à saúde.

Os cuidados primários de saúde são cuidados essenciais de saúde baseados em
métodos e tecnologias práticas, cientificamente bem fundamentadas e socialmente
aceitáveis, colocadas ao alcance universal de indivíduos e famílias da comunidade,
mediante sua plena participação e a um custo que a comunidade e o país possam
manter em cada fase de seu desenvolvimento, no espírito de autoconfiança e
autodeterminação. Fazem parte integrante tanto do sistema de saúde do país, do qual
constituem a função central e o foco principal, quanto do desenvolvimento social e
econômico global da comunidade. Representam o primeiro nível de contato dos
indivíduos, da família e da comunidade com o sistema nacional de saúde, pelo qual
os cuidados de saúde são levados o mais proximamente possível aos lugares onde
pessoas vivem e trabalham, e constituem o primeiro elemento de um continuado
processo de assistência à saúde (Organização Pan-americana da Saúde - OPAS, 1978).

No início dos anos 80, surgiram as Ações Integradas de Saúde (AIS), que visavam ao fortalecimento de um sistema unificado e descentralizado de saúde voltado para as ações integrais. Nesse sentido, as AIS surgiram de convênios entre estados e municípios, custeadas por recursos transferidos diretamente da previdência social, visando à atenção integral e universal dos cidadãos. Essas experiências somadas à constituição do SUS (BRASIL, 1988) e sua regulamentação (BRASIL, 1990) possibilitaram a construção de uma política de ABS que visasse à reorientação do modelo assistencial, tornando-se o contato prioritário da população com o sistema de saúde.

Assim, a concepção da ABS desenvolveu-se a partir dos princípios do SUS, principalmente a universalidade, a descentralização, a integralidade e a participação popular, como pode ser visto na portaria que institui a Política Nacional de Atenção Básica, definindo a ABS como:

um conjunto de ações de saúde no âmbito individual e coletivo que abrangem a promoção e proteção da saúde, prevenção de agravos, diagnóstico, tratamento, reabilitação e manutenção da saúde. É desenvolvida através do exercício de práticas gerenciais e sanitárias democráticas e participativas, sob forma de trabalho em equipe, dirigidas a populações de territórios bem delimitados, pelas quais assume a responsabilidade sanitária, considerando a dinamicidade existente no território em que vivem essas populações. Utiliza tecnologias de elevada complexidade e baixa densidade, que devem resolver os problemas de saúde de maior frequência e relevância em seu território. É o contato preferencial dos usuários com os sistemas de saúde. Orienta-se pelos princípios da universalidade, acessibilidade e coordenação do cuidado, vínculo e continuidade, integralidade, responsabilização, humanização, equidade, e participação social (BRASIL, 2006).

Atualmente, a principal estratégia de configuração da ABS no Brasil é a Saúde da família, que tem recebido importantes incentivos financeiros visando à ampliação da cobertura 
populacional e à reorganização da atenção. A Saúde da família aprofunda os processos de territorialização e responsabilidade sanitária das equipes de saúde, compostas basicamente por médico generalista, enfermeiro, auxiliares de enfermagem e agentes comunitários de saúde, cujo trabalho é referência de cuidados para a população adscrita, com um número definido de domicílios e famílias assistidos por equipe.

Entretanto, os desafios persistem e indicam a necessidade de articulação de estratégias de acesso aos demais níveis de atenção à saúde, de forma a garantir o princípio da integralidade, assim como a necessidade permanente de ajuste das ações e serviços locais de saúde, visando à apreensão ampliada das necessidades de saúde da população e à superação das iniquidades entre as regiões do país.

\subsubsection{Atenção básica e suas particularidades}

A Atenção Primária em Saúde - APS é reconhecidamente um componente-chave dos sistemas de saúde. Esse reconhecimento fundamenta-se nas evidências de seu impacto na saúde e no desenvolvimento da população nos países que a adotaram como base para seus sistemas de saúde: melhores indicadores de saúde, maior eficiência no fluxo dos usuários dentro do sistema, tratamento mais efetivo de condições crônicas, maior eficiência do cuidado, maior utilização de práticas preventivas, maior satisfação dos usuários e diminuição das iniquidades sobre o acesso aos serviços e o estado geral de saúde (OPAS, 2011; STARFIELD, 2002).

No Brasil, a APS “caracteriza-se por um conjunto de ações de saúde, no âmbito individual e coletivo", abrangendo a "promoção e a proteção da saúde", a "prevenção de agravos", o "diagnóstico e o tratamento", bem como, a "reabilitação, a redução de danos e a manutenção da saúde". Objetiva desenvolver uma "atenção integral” capaz de impactar nas condições de saúde e autonomia das pessoas, e nos determinantes e condicionantes de saúde das coletividades" (PNAB, 2012, p. 21).

Reitera-se que a atenção básica seja desenvolvida o mais próximo do convívio das pessoas, como a principal porta de entrada e centro de comunicação da Rede de Atenção à Saúde. Tem como princípios a universalidade, a acessibilidade, o vínculo, a continuidade do cuidado, além da integralidade da atenção, da responsabilização, da humanização, da equidade e da participação social (PNAB, 2012).

A Rede de Atenção à Saúde, tendo a Atenção Primária como centro, se organiza em: (i) ABS, que compreende um conjunto de ações, de caráter individual e coletivo, que engloba a promoção da saúde, a prevenção de agravos, o tratamento e a reabilitação, constituindo o 
primeiro nível da atenção do SUS; (ii) Atenção Média Complexidade, que é prestada por meio de uma rede de unidades especializadas de média complexidade, garantindo o acesso à população sob sua gestão; (iii) e Atenção Alta Complexidade, que é a atenção à saúde de terceiro nível, integrada pelos serviços ambulatoriais e hospitalares especializados de alta complexidade. É organizada por meio do sistema de referência (BRASIL, 2006). A Atenção Básica à Saúde deve ser orientada pelos princípios apresentados no Quadro 2.

Quadro 2 - Princípios da Atenção Primária à Saúde nas Redes de Atenção à Saúde

\begin{tabular}{|l|l|}
\hline \multicolumn{1}{|c|}{ Princípio } & \multicolumn{1}{c|}{ Descrição } \\
\hline Primeiro contato & Porta de entrada, de fácil acesso (organizacional e geográfico) ao cidadão. \\
\hline Integralidade & $\begin{array}{l}\text { Reconhecer e atender às necessidades de saúde da população e, quando necessário, } \\
\text { referenciar para outros pontos de assistência da rede }\end{array}$ \\
\hline Orientação familiar & $\begin{array}{l}\text { Conhecimento, pela equipe da APS, dos membros da família e dos seus problemas de } \\
\text { saúde. }\end{array}$ \\
\hline Longitudinalidade & Relação pessoal de longa duração entre profissionais de saúde e cidadãos. \\
\hline Coordenação & $\begin{array}{l}\text { Compartilhamento de informações clínicas, nos diversos pontos da rede, } \\
\text { possibilitando ao profissional da ABS acompanhar o cidadão }\end{array}$ \\
\hline Orientação comunitária & Controle social \\
\hline
\end{tabular}

Fonte: Secretária de Estado de Saúde de MG (SES/MG), 2008.

No que se refere à dinâmica do gerenciamento, o intuito é o de ligar as bases do gerenciamento aos mais importantes princípios do SUS, e também o de associar alguns pressupostos pilares da ESF. Esse desenho gerencial conduz as ações voltadas à promoção da saúde e ao desenvolvimento das pessoas na visão da longitudinalidade da ABS. Sobre esse ponto Starfield (2004, p. 142) acrescenta:

[...] a atenção primária se diferencia dos outros níveis assistenciais por quatro atributos característicos: atenção ao primeiro contato, longitudinalidade, integralidade e coordenação. Destes quatro atributos, a longitudinalidade tem relevância por compreender o vínculo do usuário com a unidade e/ou com o profissional. A população deve reconhecer a Unidade como fonte regular e habitual de atenção à saúde, tanto para as antigas quanto para as novas necessidades. Já o profissional deve conhecer e se responsabilizar pelo atendimento destes indivíduos. A longitudinalidade está fortemente relacionada à boa comunicação que tende a favorecer $o$ acompanhamento do paciente, a continuidade e efetividade do tratamento, contribuindo também para a implementação de ações de promoção e de prevenção de agravos de alta prevalência.

A atenção primária é uma parte importante na prestação de serviços públicos de saúde no sistema nacional, sendo sua provisão responsável por uma proporção significativa do orçamento de cuidados de saúde. Nesse sentido, muitos esforços deveriam ser feito para identificar variações sistemáticas no desempenho entre prestadores de atenção primária, com a visão para melhorar o desempenho em todo o sistema. 


\subsubsection{Pacto pela Saúde}

O Pacto pela Saúde foi estabelecido pela Portaria MS n. 399 de 2006 em substituição a Normativa Operacional em vigor (NOAS, 2002). As diretrizes para a política de saúde nacional definidas pelo Pacto pela Saúde, como Pacto em Defesa pelo SUS, Pacto pela Vida e Pacto de Gestão, estão vinculados a um amplo rol de Leis, Decretos e Portarias, por exemplo, o Decreto n. 7.508 de 2011 (regulamenta a Lei 8.080 de 1990, que define as regiões de saúde, o planejamento e institui o Contrato Organizativo da Ação Pública em Saúde - COAP), a Portaria MS n. 2.488 de 2011 (Política Nacional de Atenção Básica) e a Lei n. 141 de 2012 (regulamenta a Emenda Constituiconal n. 29 de 2000).

O Pacto pela Saúde é um conjunto de reformas institucionais do SUS pactuado entre as três esferas de gestão (União, Estados e Municípios) com o objetivo de promover inovações nos processos e instrumentos de gestão, visando alcançar maior eficiência e qualidade das respostas do SUS. Ao mesmo tempo, o Pacto pela Saúde redefine as responsabilidades de cada gestor em função das necessidades de saúde da população e na busca da equidade social (BRASIL, 2006).

A implementação do Pacto pela Saúde se dá pela adesão de Municípios, Estados e União ao Termo de Compromisso de Gestão (TCG). O TCG substitui os processos de habilitação das várias formas de gestão anteriormente vigentes e estabelece metas e compromissos para cada ente da federação, sendo renovado anualmente. Entre as prioridades definidas estão a redução da mortalidade infantil e materna, o controle das doenças emergentes e endemias (como dengue e hanseníase) e a redução da mortalidade por câncer de colo de útero e da mama, entre outras.

As formas de transferência dos recursos federais para estados e municípios também foram modificadas pelo Pacto pela Saúde, passando a ser integradas em cinco grandes blocos de financiamento: (i) Atenção Básica, (ii) Média e Alta Complexidade da Assistência, (iii) Vigilância em Saúde, (iv) Assistência Farmacêutica e (v) Gestão do SUS.

$\mathrm{Na}$ perspectiva de superar as dificuldades apontadas, os gestores do SUS assumem o compromisso público, da construção de um processo de pactuação de compromissos pela saúde, anualmente revisada, que tenha como base os princípios constitucionais do SUS, com ênfase nas necessidades de saúde da população e que implicará o exercício simultâneo de definição de prioridades articuladas e integradas sob a forma de três pactos: Pacto pela Vida, Pacto em Defesa do SUS e Pacto de Gestão do SUS. Os três pactos que compõem a agenda são apresentados na Figura 2. 
Figura 2 - Pacto da saúde: uma estratégia para viabilizar a equidade em saúde no Brasil

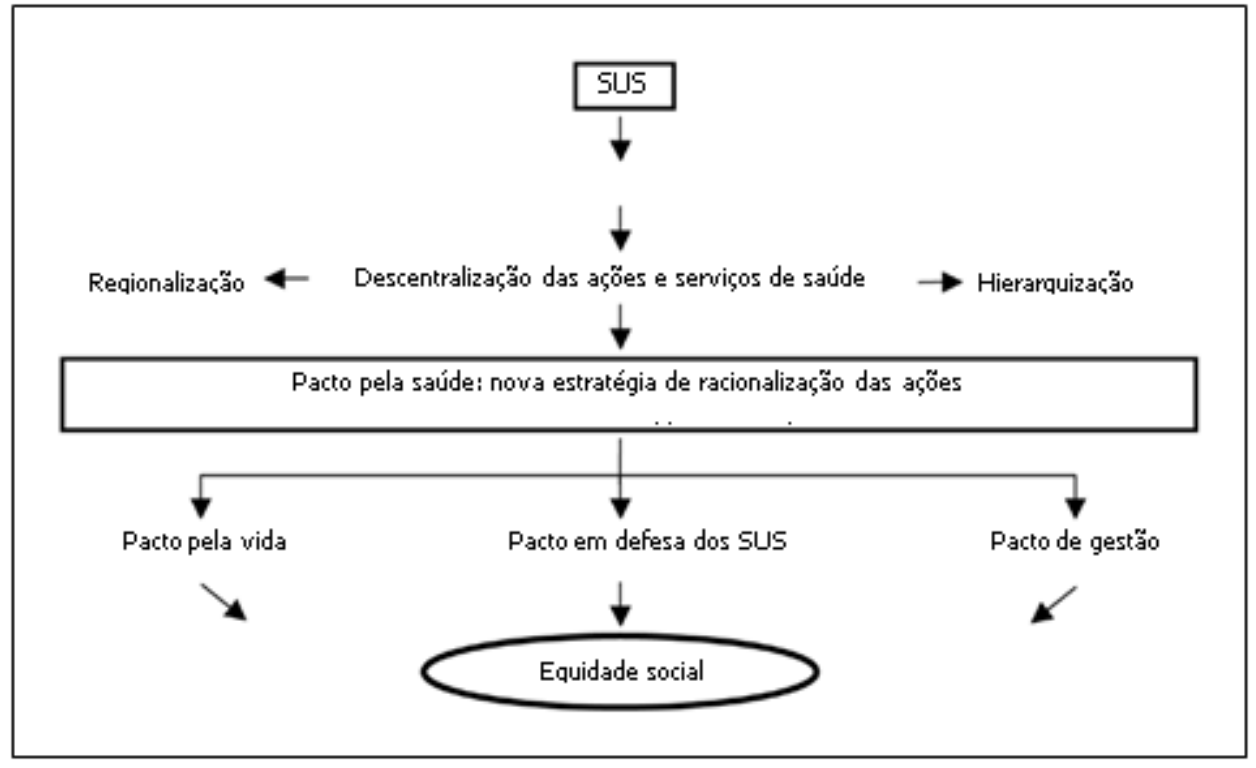

Fonte: Fadel (2009).

\subsection{Mainstream}

Estudos anteriores como os de Deprins et al. (1984) e Vanden Eeckaut et al. (1994) utilizaram da análise de envolvimento de dados DEA (BANKER et al., 1984; CHARNES et al., 1978; FÃRE et al., 1985, 1994) e Free Disposal Hull (FDH) (DEPRINS et al., 1984) para calcular a eficiência dos municípios belgas. Ultimamente, contribuições relevantes para esta literatura incluem estudos de Hayes e Chang (1994), De Borger et al. (1994) e De Borger e Kerstens (1996a, b), entre outros.

Desenvolvida por Charnes et al. (1978), a DEA é uma técnica de programação linear não paramétrica. Utilizada para análise de "dados orientado", pode ser considerara como abordagem para avaliar o desempenho de um conjunto de entidades de pares chamado Unidades de tomada de decisão (Decision Making Units - DMUs), que convertem múltiplas entradas em múltiplas saídas.

Alguns desses trabalhos tentam medir a eficiência global das administrações locais, incorporando múltiplos resultados produzidos pelos governos locais em uma única medida de eficiência. Outro grupo de artigos trata da eficiência de um único serviço, como saúde, coleta de esgoto e educação (VARELA et al., 2012).

Quanto ao Brasil, Sousa e Ramos (1999a, 1999b) aplicaram modelos não paramétricos (DEA e FDH) para medir o nível de eficiência técnica dos municípios brasileiros, usando uma única entrada agregada e cinco variáveis de saída. De forma geral, esses estudos representam a 
primeira tentativa de calcular os escores de eficiência para avaliação dos governos locais brasileiros.

O objetivo desta seção é descrever os estudos já publicados sobre o tema da Atenção Básica e do Pacto pela Saúde no Brasil. A literatura nacional é razoavelmente rica, sendo que a presente revisão abrange o período de 2007 a 2017. As buscas por publicações foram feitas no Portal de Periódicos da Coordenação de Aperfeiçoamento de Pessoal de Nível Superior (CAPES) por meio das palavras-chave "Atenção Básica" e "Pacto pela Saúde".

Os resultados iniciais somam 123 artigos, em que se escolheram apenas 17 deles, em razão da relevância da temática, que se aproximava mais da discussão sobre eficiência no SUS. Um resumo dos principais é apresentado no Quadro 3.

Dentre os diversos trabalhos, pode-se citar inicialmente Escorel (2007), que afirma que a implantação do SUS no Brasil representou uma importante inflexão no padrão historicamente consolidado de organização dos serviços de saúde no país, sendo que, na segunda metade da década, o processo de implantação do SUS caminhou pari passu à adoção de uma série de medidas governamentais voltadas para o fortalecimento da Atenção Básica de saúde (ESCOREL, 2007).

No estudo de Santos (2008), constatou-se que, ao lado do reconhecimento dos avanços do SUS e irreversibilidade destes, há questões estruturais pendentes nos mais de 17 anos da Lei Orgânica da Saúde, nos modelos de gestão do sistema e dos serviços, nos modelos de atenção à saúde e na participação democrática. No referido trabalho, foram avaliados cenários da conjuntura atual, do Pacto pela Vida em Defesa do SUS e de Gestão, da Regulamentação da EC n. 29 e do Programa de Aceleração do Crescimento - PAC-Saúde e suas intersecções. Esses aspectos levaram a alguns equacionamentos e, ao final, uma lembrança da sucessão de três conjunturas (dos anos 1980, 1990 e da década atual), visando contribuir para as buscas e escolhas de rumos.

Fadel et al. (2009), por outro lado, afirmam que, apesar da conquista de um embasamento jurídico sólido para a legitimação do SUS por meio, principalmente, de leis orgânicas, suscitou-se a necessidade de regulamentação prática do sistema, com algo que claramente dispusesse sobre as ações cotidianas em saúde.

Outro estudo diz respeito a Gadelha (2010), que caracteriza o SUS como um sistema de saúde pública, destacando o princípio da regionalização que o norteia, sendo esse referente à descentralização das ações e dos serviços de saúde e aos processos de negociação e pactuação entre os gestores. Segundo o autor supracitado, a partir de 2006, quando foi firmado o Pacto pela Saúde, obtiveram-se mudanças significativas no SUS, dentre as quais se ressaltam: a 
substituição do atual processo de habilitação pela adesão solidária aos Termos de Compromisso de Gestão; a regionalização solidária e cooperativa como eixo estruturante do processo de descentralização; a integração das várias formas de repasse dos recursos federais; e a unificação dos vários pactos hoje existentes.

Silva (2011) observou as causas da segmentação/fragmentação na atenção à saúde e nos benefícios da integração e constituição de redes para racionalizar gastos, otimizar recursos e promover uma atenção condizente com as necessidades dos usuários. O autor teve como principal objetivo analisar os desafios presentes no SUS, para promover uma integração melhor entre os serviços e organizar redes. Entre os desafios abordados há a insuficiência de recursos decorrentes do baixo financiamento público; os processos de formação e educação e seus reflexos na disponibilização dos profissionais para o sistema público; e as dificuldades inerentes à descentralização de ações e serviços de saúde no pacto federativo brasileiro. Conclui-se que, além de esforços para enfrentar esses desafios, a organização de redes regionalizadas e integradas no SUS depende do aperfeiçoamento na gestão intergovernamental, em se tratando das regiões de saúde, para qualificar a pactuação de responsabilidades entre as esferas de governo e de qualificação da atenção primária, com vistas a coordenar o cuidado e ordenar sua continuidade nos outros níveis do sistema (SILVA, 2011).

Varela et al. (2012) teve por objetivo construir uma metodologia de avaliação de desempenho dos municípios paulistas quanto à eficiência técnica na aplicação de recursos públicos nas ações de atenção básica à saúde e analisar a influência de variáveis não controláveis no processo de produção em tal área. A eficiência técnica é um dos parâmetros de avaliação de desempenho dos gestores públicos, refletindo a, capacidade de uma entidade obter máximos outputs com o menor consumo de inputs. Os resultados indicaram que seria possível aumentar, consideravelmente, a quantidade de serviços prestados à população sem a necessidade de novas dotações orçamentárias na maioria dos municípios. Além disso, verificouse que a maior proporção de idosos em uma jurisdição torna a prestação de serviços mais cara; por sua vez, maiores densidade populacional, grau de urbanização e escala dos estabelecimentos de saúde favorecem o gasto público com eficiência. Os cinco municípios paulistas considerados mais eficientes foram: Tuiuti, Nova Guataporanga, Sabino, Lins e Santos.

Segundo Varela et al. (2012) o alcance dos resultados de eficiência municipal pode ser prejudicado ou favorecido pelas variáveis ambientais ou não controláveis que, se não forem consideradas na avaliação de desempenho, podem gerar vieses. Nesse sentido, por meio da metodologia DEA em dois estágios, os escores de eficiência dos municípios foram estimados e depois ajustados com o uso da análise de regressão. Na seção 3, do presente trabalho, são 
descritos os procedimentos metodológicos utilizados com base em Varela et al. (2012), momento em que, portanto, se descreve a proposta de metodologia dos referidos autores.

Na pesquisa de Castro (2012, p. 12) é analisada a evolução do gasto social entre 1995 e 2010 em que, “[...] principalmente a partir de 1993, com o efetivo início da implementação das políticas previstas pela Constituição Federal de 1988 [...], os gastos sociais passam a aumentar de maneira sustentada". Para o referido autor, o gasto social do período ficou concentrado em seis áreas: previdência social geral; previdência e benefícios a servidores públicos; saúde; assistência social; educação; e trabalho e renda. Ainda de acordo com Castro (2012), nota-se o maior crescimento relativo do gasto social destinado à assistência social, na medida em que o país abandonou um sistema assistencialista em troca de "[...] um modelo de direitos, com uma atuação cada vez mais abrangente sobre a população brasileira" (CASTRO, 2012, p. 12).

Lima et al. (2012) analisaram a descentralização e a regionalização representantes das diretrizes constitucionais de organização do SUS que exigiram, nos últimos 20 anos, a adoção de mecanismos de coordenação e acomodação das tensões federativas em saúde no Brasil. Os autores analisaram a implantação nacional do Pacto pela Saúde, de 2006 a 2010. A pesquisa envolveu análise de documentos, de dados oficiais e realização de entrevistas com dirigentes federais, estaduais e municipais nos estados brasileiros. Buscou-se discorrer sobre o conteúdo da proposta nacional e seus desdobramentos para a política de saúde, verificando os diferentes ritmos e graus de implantação do Pacto pela Saúde, no que concerne à adesão dos Estados e Municípios e à conformação de Colegiados de Gestão Regional. Lima et al. (2012) sistematizaram os fatores condicionantes da multiplicidade das experiências observadas no país e discutiram os desafios para o avanço da descentralização e da regionalização no sistema de saúde brasileiro.

Nesse entremeio, o estudo de Gonçalves (2013) se referiu às práticas de gestão do SUS na Atenção Básica no município de Alagoinhas (BA), com a finalidade de compreender o(s) sentido(s) e/ou significado(s) sobre a gestão do cuidado na Atenção Básica de Saúde, considerando-se a participação dos gestores, trabalhadores de saúde e usuários da Atenção Básica no município; analisar a prática de gestão do SUS na Atenção Básica; e discutir a(s) competência(s) e atribuição(ões) do governo municipal (gestores, trabalhadores de saúde e munícipes), as políticas e os "novos" modelos de saúde na Atenção Básica. Para tanto, realizaram uma pesquisa qualitativa nas unidades de saúde da família. Os sujeitos participantes do estudo foram divididos em quatro grupos (gestores, trabalhadores de saúde, usuários e informantes-chave), num total de 26 indivíduos. Utilizou-se para coleta dos dados: observação sistemática, entrevista semiestruturada e análise de documentos. A partir do método de análise 
de dados que se aproxima da hermenêutica-dialética, elaboraram-se três categorias de análise: prática da gestão na Atenção Básica de Saúde: sentidos e significados; a orquestra "ideal” da racionalidade, ordem hegemônica e produtiva; e controle social: em busca da democracia.

De acordo com os resultados encontrados por Gonçalves (2013), constatou-se que as práticas de gestão do SUS na Atenção Básica do município de Alagoinha (BA) se encontram desarticuladas entre os sujeitos usuários, trabalhadores de saúde e gestores, além de se caracterizarem pela centralização do poder de decisão dos gestores em detrimento dos interesses dos usuários e trabalhadores, traduzindo a fragilidade do exercício da cidadania. Assim sendo, o controle social, a educação permanente e o planejamento em saúde como instrumentos de partilha do poder entre sujeitos têm sido apenas teorizados, reproduzindo uma gestão centralizada, já que os sentidos e significados para gestão ora aproximam, ora se afastam das práticas dos envolvidos. Na compreensão desses indivíduos, as práticas de gestão devem ser baseadas no modelo de saúde do usuário.

Mendes e Marques (2014) analisaram o financiamento do nível da Atenção Básica à saúde, com ênfase na expansão dos recursos alocados para a Estratégia Saúde da Família. A primeira parte detalhou o crescimento dos recursos do Ministério da Saúde para a Atenção Básica, particularmente os transferidos mediante o PAB Variável. O segundo item analisou as dificuldades do financiamento, tendo em vista a instabilidade dos recursos próprios municipais, e discutiu algumas sugestões de mudanças nos critérios dos recursos federais transferidos aos municípios.

No mesmo período, Soares e Santos (2014) discutiram questões relativas ao financiamento e à alocação de recursos no SUS, no contexto de dois projetos políticos distintos. O estudo considerou os gastos com saúde no Brasil, no período de 1995 a 2012, comparados aos investimentos internacionais, ao PIB e à Receita Corrente Bruta. Na análise, os autores buscaram comparar os compromissos assumidos com o SUS nas gestões dos presidentes Fernando Henrique Cardoso, Luís Inácio Lula da Silva e Dilma Rousseff, tendo observado que, com relação ao comportamento dos gastos com saúde, no âmbito federal, os governos do Partido dos Trabalhadores (PT) não diferiram dos governos do Partido da Social Democracia Brasileira (PSDB). Por conseguinte, o perfil dos gastos com saúde não conseguiu atender ao sonho da reforma sanitária dos anos 1980.

Já em 2016, Fernandes et al. (2016) investigaram a efetividade do atual modelo de financiamento de saúde pública no Brasil, em nível municipal. Após uma introdução relacionada à evolução do SUS e o sistema contábil brasileiro, com o intuito de verificar como é realizado o gasto no setor, os autores buscaram avaliar se um aumento das despesas com 
saúde, mensurado com o índice de mortalidade infantil, bem como o esforço do gestor público, medido pela sua capacidade de ampliar a arrecadação, melhoram a qualidade da saúde pública. Os resultados apresentaram que o comprometimento do administrador público é importante, ainda que o aumento puro e simples do gasto não leve a um desempenho melhor.

Nesse sentido, Medeiros (2016) analisou o financiamento da saúde pública brasileira. O referido autor verificou os impactos da escassez dos recursos, criando uma dificuldade de administração para os gestores da saúde pública, o que se agrava pela falta de materiais de trabalho na rede de Atenção Básica e na rede de saúde em toda a sua extensão.

Pretendeu-se compreender o financiamento da saúde sob o olhar dos gestores públicos e se o consideram um gasto social ou uma política de investimento nas pessoas. Tratou-se de um estudo documental com abordagem qualitativa, em que os campos de investigação foram as opiniões manifestadas a partir de entrevistas e reportagens na mídia nacional. A população foi abrangida pelos gestores do setor público da saúde, considerando-se as notícias conforme a abordagem de análise temática e, dentre os resultados obtidos, formaram-se quatro temas: gasto social ou política de investimento - a interrogação se movimenta; a dívida pública e os investimentos em saúde; as dificuldades do financiamento nos três níveis de governo; a gestão e o financiamento público da saúde. Dentre as notícias, notou-se que os gestores consideram o atual financiamento um gasto social, e a análise desses textos revelou que, a partir das opiniões dos gestores sobre o financiamento, deve ser aumentado o repasse, principalmente da união para os outros entes federados.

Por fim, Stevens et al. (2017) analisaram a mensurações de indicadores de saúde que raramente estão disponíveis para todas as populações e períodos de interesse, em que os dados disponíveis podem não ser comparáveis. Os autores observaram que As Diretrizes para o Relato Transparente e Preciso de Estimativas de Saúde (Declaração GATHER) definem as melhores práticas para a redação de estudos que calculam estimativas de saúde a várias populações, no tempo ou espaço, usando múltiplas fontes de informação. Enquadram-se no escopo da Declaração GATHER todas as estimativas quantitativas de indicadores de saúde em nível populacional (globais, regionais, nacionais ou subnacionais), abrangendo índices da situação de saúde, da incidência e prevalência de doenças, lesões e incapacidades, e funcionalidades; e de determinantes da saúde, incluindo comportamentos e exposições de saúde.

A dissertação de Kroth (2017) teve por objetivo avaliar o impacto do programa "Pacto pela Saúde" sobre o desempenho da política de saúde, em termos da eficiência e do resultado, dos municípios brasileiros no período de 2006 a 2013. Esse Pacto teve como uma de suas principais diretrizes o aprimoramento da governança da política de saúde pelos Entes 
Federados, com especial atenção à gestão por resultados, materializada na assinatura do TCG. Primeiro, analisou de forma pioneira e rigorosa o impacto causal do programa "Pacto pela Saúde". Segundo, fornece evidências substantivas sobre a forma pela qual a produção de saúde municipal responde à essa política. Terceiro, calculou os indicadores de eficiência e de vulnerabilidade municipais específicos para a Atenção Básica.

Os principais resultados desta tese foram: i) evidenciou-se que o maior tempo de adesão ao Pacto deu-se em municípios com melhores condições de saúde e, portanto, mais favoráveis de atingirem as metas pactuadas; ii) há uma correlação positiva entre tempo de adesão ao Pacto (dose) e indicador de eficiência (Indicador de Eficiência da prestação de serviços de saúde da Atenção Básica - IDEAB). Os municípios que aderiram ao Pacto apresentaram IDEAB maior, comparado com os municípios que não aderiram.

Quadro 3 - Quadro resumo dos estudos anteriores

\begin{tabular}{|c|c|c|c|}
\hline Autores & Ano & Metodologia & Resultados encontrados \\
\hline Escorel & 2007 & Estudos de caso & $\begin{array}{l}\text { A implantação do SUS no Brasil representou uma importante } \\
\text { inflexão no padrão historicamente consolidado de organização dos } \\
\text { serviços de saúde no país, sendo que, na segunda metade da década, } \\
\text { o processo de implantação do SUS caminhou pari passu à adoção de } \\
\text { uma série de medidas governamentais voltadas para o fortalecimento } \\
\text { da Atenção Básica de saúde. }\end{array}$ \\
\hline Santos & 2008 & $\begin{array}{l}\text { Análise de } \\
\text { conteúdo }\end{array}$ & $\begin{array}{l}\text { Ao lado do reconhecimento dos avanços do SUS e irreversibilidade } \\
\text { destes, há questões estruturais pendentes nos mais de } 17 \text { anos da Lei } \\
\text { Orgânica da Saúde, nos modelos de gestão do sistema e dos serviços, } \\
\text { nos modelos de atenção à saúde e na participação democrática. }\end{array}$ \\
\hline Fadel et al. & 2009 & Análise critica & $\begin{array}{l}\text { A necessidade de regulamentação prática do sistema é suscitado, com } \\
\text { algo que claramente dispusesse sobre as ações cotidianas em saúde. }\end{array}$ \\
\hline Gadelha & 2010 & Análise critica & $\begin{array}{l}\text { O SUS é caracterizado como um sistema de saúde pública, } \\
\text { destacando o princípio da regionalização que o norteia, sendo esse } \\
\text { referente à descentralização das ações e dos serviços de saúde e aos } \\
\text { processos de negociação e pactuação entre os gestores. }\end{array}$ \\
\hline Silva & 2011 & $\begin{array}{l}\text { Análise de } \\
\text { conteúdo }\end{array}$ & $\begin{array}{l}\text { Além de esforços para enfrentar desafios, a organização de redes } \\
\text { regionalizadas e integradas no SUS depende do aperfeiçoamento na } \\
\text { gestão intergovernamental, em se tratando das regiões de saúde, para } \\
\text { qualificar a pactuação de responsabilidades entre as esferas de } \\
\text { governo e de qualificação da atenção primária, com vistas a } \\
\text { coordenar o cuidado e ordenar sua continuidade nos outros níveis do } \\
\text { sistema. }\end{array}$ \\
\hline $\begin{array}{l}\text { Varela et } \\
\text { al. }\end{array}$ & 2012 & DEA & $\begin{array}{l}\text { Seria possível aumentar, consideravelmente, a quantidade de serviços } \\
\text { prestados à população sem a necessidade de novas dotações } \\
\text { orçamentárias na maioria dos municípios. Foi verificado que a maior } \\
\text { proporção de idosos em uma jurisdição torna a prestação de serviços } \\
\text { mais cara; por sua vez, maiores densidade populacional, grau de } \\
\text { urbanização e escala dos estabelecimentos de saúde favorecem o } \\
\text { gasto público com eficiência. }\end{array}$ \\
\hline Castro & 2012 & Análise temporal & $\begin{array}{l}\text { O gasto social do período de } 1995 \text { a } 2012 \text { ficou concentrado em seis } \\
\text { áreas: previdência social geral; previdência e benefícios a servidores } \\
\text { públicos; saúde; assistência social; educação; e trabalho e renda. } \\
\text { Foi encontrado também que o maior crescimento relativo do gasto } \\
\text { social destinado à assistência social, na medida em que o país } \\
\text { abandonou um sistema assistencialista em troca de "[...] um modelo }\end{array}$ \\
\hline
\end{tabular}




\begin{tabular}{|c|c|c|c|}
\hline & & & $\begin{array}{l}\text { de direitos, com uma atuação cada vez mais abrangente sobre a } \\
\text { população brasileira". }\end{array}$ \\
\hline Lima et al. & 2012 & $\begin{array}{l}\text { Análise } \\
\text { documental }\end{array}$ & $\begin{array}{l}\text { Os fatores condicionantes da multiplicidade das experiências } \\
\text { observadas no país foram sistematizados e os desafios para o avanço } \\
\text { da descentralização e da regionalização no sistema de saúde brasileiro } \\
\text { foram discutidos. }\end{array}$ \\
\hline Gonçalves & 2013 & $\begin{array}{l}\text { Pesquisa } \\
\text { qualitativa }\end{array}$ & $\begin{array}{l}\text { As práticas de gestão do SUS na Atenção Básica do município de } \\
\text { Alagoinha (BA) se encontram desarticuladas entre os sujeitos } \\
\text { usuários, trabalhadores de saúde e gestores, além de se caracterizarem } \\
\text { pela centralização do poder de decisão dos gestores em detrimento } \\
\text { dos interesses dos usuários e trabalhadores, traduzindo a fragilidade } \\
\text { do exercício da cidadania. } \\
\text { O controle social, a educação permanente e o planejamento em saúde } \\
\text { como instrumentos de partilha do poder entre sujeitos têm sido } \\
\text { apenas teorizados, reproduzindo uma gestão centralizada, já que os } \\
\text { sentidos e significados para gestão ora aproximam, ora se afastam das } \\
\text { práticas dos envolvidos. }\end{array}$ \\
\hline $\begin{array}{l}\text { Mendes e } \\
\text { Marques }\end{array}$ & 2014 & $\begin{array}{l}\text { Pesquisa } \\
\text { quantitativa }\end{array}$ & $\begin{array}{l}\text { A primeira parte detalhou o crescimento dos recursos do Ministério } \\
\text { da Saúde para a Atenção Básica, particularmente os transferidos } \\
\text { mediante o PAB Variável. O segundo item analisou as dificuldades } \\
\text { do financiamento, tendo em vista a instabilidade dos recursos } \\
\text { próprios municipais, e discutiu algumas sugestões de mudanças nos } \\
\text { critérios dos recursos federais transferidos aos municípios. }\end{array}$ \\
\hline $\begin{array}{l}\text { Soares e } \\
\text { Santos }\end{array}$ & 2014 & $\begin{array}{l}\text { Pesquisa } \\
\text { exploratória }\end{array}$ & $\begin{array}{l}\text { O comportamento dos gastos com saúde, no âmbito federal, os } \\
\text { governos do PT não diferiram dos governos do PSDB. Por } \\
\text { conseguinte, o perfil dos gastos com saúde não conseguiu atender ao } \\
\text { sonho da reforma sanitária dos anos } 1980 \text {. }\end{array}$ \\
\hline $\begin{array}{l}\text { Mendes e } \\
\text { Weiller }\end{array}$ & 2015 & $\begin{array}{l}\text { Pesquisa } \\
\text { exploratória }\end{array}$ & $\begin{array}{l}\text { O arcabouço legal desenvolvido no Brasil assegura a constante } \\
\text { ampliação das renúncias fiscais, principalmente no setor da saúde, } \\
\text { contribuindo para a ampliação da cobertura de planos de saúde. } \\
\text { Há a efetiva transformação do direito à saúde em garantia de consumo } \\
\text { de produtos e serviços, denotando o processo de mercantilização } \\
\text { sofrido por essa política pública. }\end{array}$ \\
\hline $\begin{array}{l}\text { Fernandes } \\
\text { et al. }\end{array}$ & 2016 & $\begin{array}{l}\text { Pesquisa } \\
\text { qualitativa }\end{array}$ & $\begin{array}{l}\text { O comprometimento do administrador público é importante, ainda } \\
\text { que o aumento puro e simples do gasto não leve a um desempenho } \\
\text { melhor. }\end{array}$ \\
\hline Medeiros & 2016 & $\begin{array}{l}\text { Análise temática } \\
\text { proposta por } \\
\text { Minayo }\end{array}$ & $\begin{array}{l}\text { Gestores consideram o atual financiamento um gasto social, e a } \\
\text { análise das opiniões manifestadas a partir de entrevistas com gestores } \\
\text { e reportagens na mídia nacional revelou que, a partir das opiniões } \\
\text { desses gestores sobre o financiamento, deve ser aumentado o repasse, } \\
\text { principalmente da união para os outros entes federados. }\end{array}$ \\
\hline $\begin{array}{l}\text { Stevens et } \\
\text { al. }\end{array}$ & 2017 & $\begin{array}{l}\text { A declaração } \\
\text { GATHER }\end{array}$ & $\begin{array}{l}\text { Foi observado que As Diretrizes para o Relato Transparente e Preciso } \\
\text { de Estimativas de Saúde (Declaração GATHER) definem as } \\
\text { melhores práticas para a redação de estudos que calculam estimativas } \\
\text { de saúde a várias populações, no tempo ou espaço, usando múltiplas } \\
\text { fontes de informação. }\end{array}$ \\
\hline Kroth & 2017 & $\begin{array}{l}\text { Avaliação } \\
\text { econômica de } \\
\text { políticas } \\
\text { públicas }\end{array}$ & $\begin{array}{l}\text { Foi evidenciado que o maior tempo de adesão ao Pacto deu-se em } \\
\text { municípios com melhores condições de saúde e, portanto, mais } \\
\text { favoráveis de atingirem as metas pactuadas. } \\
\text { Há uma correlação positiva entre tempo de adesão ao Pacto (dose) e } \\
\text { indicador de eficiência (IDEAB). Os municípios que aderiram ao } \\
\text { Pacto apresentaram IDEAB maior, comparado com os municípios } \\
\text { que não aderiram }\end{array}$ \\
\hline
\end{tabular}

Fonte: elaborado pela autora. 


\section{METODOLOGIA}

Este capítulo tem por objetivo descrever os procedimentos utilizados na realização desta pesquisa. Na estrutura composta por sete seções, apresentam-se as principais características do estudo, as etapas adotadas para coleta e tratamento dos dados, os critérios avaliados para seleção das variáveis, a dimensão do modelo de desempenho utilizado no cenário brasileiro, as características do caso prático e as limitações da pesquisa.

\subsection{Caracterização do estudo}

Com o objetivo de avaliar a eficiência alocativa na APS nos municípios brasileiros, além de averiguar possíveis disparidades regionais e de fatores socioeconômicos e de características do sistema de saúde, com base no gasto (inputs) e nos serviços de atenção básica prestados (outputs) no Brasil, foi utilizada o DEA, com orientação para a maximização de outputs, a partir do referencial de Varela et al. (2012).

Trata-se de um estudo descritivo, com abordagem predominantemente quantitativa. $\mathrm{O}$ estudo foi realizado por meio de um censo dos municípios brasileiros. Foram excluídos inicialmente os municípios de Brasília/DF, Fernando de Noronha/PE e Paraíso das Águas/MS, por não possuírem informações para todas as bases de dados utilizadas ${ }^{1}$, quais sejam: o Sistema de Informações Ambulatoriais (SIA), o Sistema de Informações da Atenção Básica (SIAB) e o Sistema de Informações sobre Orçamentos Públicos em Saúde (SIOPS).

Assim, no primeiro momento, a partir do DEA, estimou-se um limite de produção, considerando variáveis ou input discricionários e outputs relativos aos serviços de atenção básica à saúde prestados pelos municípios brasileiros, que, para recebem recursos do Fundo Nacional de Saúde, obrigam-se a alimentar as bases de dados administradas pelo Ministério da Saúde (e.g., SIA, SIAB e o SIOPS) (VARELA et al., 2012). Ver sobre coleta e tratamento dos dados nas subseções a seguir.

\footnotetext{
${ }^{1}$ O SIA contém informações sobre a produção ambulatorial de baixa, média e alta complexidades em termos de quantidades/valores aprovados e quantidades/valores apresentados. O SIAB possui dados gerados a partir do trabalho das Equipes de Saúde da Família (ESF) e Agentes Comunitários de Saúde (ACS). Já o SIOPS apresenta dados sobre receitas e despesas dos municípios na área de saúde e um conjunto de indicadores gerados a partir de tais informações (VARELA et al., 2012, p. 631).
} 


\subsection{Análise Envoltória de Dados}

A Análise por Envoltória de Dados (DEA) é uma técnica baseada em programação linear, com o objetivo de medir o desempenho de unidades operacionais ou tomadoras de decisão (Decision Making Units - DMUs), quando a presença de múltiplas entradas e múltiplas saídas torna difícil realizar uma comparação (VILELA, 2004).

O modelo DEA tem a característica de comparar as unidades para determinar a eficiência técnica individual e comparada (i.e., relativa). $\mathrm{O}$ objetivo da técnica é construir um conjunto de referência, por meio do qual as DMUs podem ser classificadas em unidades eficientes e ineficientes (SOARES DE MELLO et al., 2005). A teoria econômica da análise de eficiência é baseada no trabalho de Debreu (1951) e Koopmans (1951) sobre análise de produtividade, em que se considera a possibilidade de produção (curva de eficiência) de determinados produtos (outputs) a partir da utilização combinada dos insumos (inputs).

Em outras palavras, os vários modelos DEA baseiam-se na análise de eficiência das unidades tomadoras de decisão (DMUs) com múltiplos insumos (inputs) e produtos (outputs) e partem da ideia de construir uma curva de possibilidade de produção (chamada fronteira de eficiência), em que as DMUs mais eficientes se situem sobre a curva, enquanto as ineficientes se situem internamente abaixo da fronteira. Especificamente, quando orientado a output, o propósito do modelo DEA é estimar, para cada DMU, o escore de eficiência considerando a maximização dos outputs em função do consumo de um grupo de inputs.

De forma geral, é preciso cumprir três etapas de modelagem, conforme apresentado na Figura 3.

Figura 3 - Etapas para implementar a modelagem por DEA

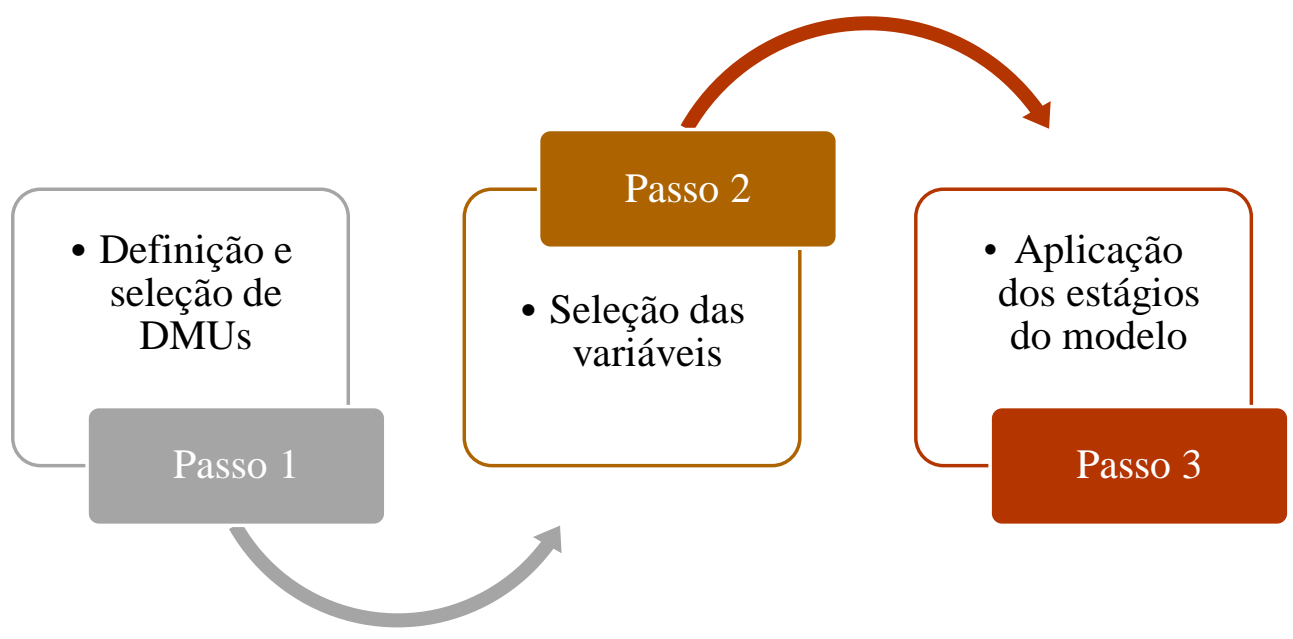

Fonte: Elaborado pela autora. 
No passo 1, conforme Figura 3, definiu-se como unidade de análise (DMU) deste estudo o município, considerado o responsável pela subfunção atenção básica à saúde. A população, portanto, foi composta pelos 5.570 municípios brasileiros. A partir desses, selecionaram-se inicialmente 5.567, para os quais estavam disponíveis informações no SIA, SIAB e SIOPS, tal qual mencionado na seção 3.1. Ver mais sobre seleção da amostra na seção 3.3.

Sobre a seleção de variáveis, passo 2 da Figura 2, utilizaram-se as mesmas propostas por Varela et al. (2012), quais sejam: (a) despesa com atenção básica como input único; e (b) cinco outputs referentes ao atendimento ambulatorial de atenção básica, ao PSF (Programa de Saúde da Família) e ao PACS (Programa de Agentes Comunitários de Saúde) (cf. Figura 4, subseção 3.3). Ver mais sobre seleção das variáveis na seção 3.3.

Além disso, ainda considerando a metodologia de Varela et al. (2012), ressalta-se que no processo de produção, do consumo de inputs para transformação em outputs, existem variáveis ambientais ou exógenas que podem influenciar a eficiência de uma DMU e, portanto, deveriam ser consideradas na análise (Bradford, Malt e Oates (1969). Todavia, as variáveis exógenas não controláveis, como o próprio nome sugere, não estão sob o controle dos gestores de uma DMU, sendo possível, conforme alternativa apresentada por Varela et al. (2012), no passo 3 da Figura 1, usar o modelo em dois estágios. Segundo a metodologia de Varela, et al (2012, p. 35):

\footnotetext{
No primeiro estágio, uma fronteira de produção é estimada a partir dos inputs discricionários e outputs de uma amostra de DMUs, sem considerar as variáveis não controláveis. No segundo estágio, os escores de eficiência são tomados como variável dependente em um modelo de regressão e as variáveis ambientais como variáveis independentes. Os sinais dos coeficientes dos termos da regressão indicam a direção da influência das variáveis não controláveis nos escores de eficiência e os testes de hipóteses padrão são usados para avaliar a força da relação.

A regressão do segundo estágio também permite ajustar todos os escores de eficiência pelo uso dos coeficientes estimados em um ambiente comum
}

Ver mais sobre escolha e aplicação do modelo na seção 3.6.

\subsection{Descrição das etapas}

Para avaliação da eficiência das DMUs, conforme entendimento de Varela et al. (2012, p. 625):

[...] entre os 5.570 municípios brasileiros, existem estruturas muito diferenciadas de sistemas de saúde e, consequentemente, dos tipos de serviços 
prestados. Além disso, diversas ações são de competência partilhada, envolvendo fluxo de recursos e pacientes entre municípios delimitados por uma região, macrorregião ou estado, conforme o grau de complexidade. Sendo assim, é preciso atenção para que não se execute uma análise comparativa do desempenho de unidades muito desiguais quanto ao processo de produção em saúde. Nesse sentido, optou-se por comparar o desempenho dos municípios brasileiros quanto à produção de outputs diretos relativos à subfunção atenção básica à saúde. Isso porque a responsabilidade por essa subfunção é exclusiva de cada município, diminuindo as correlações e interdependências dos recursos municipais de saúde e tornando possível a definição do município como um núcleo de input-output.

Assim, para os municípios brasileiros, foi calculada uma função de produção composta de um insumo (input) e de cinco produtos diretos referentes ao atendimento ambulatorial de atenção básica, ao PSF (Programa de Saúde da Família) e ao PACS (Programa de Agentes Comunitários de Saúde) (outputs 1 a 5), conforme Figura 4.

Figura 4 - Variáveis de input discricionário e outputs do modelo de eficiência técnica
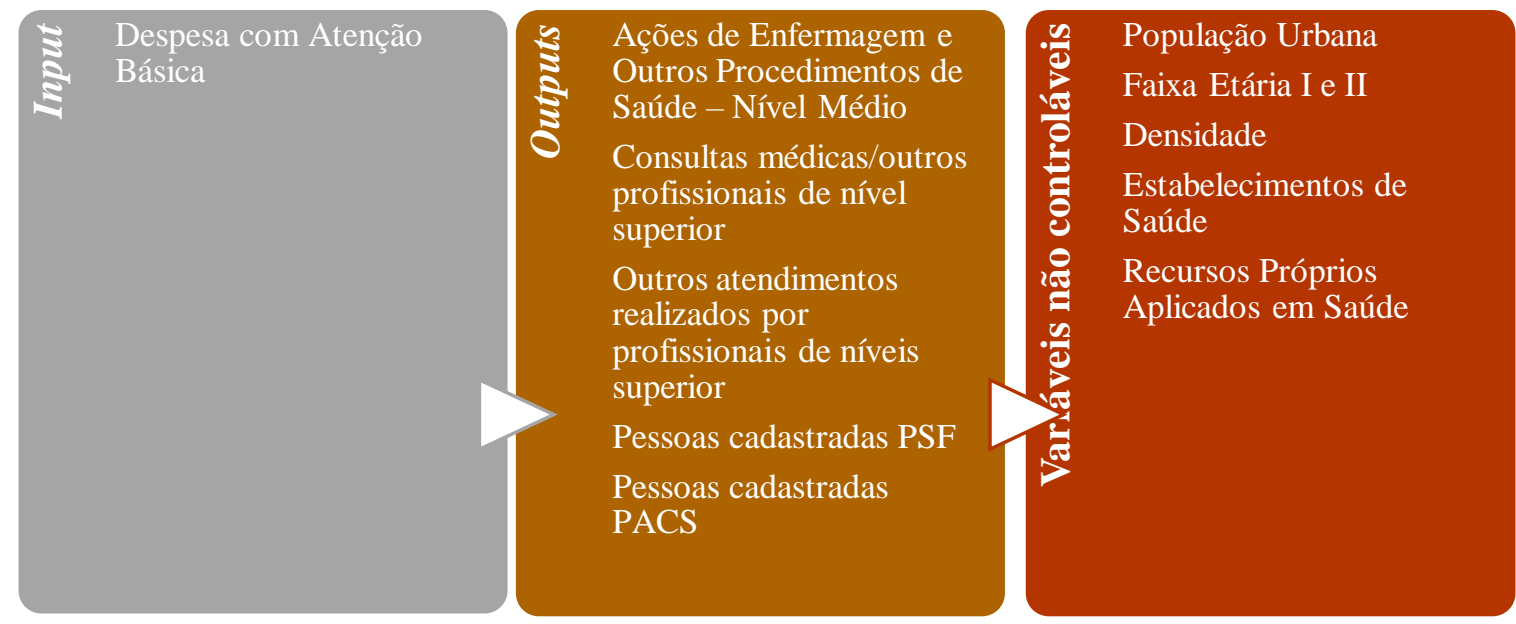

Fonte: SIOPS, SIAB, SIA (2017).

\subsection{Escore de eficiência técnica}

Neste primeiro estágio, uma fronteira de eficiência foi estimada a partir do input discricionário e dos outputs inerentes aos serviços de atenção básica à saúde oferecidos nos municípios brasileiros. Conforme mencionado, o requisito para auferir recursos do Fundo Nacional de Saúde, os governos locais são indispensáveis nas bases de dados do Ministério da Saúde, dentre essas: o SIA, o SIAB e o SIOPS.

Considerando o entendimento de Varela et al. (2012), dentre os 5.567 municípios brasileiros há um conjunto de arranjos e fatores peculiares no que se refere ao sistema de saúde e, por conseguinte os tipos de atendimentos realizados são característicos da sua localidade. 
Nesse sentido, no presente estudo, tal qual os autores de referência, optou-se por comparar o desempenho dos municípios brasileiros quanto à produção de outputs diretos relativos à subfunção atenção básica à saúde. Para tanto, foi usada o DEA com orientação para a maximização de outputs, conforme Varela et al. (2012).

Para os municípios brasileiros, foi calculada uma função de eficiência composta de um insumo (input) e de cinco produtos (outputs) diretos referentes ao atendimento ambulatorial de atenção básica, ao Programa de Saúde da Família (PSF) e ao Programa de Agentes Comunitários de Saúde (PACS) (outputs 1 a 5), conforme Figura 4.

Nessa primeira fase foram excluídos da análise os municípios com falta de dados sobre despesa com atenção básica e por apresentarem inconsistências nos dados sobre a produção ambulatorial em atenção básica (ver subseção 3.7). Ao todo, 5.111 observações foram eliminadas, o que representa $91,6 \%$ da população objeto de estudo.

Mesmo após exclusões, diante do elevado número de município na amostra considerada, existe uma tendência de reduzir a média das pontuações de eficiência, pois quanto maior o número unidades, maior poderá ser o número de unidades na fronteira. Portanto, considerando o total de 459 municípios restantes e com o objetivo de tornar os dados que restaram mais homogêneos e livre de vieses, foi utilizada uma modelagem em dois estágios, tal qual proposto por Varela et al. (2012).

\subsection{Modelagem em dois estágios}

Com o objetivo de descobrir quais conjuntos de variáveis são relativamente independentes uma das outras, Varela et al. (2012) propõe uma modelagem em dois estágios. Em síntese, a técnica consistiu em calcular, em um primeiro estágio, uma medida (ou escore) de eficiência com DEA e, com o resultado, iniciar o segundo estágio, que consiste na regressão. O DEA foi usada com o objetivo de eliminar o efeito de escala dos operadores, e, para isso, definiu-se como (i) outputs as variáveis relacionadas com o tamanho, ou seja, foram utilizadas as variáveis de Ações de Enfermagem e Outros Procedimentos de Saúde - Nível Médio, consultas médicas/outros profissionais de nível superior, outros atendimentos realizados por profissionais de níveis superior, pessoas cadastradas PSF e pessoas cadastradas PACS, e (ii) inputs a Despesa com Atenção Básica.

No segundo estágio, com o resultado deste escore foi realizada uma regressão, com a finalidade de identificar quais os fatores determinam a eficiência da amostra considerada. Para tanto, utilizou-se a regressão linear múltipla, que é uma técnica multivariada, cuja finalidade 
principal é obter uma relação matemática entre uma das variáveis estudadas (variável dependente ou resposta) e o restante das variáveis que descrevem o sistema (variáveis independentes ou explicativas), e reduzir um grande número de variáveis para poucas dimensões com o mínimo de perda de informação, permitindo a detecção dos principais padrões de similaridade, associação e correlação entre as variáveis.

Sua principal aplicação, após encontrar a relação matemática, é produzir valores para a variável dependente quando se têm as variáveis independentes (cálculo dos valores preditivos). Ou seja, pode ser usada na predição de resultados, por meio da regra estatística dos mínimos quadrados ordinários. Ver mais sobre variáveis do modelo no Quadro 4 (subseção 3.6).

\subsection{Amostragem e coleta de dados}

Após as exclusões, por ausência de dados suficientes, a amostra final do presente estudo conta 133 municípios brasileiros, de todos os estados que integram as diversas regiões do Brasil. Algumas apresentam várias características em comum, apesar de, no entanto, não haver homogeneidade em nível municipal, sendo que cada unidade de análise (i.e., município) apresenta peculiaridades socioeconômicas (MATOS et al, 2017; MEZA et al., 2005).

A escolha por todas as regiões deve-se a relevância dessas na economia no Brasil e pela diversidade socioeconômica de cada, como apontado pelo Instituto Brasileiro de Geografia e Estatística (IBGE, 2010). Para cada unidade em análise, coletaram-se informações sobre despesa com a Atenção Básica, Ações de Enfermagem e Outros Procedimentos - Nível Médio, Ações Médicas Básicas, Ações Executadas por Outros Profissionais - Nível Superior, Pessoas Cadastradas pelo PSF e Pessoas Cadastradas pelo PACS para os anos de 2015 e 2016. Ao final, os resultados de 2015 e 2016 apresentaram relevante semelhança, ou seja, não houve discrepância significativa. Por essa razão, optou-se por descrever e avaliar apenas os resultados mais recentes, isto é, para o ano de 2016.

Conforme mencionado, em primeiro momento, uma fronteira de produção foi estimada a partir do input discricionário e dos outputs relativos aos serviços de atenção básica à saúde prestados pelos municípios brasileiros. Após o cálculo do escore de eficiência para cada unidade, esse foi tomado como variável dependente no modelo de regressão. As variáveis independentes foram aquelas listadas no Quadro 4. 
Quadro 4 - Variáveis não controláveis do modelo de eficiência dos municípios

\begin{tabular}{|c|c|c|c|}
\hline Tipo & Variável & Descrição & Fonte \\
\hline IND 1 & População Urbana & $\begin{array}{l}\text { Percentual da População urbana em relação à } \\
\text { população total }\end{array}$ & IBGE \\
\hline IND 2 & Faixa Etária I & $\begin{array}{l}\text { Percentual da População com idade entre } 0 \text { a } 18 \\
\text { anos }\end{array}$ & DATASUS \\
\hline IND 3 & Faixa Etária II & Percentual da População com idade 60 ou mais. & DATASUS \\
\hline IND 4 & Densidade Populacional & $\begin{array}{l}\text { Quantidade de procedimentos realizados neste tipo } \\
\text { de ação }\end{array}$ & IBGE \\
\hline IND 5 & $\begin{array}{l}\text { Escala dos } \\
\text { Estabelecimentos de Saúde }\end{array}$ & $\begin{array}{l}\text { População dividida pela quantidade de } \\
\text { estabelecimentos ligados à gestão pública } \\
\text { municipal que prestam serviços de atenção básica }\end{array}$ & DATASUS \\
\hline IND 6 & $\begin{array}{l}\text { Percentual de Recursos } \\
\text { Próprio Aplicados na } \\
\text { Função Saúde }\end{array}$ & $\begin{array}{l}\text { Percentual de aplicação de recursos próprios } \\
\text { aplicados em saúde calculados em conformidades } \\
\text { com a Emenda Constitucional } 29 / 2000 \text {. }\end{array}$ & SIOPS/DATASUS \\
\hline
\end{tabular}

Fonte: Adaptado de Varela et al (2012).

O termo de erro da regressão reflete os escores de eficiência de cada município brasileiro ajustado pelos efeitos dos inputs não controláveis, tal qual metodologia de Varela et al. (2012). 


\section{RESULTADOS}

\subsection{Primeiro estágio}

Considerando as variáveis da Figura 4 (ver subseção 3.3), estimou-se a fronteira de eficiência para os 133 municípios brasileiros da amostra final. O modelo DEA foi orientado a output e com retorno constante de escala, tal qual metodologia proposta por Varela et al. (2012).

Dentre todos os 133 municípios, a Tabela 1 mostra os escores de eficiência para apenas 17 DMUs com escore maior ou igual a 10\% (na fronteira de eficiência padrão) - os demais municípios constam na Tabela 2. Além desse escore, apresentam-se também na Tabela 1, aqueles obtidos ainda nas fronteiras invertida, composta e composta normalizada. Dentre esses 17 municípios, destacam-se Salvador/BA, Belo Horizonte/MG, São Paulo/SP e Restinga Seca/RS que obtiveram os maiores escores de eficiência (fronteira padrão) (ver Tabela 1).

Tabela 1 - Escores de eficiência no primeiro para DMUS com eficiência padrão > 10\%

\begin{tabular}{|c|c|c|c|c|c|c|}
\hline $\begin{array}{c}\text { Classificação } \\
\text { DEA }\end{array}$ & DMU & Município & Padrão & Invertida & Composta & Composta* \\
\hline $1^{\circ}$ & DMU74 & Salvador & 100,0 & 0,1 & 100,0 & 100,0 \\
\hline $2^{o}$ & DMU79 & Belo Horizonte & 100,0 & 0,3 & 99,8 & 99,9 \\
\hline $3^{\circ}$ & DMU109 & São Paulo & 100,0 & 0,0 & 100,0 & 100,0 \\
\hline $4^{\circ}$ & DMU124 & Restinga Seca & 100,0 & 28,4 & 85,8 & 85,8 \\
\hline $5^{\circ}$ & DMU27 & Fortaleza & 65,5 & 0,9 & 82,3 & 82,3 \\
\hline $6^{\circ}$ & DMU94 & Rio de Janeiro & 31,3 & 0,1 & 65,6 & 65,6 \\
\hline $7^{\circ}$ & DMU91 & Duque de Caxias & 25,8 & 5,7 & 60,0 & 60,0 \\
\hline $8^{\circ}$ & DMU24 & São Luís & 24,0 & 0,5 & 61,7 & 61,7 \\
\hline $9^{\circ}$ & DMU25 & Teresina & 21,4 & 0,5 & 60,4 & 60,4 \\
\hline $10^{\circ}$ & DMU8 & Belém & 19,0 & 0,2 & 59,4 & 59,4 \\
\hline $11^{\circ}$ & DMU90 & Vitória & 17,7 & 0,2 & 58,7 & 58,7 \\
\hline $12^{\circ}$ & DMU106 & São Bernardo do Campo & 17,0 & 0,5 & 58,3 & 58,3 \\
\hline $13^{\circ}$ & DMU95 & Campinas & 16,0 & 1,0 & 57,5 & 57,5 \\
\hline $14^{\circ}$ & DMU7 & Ananindeua & 15,2 & 0,8 & 57,2 & 57,2 \\
\hline $15^{\circ}$ & DMU105 & Santo André & 14,6 & 0,4 & 57,1 & 57,1 \\
\hline $16^{\circ}$ & DMU93 & Nova Iguaçu & 12,6 & 1,0 & 55,8 & 55,8 \\
\hline $17^{\circ}$ & DMU123 & Porto Alegre & 10,3 & 0,8 & 54,8 & 54,8 \\
\hline
\end{tabular}

Fonte: Dados da pesquisa.

* Eficiência Normalizada

Esses primeiros quatro municípios, realçados na Tabela 1, por apresentarem escore de eficiência na fronteira padrão de $100 \%$, destacam-se dentre todos os municípios avaliados no presente estudo. Ainda, Salvador/BA e São Paulo/SP, por apresentaram escore de eficiência na fronteira composta normalizada de $100 \%$, são os municípios considerados eficientes dentre toda 
a amostra analisada - todos os demais, são ineficientes, se comparado a esses dois.

De forma geral, dentre os 17 municípios elencados na Tabela 1, encontram-se a maioria das capitais estaduais, ou ainda, grandes cidades paulistas. Esses apresentam em comum: elevada densidade populacional, baixo número de habitantes na zona rural, acesso a água tratada e rede de esgoto ( saneamento básico), maior aderência as campanhas de vacinação, mais acesso a rede de saúde, maior número de estabelecimentos de saúde e uma rede de saúde mais organizada.

Já o município de Restinga Seca/RS, único município do interior do Brasil que se destacou como eficiente, apresenta uma política social de saúde que a prefeitura vem adotando há mais de 10 anos, por meio de campanhas de conscientização da população e deslocamento das equipes médicos/ hospitalares até aquelas pessoas que têm dificuldades para acessar a rede básica de saúde. Esse município investe em uma política de prevenção a doenças e promoção da saúde.

Segundo dados municipais, o investimento público e a gestão qualificada em saúde refletem diretamente na melhoria da qualidade de vida da população, no aumento da esperança de vida ao nascer, no aumento da expectativa de vida da população, na redução de internações por causas sensíveis à atenção básica - ICSAB (internações são mais dispendiosas do que tratamentos ambulatoriais e prevenção e significam agravo nas condições de saúde), na redução da mortalidade, entre outros indicadores de saúde sensíveis a estes investimentos.

A melhoria da qualidade de vida e saúde da população tem relação direta positiva com indicadores socioeconômicos, tais como a estabilidade laboral e financeira das famílias (pela diminuição de afastamentos por adoecimento e dos gastos com saúde), redução da desigualdade social em saúde e, por estas razões, contribui para a estabilidade e crescimento econômico e social. Conforme Censo (2010), a população de Restinga Seca/RS soma 15.828 habitantes, com $17,2 \%$ da população idosa e $16,1 \%$ da população menor de 12 anos. Por outro lado, $43 \%$ referem-se a habitantes da zona rural do município.

Considerando as variáveis tomadas no modelo DEA, é possível refletir sobre o impacto da densidade populacional na eficiência alocativa. Essa variável, especificamente, pode contribuir para tornar os custos da prestação de serviços em saúde mais elevados, 
principalmente em se tratando dos serviços de atenção básica que se caracterizam por (i) demandarem alta capilaridade, e (ii) apresentarem especificidades locais, o que pode gerar perdas de economia de escala. Por outro lado, grandes cidades, tal quais os municípios da Tabela 1, possuem, em geral, boa organização dos estabelecimentos de saúde, que, portanto, tendem a apresentar melhor capacidade de atendimento frente a um elevado volume de pessoas/pacientes. Além disso, é preciso considerar o percentual de recursos próprios (municipais) aplicados na função saúde que, por exigência constitucional, deve ser no mínimo de $15 \%$. Entende-se que, no caso desses 17 municípios, essa norma gere impacto positivo, indicando boa governança da função saúde, especificamente da atenção básica.

Considerando (i) os argumentos acima apresentados e (ii) a amplitude dos outputs do modelo DEA - que, por limitação inerente ao próprio modelo, impacta a percepção de eficiência relativa das DMUS -, esse grupo de 17 municípios foram considerados outliers da amostra. Assim, no modelo de regressão linear (segundo estágio, descrito na subseção 4.2 a seguir), os referidos 17 municípios foram tratados como um grupo em separado. Em outras palavras, no segundo estágio, estimaram-se modelos de regressão para duas subamostras: (i) grupo de 17 municípios eficientes; e (ii) grupo de 166 municípios ineficientes (ver mais detalhes na subseção 4.2).

Ainda no primeiro estágio, para os 116 municípios ineficientes, os escores da fronteira padrão, invertida, composta e composta normalizada são apresentados na Tabela 2. Conforme mencionado, esse grupo de municípios são considerados ineficientes em relação aos 17 apresentados na Tabela 1. Por essa razão, a análise da Tabela 2 está centrada nos maiores escores na fronteira invertida - em realce amarelo estão municípios com escores de $100 \%$, tidos como os mais ineficientes de toda a amostra de 133 municípios.

Tabela 2 - Escores de eficiência para DMUS com eficiência padrão < 10\%

\begin{tabular}{cllrrrr}
\hline $\begin{array}{c}\text { Classificação } \\
\text { DEA }\end{array}$ & \multicolumn{1}{c}{ Município } & DMU & Padrão & Invertida & Composta & Composta* \\
\hline $1^{\mathbf{0}}$ & Guarulhos & DMU96 & 9,72 & 0,32 & 54,70 & 54,71 \\
$2^{\mathbf{o}}$ & Feira de Santana & DMU59 & 8,69 & 0,41 & 54,14 & 54,15 \\
$3^{\mathbf{0}}$ & Taboão da Serra & DMU110 & 8,48 & 3,73 & 52,38 & 52,39 \\
$4^{\mathbf{o}}$ & Londrina & DMU114 & 8,03 & 0,86 & 53,59 & 53,60 \\
$5^{\mathbf{o}}$ & Curitiba & DMU113 & 7,46 & 0,74 & 53,36 & 53,37 \\
$6^{\mathbf{0}}$ & São José dos Campos & DMU108 & 4,80 & 1,31 & 51,75 & 51,76 \\
$7^{\mathbf{0}}$ & Praia Grande & DMU100 & 4,45 & 0,69 & 51,88 & 51,89 \\
$8^{\mathbf{o}}$ & São José do Rio Preto & DMU107 & 3,98 & 0,84 & 51,57 & 51,58 \\
$9^{\mathbf{o}}$ & Caruaru & DMU39 & 3,21 & 0,98 & 51,12 & 51,12 \\
$1^{\mathbf{o}}$ & Ibirubá & DMU122 & 3,01 & 17,69 & 42,66 & 42,66 \\
$11^{\mathbf{o}}$ & Pilar do Sul & DMU99 & 2,83 & 61,58 & 20,63 & 20,63 \\
$1^{\mathbf{o}}$ & Ribeirão Preto & DMU102 & 2,29 & 1,14 & 50,58 & 50,59 \\
$13^{\mathbf{o}}$ & Sobral & DMU32 & 1,95 & 2,18 & 49,89 & 49,90
\end{tabular}




\begin{tabular}{|c|c|c|c|c|c|c|}
\hline $\begin{array}{c}\text { Classificação } \\
\text { DEA }\end{array}$ & Município & DMU & Padrão & Invertida & Composta & Composta* \\
\hline $14^{\circ}$ & Chapecó & DMU115 & 1,88 & 2,46 & 49,71 & 49,72 \\
\hline $15^{\circ}$ & Condeúba & DMU56 & 1,07 & 43,05 & 29,01 & 29,02 \\
\hline $16^{\circ}$ & Monte Carmelo & DMU83 & 0,96 & 17,45 & 41,76 & 41,76 \\
\hline $17^{\circ}$ & Mocajuba & DMU12 & 0,57 & 27,45 & 36,56 & 36,57 \\
\hline $18^{\circ}$ & Caldas Novas & DMU133 & 0,53 & 20,71 & 39,91 & 39,92 \\
\hline $19^{\circ}$ & Tailândia & DMU19 & 0,42 & 9,77 & 45,33 & 45,33 \\
\hline $20^{\circ}$ & São Cristóvão & DMU55 & 0,41 & 52,27 & 24,07 & 24,07 \\
\hline $21^{\circ}$ & Açu & DMU33 & 0,40 & 9,12 & 45,64 & 45,65 \\
\hline $22^{\circ}$ & Vargem Grande Paulista & DMU111 & 0,40 & 44,75 & 27,83 & 27,83 \\
\hline $23^{\circ}$ & Santana do Araguaia & DMU17 & 0,39 & 11,70 & 44,34 & 44,35 \\
\hline $24^{\circ}$ & Bom Conselho & DMU37 & 0,39 & 12,55 & 43,92 & 43,93 \\
\hline $25^{\circ}$ & Salinópolis & DMU16 & 0,38 & 10,40 & 44,99 & 45,00 \\
\hline $26^{\circ}$ & Bom Jardim & DMU38 & 0,37 & 10,62 & 44,88 & 44,89 \\
\hline $27^{\circ}$ & Cianorte & DMU112 & 0,36 & 12,16 & 44,10 & 44,11 \\
\hline $28^{\circ}$ & Rio do Sul & DMU116 & 0,35 & 77,99 & 11,18 & 11,18 \\
\hline $29^{\circ}$ & Curaçá & DMU57 & 0,34 & 32,25 & 34,04 & 34,05 \\
\hline $30^{\circ}$ & Jaru & DMU1 & 0,33 & 53,21 & 23,56 & 23,56 \\
\hline $31^{\circ}$ & Ipirá & DMU60 & 0,33 & 15,14 & 42,59 & 42,60 \\
\hline $32^{\circ}$ & Videira & DMU118 & 0,32 & 41,25 & 29,54 & 29,54 \\
\hline $33^{\circ}$ & Palmares & DMU44 & 0,32 & 23,53 & 38,40 & 38,41 \\
\hline $34^{\circ}$ & São Lourenço do Sul & DMU127 & 0,32 & 11,60 & 44,36 & 44,37 \\
\hline $35^{\circ}$ & Jacundá & DMU11 & 0,32 & 13,23 & 43,54 & 43,55 \\
\hline $36^{\circ}$ & Presidente Epitácio & DMU101 & 0,30 & 10,99 & 44,66 & 44,66 \\
\hline $37^{\circ}$ & Araxá & DMU78 & 0,29 & 18,83 & 40,73 & 40,74 \\
\hline $38^{\circ}$ & Mauriti & DMU30 & 0,29 & 32,87 & 33,71 & 33,71 \\
\hline $39^{\circ}$ & Guaporé & DMU120 & 0,28 & 17,65 & 41,32 & 41,32 \\
\hline $40^{\circ}$ & Itabaianinha & DMU54 & 0,27 & 12,77 & 43,75 & 43,76 \\
\hline $41^{\circ}$ & Jaguaquara & DMU65 & 0,27 & 11,30 & 44,48 & 44,49 \\
\hline $42^{\circ}$ & Nova Ubiratã & DMU131 & 0,26 & 73,14 & 13,56 & 13,57 \\
\hline $43^{\circ}$ & Guaxupé & DMU82 & 0,26 & 84,66 & 7,80 & 7,80 \\
\hline $44^{\circ}$ & Nazaré da Mata & DMU43 & 0,26 & 17,64 & 41,31 & 41,32 \\
\hline $45^{\circ}$ & União dos Palmares & DMU52 & 0,26 & 20,99 & 39,63 & 39,64 \\
\hline $46^{\circ}$ & Morro do Chapéu & DMU71 & 0,26 & 23,66 & 38,30 & 38,31 \\
\hline $47^{\circ}$ & Candelária & DMU119 & 0,26 & 40,29 & 29,99 & 29,99 \\
\hline $48^{\circ}$ & Itapetinga & DMU63 & 0,24 & 90,49 & 4,88 & 4,88 \\
\hline $49^{\circ}$ & Tracuateua & DMU20 & 0,24 & 10,90 & 44,67 & 44,68 \\
\hline $50^{\circ}$ & Itaocara & DMU92 & 0,24 & 29,73 & 35,25 & 35,26 \\
\hline $51^{\circ}$ & Santana do Acaraú & DMU31 & 0,23 & 21,40 & 39,41 & 39,42 \\
\hline $52^{\circ}$ & São Francisco do Sul & DMU117 & 0,22 & 12,00 & 44,11 & 44,12 \\
\hline $53^{\circ}$ & Domingos Martins & DMU87 & 0,22 & 11,39 & 44,42 & 44,42 \\
\hline $54^{\circ}$ & Aliança & DMU35 & 0,22 & 16,77 & 41,73 & 41,73 \\
\hline $55^{\circ}$ & Francisco Sá & DMU81 & 0,22 & 15,74 & 42,24 & 42,25 \\
\hline $56^{\circ}$ & Mirador & DMU23 & 0,22 & 32,47 & 33,87 & 33,88 \\
\hline $57^{\circ}$ & Itiúba & DMU64 & 0,21 & 24,60 & 37,80 & 37,81 \\
\hline $58^{\circ}$ & Luís Eduardo Magalhães & DMU67 & 0,20 & 22,96 & 38,62 & 38,63 \\
\hline $59^{\circ}$ & Itararé & DMU97 & 0,20 & 19,19 & 40,50 & 40,51 \\
\hline $60^{\circ}$ & Tucumã & DMU21 & 0,20 & 20,93 & 39,64 & 39,64 \\
\hline $61^{\circ}$ & Santa Bárbara & DMU85 & 0,19 & 100,00 & 0,10 & 0,10 \\
\hline $62^{\circ}$ & Santa Cruz das Palmeiras & DMU103 & 0,19 & 100,00 & 0,10 & 0,10 \\
\hline $63^{\circ}$ & Santa Maria da Boa Vista & DMU46 & 0,19 & 31,64 & 34,28 & 34,28 \\
\hline $64^{\circ}$ & Juquiá & DMU98 & 0,19 & 54,73 & 22,73 & 22,74 \\
\hline $65^{\circ}$ & Marco & DMU29 & 0,18 & 47,41 & 26,38 & 26,39 \\
\hline $66^{\circ}$ & Pinheiros & DMU89 & 0,18 & 41,64 & 29,27 & 29,27 \\
\hline $67^{\circ}$ & Glória do Goitá & DMU40 & 0,17 & 34,80 & 32,69 & 32,69 \\
\hline $68^{\circ}$ & Ubatã & DMU76 & 0,17 & 29,06 & 35,55 & 35,56 \\
\hline $69^{\circ}$ & Curuçá & DMU10 & 0,17 & 28,20 & 35,98 & 35,99 \\
\hline $70^{\circ}$ & Ibiapina & DMU28 & 0,17 & 29,90 & 35,13 & 35,14 \\
\hline $71^{\circ}$ & Jitaúna & DMU66 & 0,17 & 30,53 & 34,82 & 34,83 \\
\hline
\end{tabular}




\begin{tabular}{|c|c|c|c|c|c|c|}
\hline $\begin{array}{c}\text { Classificação } \\
\text { DEA }\end{array}$ & Município & DMU & Padrão & Invertida & Composta & Composta* \\
\hline $72^{\circ}$ & Passira & DMU45 & 0,17 & 24,23 & 37,97 & 37,97 \\
\hline $73^{\circ}$ & Maracás & DMU69 & 0,17 & 22,70 & 38,74 & 38,74 \\
\hline $74^{\circ}$ & Codajás & DMU4 & 0,16 & 77,03 & 11,57 & 11,57 \\
\hline $75^{\circ}$ & Barra de Guabiraba & DMU36 & 0,16 & 100,00 & 0,08 & 0,08 \\
\hline $76^{\circ}$ & Pombal & DMU34 & 0,16 & 51,74 & 24,21 & 24,22 \\
\hline $77^{\circ}$ & Carnaubal & DMU26 & 0,16 & 29,99 & 35,09 & 35,09 \\
\hline $78^{\circ}$ & Viçosa & DMU53 & 0,15 & 28,47 & 35,84 & 35,85 \\
\hline $79^{\circ}$ & Água Branca & DMU47 & 0,15 & 21,74 & 39,21 & 39,22 \\
\hline $80^{\circ}$ & Guarani das Missões & DMU121 & 0,15 & 97,47 & 1,34 & 1,34 \\
\hline $81^{\circ}$ & Pacajá & DMU13 & 0,15 & 30,17 & 34,99 & 34,99 \\
\hline $82^{\circ}$ & Miguel Calmon & DMU70 & 0,15 & 23,11 & 38,52 & 38,53 \\
\hline $83^{\circ}$ & Santa Fé do Sul & DMU104 & 0,14 & 69,64 & 15,25 & 15,26 \\
\hline $84^{\circ}$ & Campo Novo do Parecis & DMU129 & 0,14 & 24,86 & 37,64 & 37,65 \\
\hline $85^{\circ}$ & Macaparana & DMU42 & 0,14 & 100,00 & 0,07 & 0,07 \\
\hline $86^{\circ}$ & Fátima & DMU58 & 0,14 & 28,67 & 35,74 & 35,74 \\
\hline $87^{\circ}$ & Rosário Oeste & DMU132 & 0,14 & 20,31 & 39,91 & 39,92 \\
\hline $88^{\circ}$ & Itacaré & DMU61 & 0,14 & 21,38 & 39,38 & 39,39 \\
\hline $89^{\circ}$ & Carandaí & DMU80 & 0,14 & 100,00 & 0,07 & 0,07 \\
\hline $90^{\circ}$ & Rio Maria & DMU15 & 0,12 & 55,90 & 22,11 & 22,11 \\
\hline $91^{\circ}$ & Pão de Açúcar & DMU51 & 0,12 & 46,97 & 26,57 & 26,58 \\
\hline $92^{\circ}$ & São Sepé & DMU128 & 0,12 & 23,61 & 38,25 & 38,26 \\
\hline $93^{\circ}$ & Valente & DMU77 & 0,12 & 88,51 & 5,80 & 5,81 \\
\hline $94^{\circ}$ & Rorainópolis & DMU6 & 0,11 & 90,78 & 4,67 & 4,67 \\
\hline $95^{\circ}$ & Serra Dourada & DMU75 & 0,11 & 36,07 & 32,02 & 32,03 \\
\hline $96^{\circ}$ & Chapada dos Guimarães & DMU130 & 0,10 & 87,25 & 6,42 & 6,43 \\
\hline $97^{\circ}$ & Cacimbinhas & DMU48 & 0,10 & 40,78 & 29,66 & 29,66 \\
\hline $98^{\circ}$ & Canapi & DMU49 & 0,10 & 46,72 & 26,69 & 26,69 \\
\hline $99^{\circ}$ & Brasil Novo & DMU9 & 0,09 & 38,48 & 30,80 & 30,81 \\
\hline $100^{\circ}$ & Atílio Vivacqua & DMU86 & 0,09 & 51,21 & 24,44 & 24,45 \\
\hline $101^{\circ}$ & Ibiraçu & DMU88 & 0,09 & 100,00 & 0,04 & 0,04 \\
\hline $102^{\circ}$ & Jurema & DMU41 & 0,09 & 33,35 & 33,37 & 33,38 \\
\hline $103^{\circ}$ & Peçanha & DMU84 & 0,09 & 37,34 & 31,38 & 31,38 \\
\hline $104^{\circ}$ & Japaratinga & DMU50 & 0,09 & 50,69 & 24,70 & 24,70 \\
\hline $105^{\circ}$ & Maraã & DMU5 & 0,08 & 58,15 & 20,97 & 20,97 \\
\hline $106^{\circ}$ & Benjamin Constant & DMU3 & 0,08 & 93,99 & 3,05 & 3,05 \\
\hline $107^{\circ}$ & Itajuípe & DMU62 & 0,08 & 46,40 & 26,84 & 26,85 \\
\hline $108^{\circ}$ & Palmeiras & DMU72 & 0,06 & 48,31 & 25,88 & 25,88 \\
\hline $109^{\circ}$ & Peixe-Boi & DMU14 & 0,05 & 100,00 & 0,03 & 0,03 \\
\hline $110^{\circ}$ & Malhada de Pedras & DMU68 & 0,05 & 100,00 & 0,03 & 0,03 \\
\hline $111^{\circ}$ & Santa Bárbara do Sul & DMU125 & 0,05 & 100,00 & 0,03 & 0,03 \\
\hline $112^{\circ}$ & Alto Parnaíba & DMU22 & 0,05 & 100,00 & 0,03 & 0,03 \\
\hline $113^{\circ}$ & Amaturá & DMU2 & 0,05 & 69,31 & 15,37 & 15,37 \\
\hline $114^{\circ}$ & Planaltino & DMU73 & 0,04 & 100,00 & 0,02 & 0,02 \\
\hline $115^{\circ}$ & Santarém Novo & DMU18 & 0,04 & 100,00 & 0,02 & 0,02 \\
\hline $116^{\circ}$ & Santo Augusto & DMU126 & 0,03 & 100,00 & 0,01 & 0,01 \\
\hline
\end{tabular}

Fonte: Dados da pesquisa.

* Eficiência Normalizada

Quanto maior o escore na fronteira invertida, mais ineficiente é a DMU; e, ainda, o escore de 100\% indica os municípios com pior desempenho, a saber (Tabela 2): Santo Augusto/PA, Santarém Novo/PA, Planaltino/BA, Alto Paraíba/MG, Santa Bárbara do Sul/RS, Malhada de Pedras/BA Peixe-Boi/PA, Ibiraçu/ES, Carandaí/MG, Macaparana/PE Barra de Guabiraba/PE Santa Cruz das Palmeiras/SP e Santa Bárbara/MG. 
Fator de destaque para esses municípios é que a maioria se encontra no interior dos estados, em regiões brasileiras mais carentes. Além disso, esses municípios têm em comum: elevada densidade populacional, pois possuem um alto número de habitantes na zona rural e com grandes dificuldades de acesso aos serviços e recursos de saúde, escolaridade baixa e sem as condições sanitárias básicas. Outro fator que também pode contribuir para a ineficiência é o elevado número da população na faixa etária abaixo de 18 , que gera impactos relevantes no gasto com atenção básica a saúde - considerando questões relativas a gravidez precoce, os cuidados da primeira infância (e.g., consultas pediátricas mensais até 12 meses) e das crianças em idade escolar.

\subsection{Segundo estágio}

No segundo estágio, conforme metodologia de Varela et al. (2012), para a análise de regressão múltipla tomou-se como variáveis independentes os inputs não controláveis (ver Quadro 4, subseção 3.6) e como dependente (explicada) o logaritmo natural dos escores de Farrell (o inverso da medida Shephard - eficiência padrão usada no primeiro estágio). Utilizouse regressão múltipla realizada com o método stepwise, também com base na metodologia dos referidos autores.

Conforme mencionado, estimaram-se modelos de regressão para: (i) o primeiro grupo de 17 município eficientes (Tabela 1, subseção 4.1); e (ii) o segundo grupo de 166 municípios ineficientes (Tabela 2, subseção 4.1). Em ambos, para determinar se a associação entre a resposta e cada termo no modelo é estatisticamente significativa, comparou-se o valor-p para o termo com o seu nível de significância $(\alpha=0,05)$ a fim de avaliar a hipótese nula. A hipótese nula $\left(\mathrm{H}_{0}\right)$ é que não há nenhuma associação entre o termo $\left(\mathrm{x}_{\mathrm{i}}\right)$ e a resposta $(\mathrm{y})$. Conforme Varela et al. (2012), se o valor-p for menor ou igual ao nível de significância, é possível concluir que há uma associação estatisticamente significativa entre a variável de resposta e o termo.

\subsubsection{Regressão para DMUs eficientes no primeiro estágio}

Para a elaboração de um modelo de regressão para as DMUs consideradas eficientes no estágio 1, os inputs não controláveis foram as variáveis independentes; e, os escores da medida Shephard-eficiência usada no primeiro estágio, a variável dependente.

A Tabela 3 demonstra o resultado da análise de regressão múltipla realizada com o método stepwise para os municípios considerados eficientes - a equação da regressão é 
apresentada no Apêndice A. A variável Faixa Etária II (60 anos ou mais) (FEII) (-0.0008735) pode ser considerada diferente de zero a um nível de significância de 0,05, ou seja, quando incluída no modelo, esta variável implica em redução da eficiência do município, de forma significativa $(\mathrm{p}<0.05)$.

Tabela 3 - Modelo de Regressão Múltipla utilizando todas as variáveis não controláveis, para as DMUs consideradas eficientes

\begin{tabular}{lccc}
\hline \hline \multicolumn{4}{c}{$\mathbf{R}^{\mathbf{2}} \mathbf{7 0 , 4 \%}$} \\
Variável & $\begin{array}{c}\text { Coeficientes } \\
\text { Não Padronizados }\end{array}$ & $\mathbf{T}$ & Sig. $\left(\mathbf{p}\right.$ - valor) ${ }^{(\mathbf{1})}$ \\
\hline Constant $\widehat{\boldsymbol{\beta}}$ & 1.7047 & 3.37 & $0.007^{* *}$ \\
DD & 0.00004118 & 1.46 & $0.174 \mathrm{~ns}$ \\
ES & 0.001825 & 0.35 & $0.734 \mathrm{~ns}$ \\
FEI & -0.0002352 & -1.40 & $0.191 \mathrm{~ns}$ \\
FEII & -0.0008735 & -2.89 & $0.016^{*}$ \\
P & 0.00019144 & 2.08 & $0.064 \mathrm{~ns}$ \\
RS & -0.06295 & -2.97 & $0.014^{*}$ \\
\hline \hline
\end{tabular}

Fonte: Dados da pesquisa.

(1) Teste t de Student (Regressão Múltipla) (p-valor <0.05).

** Valores Altamente significativos; *Valores Significativos; ${ }^{\text {NS }}$ Valores Não Significativos.

$\mathrm{H}_{1}$ : Existe diferença significativa entre os coeficientes $(\mathrm{p}<0.05)$.

Nota: DD - Densidade demográfica $2010\left(\mathrm{hab} / \mathrm{km}^{2}\right)$; ES - Estabelecimentos de Saúde; FEI - Faixa Etária I (0 a 19 anos); FEII - Faixa Etária II (60 anos ou mais); P - População (Censo IBGE 2010); RS - Recursos Saúde (\%).

A variável Recursos de Saúde (RS) com coeficiente negativo (-0.06295) mostra que na medida em que há redução no percentual dos recursos de saúde destinados aos municípios, ocorre uma redução significativa $(\mathrm{p}<0.05)$ na medida de eficiência do município. As demais variáveis não se mostraram significativas quando adicionadas ao modelo, indicando que, na presença das outras variáveis, tais fatores não ajudam a explicar a eficiência da obtenção de outputs diretos em atenção básica.

Os pressupostos do modelo de regressão - normalidade dos resíduos e homocedasticidade - também foram testados. Os resultados (ver Apêndice A) apontaram para a aceitação do modelo. $\mathrm{O} \mathrm{R}^{2}$ sinaliza que $70,4 \%$ da variação nos escores de eficiência obtidos na primeira etapa podem ser explicados pelas condições ambientais dos municípios, ou seja, pelas variáveis tomadas como independentes, com destaque para as variáveis: FEII - Faixa Etária II (60 anos ou mais) e Recursos Saúde, com efeito negativo.

Salienta-se que, dado o p-valor da estatística F calculado na tabela ANOVA (ver Apêndice A), e dado o nível de significância de 5\%, a informação trazida pelas variáveis explicativas é significativamente melhor do que o que significaria uma média básica, ou seja, o 
modelo com estas duas variáveis significativas explica satisfatoriamente a variação da ineficiência do município.

\subsubsection{Regressão para DMUs ineficientes no primeiro estágio}

Semelhante aos procedimentos detalhados na subseção 4.2.1, estimou-se um modelo de regressão para os 116 municípios ineficientes, conforme resultados apresentados na Tabela 4 a equação da regressão é apresentada no Apêndice B. A variável Densidade Demográfica (DD) (0.00000911) pode ser considerado diferente de zero a um nível de significância de 0,05 , ou seja, quando incluída no modelo, esta variável implica em aumento da ineficiência do município, de forma significativa ( $\mathrm{p}<0.05)$. A variável Recursos de Saúde $(\mathrm{RS})$ com coeficiente negativo (-0.0006013) mostra que, na medida em que há redução no percentual dos recursos de saúde, ocorre um aumento significativo $(\mathrm{p}<0.05)$ na medida de ineficiência do município. As demais variáveis não se mostraram significativas.

Tabela 4 - Modelo de Regressão Múltipla para os 116 municípios ineficientes

\begin{tabular}{lccc}
\hline \multicolumn{2}{c}{$\mathbf{R}^{\mathbf{2}=\mathbf{4 2 , 7 \%}}$} & \\
\hline Variável & $\begin{array}{c}\text { Coeficientes } \\
\text { Não Padronizados }\end{array}$ & $\mathbf{T}$ & Sig. (p- valor) $^{(\mathbf{1})}$ \\
\hline Constant $\widehat{\boldsymbol{\beta}}$ & 0.017902 & 2.06 & $0.041^{*}$ \\
DD & 0.00000911 & 8.08 & $0.000^{* *}$ \\
ES & 0.0001802 & 1.66 & $0.099 \mathrm{~ns}$ \\
FEI & 0.00000007 & 0.05 & $0.961 \mathrm{~ns}$ \\
FEII & -0.00000121 & -0.49 & 0.626 \\
P & -0.00000006 & -0.08 & 0.933 \\
RS & -0.0006013 & -1.48 & $0.040^{*}$ \\
\hline \hline
\end{tabular}

Fonte: Dados da pesquisa.

(1) Teste t de Student (Regressão Múltipla) (p-valor <0.05).

** Valores Altamente significativos; *Valores Significativos; ${ }^{\text {NS }}$ Valores Não Significativos.

$\mathrm{H}_{1}$ : Existe diferença significativa entre os coeficientes $(\mathrm{p}<0.05)$.

Nota: DD - Densidade demográfica $2010\left(\mathrm{hab} / \mathrm{km}^{2}\right)$; ES - Estabelecimentos de Saúde; FEI - Faixa Etária I (0 a 19 anos); FEII - Faixa Etária II (60 anos ou mais); P - População (Censo IBGE 2010); RS - Recursos Saúde (\%).

Os pressupostos do modelo de regressão - normalidade dos resíduos e homocedasticidade - também foram testados para a variável ineficiência (escore) (ver Apêndice B). Os resultados apontaram para a aceitação do modelo. $\mathrm{O} \mathrm{R}^{2}$ sinaliza que $42,7 \%$ da variação nos escores de ineficiência obtidos na primeira etapa podem ser explicados pelas condições ambientais dos municípios, ou seja, pelas variáveis tomadas como independentes, com destaque para: Densidade demográfica $2010\left(\mathrm{hab} / \mathrm{km}^{2}\right)$ com efeito positivo e Recursos 
Saúde com efeito negativo.

Dado o p-valor da estatística F calculado na tabela ANOVA (ver Apêndice B), e dado o nível de significância de 5\%, a informação trazida pelas variáveis explicativas é significativamente melhor do que o que significaria uma média básica, ou seja, o modelo com estas duas variáveis significativas explica satisfatoriamente a variação da ineficiência do município

\subsubsection{Limitações da pesquisa}

Como principal limitação do estudo, tem-se a exclusão de vários municípios brasileiros, que não puderam compor a amostra final por falta de dados sobre a despesa com atenção básica (no SIOPS) e por apresentarem inconsistências nos dados sobre a produção ambulatorial em atenção básica (no SIAB). Essa inconsistência devem-se, principalmente, a: (i) informações disponíveis para alguns anos e ausentes para outros; (ii) valores muitos discrepantes, comparativamente a anos anteriores, principalmente no que se refere aos outputs - o que denota possível erro informacional, considerando a racionalidade e limite produtivo para as variáveis (e.g., aumento relevante entre 2015 e 2016 do número de o número das ações de enfermagem e outros procedimentos de saúde de Nível Médio, incompatível com a variável em questão.

Há ainda as limitações do modelo DEA, que, por ser uma técnica não paramétrica, não permite a extrapolação de suas conclusões, que estão restritas às unidades de análise e às variáveis em análise. Além disso, por se tratar de um método não-estocástico, a fronteira gerada pela DEA é suscetível a erros de medida.

Outra limitação refere-se a metodologia de Varela et al. (2012). No presente estudo, tomou-se como integralmente válida a proposta dos referidos autores, não sendo feita adaptações ou modificações. Isso porque objetivou-se validar tal metodologia para todos os municípios brasileiros. Assim, a metodologia foi seguida em seu passo-a-passo, ampliando-se apenas a amostra analisada. 


\section{CONCLUSÃO}

Considerando os resultados apresentados, observou-se que, no processo de avaliação de uma política pública, depara-se com dificuldade decorrentes da ausência de informações dos diversos municípios brasileiros, além de dificuldades relacionadas à identificação dos produtos diretos e, sobretudo, finais das políticas públicas, no que se refere à avaliação da qualidade, efetividade e eficiência. Nesse sentido, utilizando a metodologia de Varela et al. (2012), o presente estudo se propôs a avaliar o desempenho dos municípios, quanto à eficiência na aplicação de recursos públicos nas ações de atenção básica à saúde e analisar a influência de variáveis não controláveis no processo de produção em tal área. A metodologia demonstrou-se válida e relevante, considerando as potencialidades de avaliação e a relevância dos resultados obtidos.

Assim como os referidos autores, para atingir os resultados encontrados utilizou-se uma modelagem em dois estágios. No primeiro estágio, a partir do modelo DEA, os escores de eficiência de 133 municípios brasileiros foram calculados com base em um input discricionário - despesa liquidada com atenção básica - e cinco outputs diretos representativos da atenção básica à saúde - número de procedimentos nesse nível de atenção e cobertura dos programas PSF e PACS.

Os resultados evidenciaram que apenas 17 municípios, dentre os analisados, foram classificados como eficientes. A maioria desses são capitais estaduais que, a despeito do elevado número de habitantes na terceira idade - uma das variáveis que explicam o escore de eficiência alcançado -, apresentam boa governança no setor público, em especial, na gestão dos serviços de atenção primária a saúde. Para os municípios ineficientes, identificou-se densidade populacional como explicativa para o pior desempenho na alocação de recursos. Para esse segundo grupo, características como número de habitantes na zona rural e elevada população jovem foram consideradas como possíveis fatores que geram complexidade para o alcance de melhores resultados.

O percentual de recursos aplicados a função saúde foi outra variável explicativa significante, tanto no modelo para as DMUs eficientes quanto ineficientes. A despeito desse resultado, se comparado o gasto per capita com saúde (ver Apêndice C) dos municípios mais eficientes e mais ineficientes, observa-se certa incongruência nos valores. Isso porque a capital baiana, uma das mais eficientes dentre os municípios analisados, apresenta gasto per capita de $\mathrm{R} \$ 414,74 /$ hab; valor esse inferior, por exemplo, aos R\$ 709,99/hab de Carandaí/MG, um dos 
municípios mais ineficientes.

Assim, considerando que (i) a densidade demográfica foi identificada como fator determinante para ineficiência e o elevado número de idosos para a eficiência, e que (ii) grandes municípios, tais como as capitais estaduais, obtiveram melhor desempenho do que municípios localizados em regiões carentes, sem saneamento básico adequado e com maioria da população na zona rural; apresenta-se uma nova problemática para a consolidação do SUS no que se refere à sua porta de entrada - a atenção básica. Em outras palavras, ao realizar uma avaliação de desempenho comparativa entre os municípios brasileiros, não se pode deixar de considerar que existem condições socioeconômicas particularidades a cada localidade. Tal qual o resultado de Varela et al. (2012), verificou-se, ao final do modelo de regressão múltipla que, em média, os escores de eficiência ajustados foram menores do que os originalmente calculados, indicando que as variáveis não controláveis têm um impacto líquido positivo.

Por fim, destaca-se que no grupo dos municípios ineficientes (escore na fronteira invertida de $100 \%$ ), constatou-se que a amostra era formada por municípios de porte pequeno. Os resultados evidenciaram que os municípios dessa magnitude, são tidos como ineficientes. Em comum, esses apresentam uma grande parcela de população na zona rural, um elevado número da população na faixa etária I ( 0 a 19 anos ) e uma reduzida escala de estabelecimentos de saúde, características que de maneira individual ou em conjunto, por um ou mais municípios, podem comprometer seu desempenho. Decorrente desse resultado, questiona-se: municípios em regiões carentes conseguem atender a condições mínimas para a ofertar os serviços de saúde e, portanto, a atenção básica necessariamente deve ser tida como responsabilidade exclusiva dos gestores desses municípios em questão?

Para pesquisas futuras sugere-se a avaliação das outras subfunções do setor em saúde, como, por exemplo, atendimento ambulatorial de média e alta complexidades. Outro recorte possível é o de agrupar as atividades com características semelhantes de produção entre os municípios ou dividir esses municípios de acordo com sua capacidade de produção e atendimento. Ou ainda avaliar as regiões ou macrorregiões de saúde como centro de responsabilidades e não o município, que parece ser uma alternativa aceitável, haja vista as diretrizes do SUS quanto à organização dos serviços de saúde em redes regionalizadas.

Diante de um cenário de crise econômica, quando o assunto trata da avaliação de determinantes do desempenho das firmas, a teoria VBR e seus desdobramentos podem levar a reflexões quanto as necessidades por recursos no setor de saúde, que, a despeito do volume, parecem ter de ser cuidadosamente gerenciados, devido à restrição causadas por mudanças governamentais e pelo aumento das demandas por serviços e tratamentos de saúde. 
Compreender como os recursos são mobilizados e transformados em capacidades organizacionais representa uma ferramenta de direcionamento estratégico e, até de sobrevivência, para as instituições inseridas em tal complexidade.

Quando os recursos externos são limitados, as organizações são obrigadas a olhar internamente para realizar possíveis dotações financeiras para áreas especializadas que demandam mais necessidade de recursos. Este foco interno se conecta com um crescente reconhecimento de que o desempenho organizacional é fortemente influenciado por ações individuais em vários níveis de uma organização do setor público - tal qual a abordagem das Equipes de Saúde da Família na atenção básica. 


\section{REFERENCIAS}

ARANTES, C. I. S. et al. O controle social no Sistema Único de Saúde: concepções e ações de enfermeiras da atenção básica. Texto Contexto Enfermagem, Florianópolis, v. 16, n. 3, p. 470-478, jul./set. 2007.

BANCO MUNDIAL. Financing health services in developing countries: an agend for reform. Washington: World Bank, 1987.

Strengthening World Bank Group engagement on governance and

anticorruption. Washington: World Bank, 2007. Press, 2000.

World development report: investing in health. Nova York: Oxford University

BANKER, R. D.; CHARNES, A.; COOPER, W. W. Some models for estimating technical and scale efficiencies in data envelopment analysis. Management Science, [S.1.], v. 30, p. 1078-1092, 1984.

BARBOSA, A. M. G. Políticas de saúde e participação social. Revista Profissão Docente, Uberaba, v. 9, n. 21, p. 41-69, jan./jul. 2013.

BARNEY, J. Commentary: a hierarchy of corporate resources (A. L. Brumagin). In: SHRIVASTAVA, P.; HUFF, A. S.; DUTTON, J. E. (Eds.). Advances in strategic management. Greenwich: Jai Press, 1994. vol. 10/A, p. 113-125.

BARNEY, J. Firm resources and sustained competitive advantage. Journal of Management, [S.1], v. 17, n. 1, p. 99-120, 1991.

BARNEY, J. Gaining and sustaining competitive advantage. Reading: Adisson Wesley, 1996.

BARNEY, J. Gaining and sustaining competitive advantage. Reading: Addison Wesley, 1997.

BARNEY, J. Integrating organizational behavior and strategy formulation research: a resource based analysis. In: SHRIVASTAVA, P.; HUFF, A. S.; DUTTON, J. E.

(Eds.). Advances in strategic management. Greenwich: Jai Press, 1992. vol. 8, p. 203-227.

BARNEY, J.; HESTERLY, W. Organizational economics: understanding the relationship between organizations and economic analysis. In: CLEGG, S. R.; HARDY, C.; NORD, W. R. (Eds.). Handbook of organization studies. London: Sage Publications, 1996. p. 115-147.

BORGER, B. de; KERSTENS, K. Cost efficiency of Belgian local governments: a comparative analysis of FDH, DEA, and econometric approaches. Regional Science and Urban Economics, v. 26, p. 145-170, 1996a. 
BORGER, B. de; KERSTENS, K. Radial and non radial measures of technical efficiency: an empirical illustration for Belgian local governments using an FDH reference technology. Journal of Productivity Analysis, v. 7, p. 41-62, 1996b.

BRADFORD, D. F.; MALT, R. A.; OATES, W. E. The rising cost of local public services: some evidence and reflections. The National Tax Journal, [S.1.], v. 22, n. 2, p. 185-202, 1969.

BRASIL. Constituição da República Federativa do Brasil de 1988. Diário Oficial [da] República Federativa do Brasil. Brasília, DF, 5 out. 1988. Disponível em: <http://www.senado.gov.br/sf/legislacao/const/>. Acesso em: 29 jun. 2017.

BRASIL. Decreto $\mathrm{n}^{\circ} 7.508$, de 28 de junho de 2011. Regulamenta a Lei $\mathrm{n}^{\circ}$ 8.080, de 19 de setembro de 1990, para dispor sobre a organização do Sistema Único de Saúde - SUS, o planejamento da saúde, a assistência à saúde e a articulação interfederativa, e dá outras providências. Diário Oficial [da] República Federativa do Brasil. Brasília, DF, 28 jun. 2011. Disponível em: <http://www.planalto.gov.br/ccivil_03/_ato20112014/2011/decreto/d7508.htm>. Acesso em: 10 nov. 2017.

BRASIL. Emenda Constitucional n ${ }^{\circ}$ 29, de 13 de setembro de 2000. Altera os arts. 34, 35, 156, 160, 167 e 198 da Constituição Federal e acrescenta artigo ao Ato das Disposições Constitucionais Transitórias, para assegurar os recursos mínimos para o financiamento das ações e serviços públicos de saúde. Diário Oficial [da] República Federativa do Brasil. Brasília, DF, 13 set. 2000. Disponível em:

<http://www.planalto.gov.br/ccivil_03/constituicao/emendas/emc/emc29.htm>. Acesso em: 10 nov. 2017.

BRASIL. Lei Complementar no 141, de 13 de janeiro de 2012. Regulamenta o § 3o do art. 198 da Constituição Federal para dispor sobre os valores mínimos a serem aplicados anualmente pela União, Estados, Distrito Federal e Municípios em ações e serviços públicos de saúde; estabelece os critérios de rateio dos recursos de transferências para a saúde e as normas de fiscalização, avaliação e controle das despesas com saúde nas 3 (três) esferas de governo; revoga dispositivos das Leis nos 8.080, de 19 de setembro de 1990, e 8.689, de 27 de julho de 1993; e dá outras providências. Diário Oficial [da] República Federativa do Brasil. Brasília, DF, 13 jan. 2012. Disponível em: <http://www.planalto.gov.br/ccivil_03/leis/LCP/Lcp141.htm>. Acesso em: 10 nov. 2017.

BRASIL. Lei no 8.080, de 19 de setembro de 1990. Dispõe sobre as condições para a promoção, proteção e recuperação da saúde, a organização e o funcionamento dos serviços correspondentes e dá outras providências. Diário Oficial [da] República Federativa do Brasil. Brasília, DF, 19 set. 1990a. Disponível em: <http://www.planalto.gov.br/ccivil_03/leis/L8080.htm>. Acesso em: 10 nov. 2017.

BRASIL. Lei no 8.142, de 28 de dezembro de 1990. Dispõe sobre a participação da comunidade na gestão do Sistema Único de Saúde (SUS) e sobre as transferências intergovernamentais de recursos financeiros na área da saúde e dá outras providências. Diário Oficial [da] República Federativa do Brasil. Brasília, DF, 28 dez. 1990b. Disponível em: <http://www.planalto.gov.br/ccivil_03/leis/L8142.htm>. Acesso em: 10 nov. 2017. 
BRASIL. Ministério da Saúde. Índice de Desempenho do Sistema Único de Saúde (IDSUS). 2017a. Disponível em: 〈http://idsus.saude.gov.br/>. Acesso em: 01 out. 2017.

BRASIL. Ministério da Saúde. Índice de Desempenho do Sistema Único de Saúde (IDSUS). 2011a. Disponível em: <http://idsus.saude.governobr/documentos.html>. Acesso em: 10 set. 2015.

BRASIL. Ministério da Saúde. Portaria no 204, de 29 de janeiro de 2007. Regulamenta o financiamento e a transferência dos recursos federais para as ações e os serviços de saúde, na forma de blocos de financiamento, com o respectivo monitoramento e controle. Diário Oficial [da] República Federativa do Brasil. Brasília, DF, 29 jan. 2007. Disponível em: <http://bvsms.saude.gov.br/bvs/saudelegis/gm/2007/prt0204_29_01_2007.html >. Acesso em: 10 nov. 2017.

BRASIL. Ministério da Saúde. Portaria no 399, de 22 de fevereiro de 2006. Divulga o Pacto pela Saúde 2006 - Consolidação do SUS e aprova as Diretrizes Operacionais do Referido Pacto. Diário Oficial [da] República Federativa do Brasil. Brasília, DF, 22 fev. 2006. Disponível em:

<http://bvsms.saude.gov.br/bvs/saudelegis/gm/2006/prt0399_22_02_2006.html>. Acesso em: 10 nov. 2017.

BRASIL. Ministério da Saúde. Portaria nº 699, de 30 de março de 2006. Regulamenta as Diretrizes Operacionais dos Pactos Pela Vida e de Gestão. Diário Oficial [da] República Federativa do Brasil. Brasília, DF, 30 mar. 2006. Disponível em:

<http://bvsms.saude.gov.br/bvs/saudelegis/gm/2006/prt0699_30_03_2006.html >. Acesso em: 10 nov. 2017.

BRASIL. Ministério da Saúde. Portaria nº 2.135, de 25 de setembro de 2013. Estabelece diretrizes para o processo de planejamento no âmbito do Sistema Único de Saúde (SUS).

Diário Oficial [da] República Federativa do Brasil. Brasília, DF, 2013a. Disponível em: <http://bvsms.saude.gov.br/bvs/saudelegis/gm/2013/prt2135_25_09_2013.html >. Acesso em: 5 out. 2017.

BRASIL. Ministério da Saúde. Portaria no 2.203, de 5 de novembro de 1996. Diário Oficial [da] República Federativa do Brasil. Brasília, DF, 5 nov. 1996. Disponível em: <http://bvsms.saude.gov.br/bvs/saudelegis/gm/1996/prt2203_05_11_1996.html>. Acesso em: 10 nov. 2017.

BRASIL. Ministério da Saúde. Portaria n 2.488, de 21 de outubro de 2011. Aprova a Política Nacional de Atenção Básica, estabelecendo a revisão de diretrizes e normas para a Organização da Atenção Básica, para a Estratégia Saúde da Família (ESF) e o Programa de Agentes Comunitários de Saúde (PACS). Diário Oficial [da] República Federativa do Brasil. Brasília, DF, 21 out. 2011b. Disponível em: <http://bvsms.saude.gov.br/bvs/saudelegis/gm/2011/prt2488_21_10_2011.html>. Acesso em: 10 nov. 2017.

BRASIL. Ministério da Saúde. Rede de atenção às urgências e emergências: saúde toda hora. 2017b. Disponível em:

<http://dab.saude.gov.br/portaldab/smp_ras.php?conteudo=rede_emergencias>. Acesso em: 28 ago. 2017. 
BROGNOLI, Jorge Henrique. Gestão hospitalar sob a lente da visão baseada em recursos (VBR): um estudo de caso do hospital e maternidade Jaraguá-HMJ. Programa de PósGraduação em Administração, 2017.

CARVALHO, M. A. (2001, jan.-mar.) Políticas públicas e competitividade da agricultura. Revista de Economia Política, 1(81).

CASTRO, J. A. de et al. Gasto social federal: prioridade macroeconômica no período 19952010. Brasília: IPEA, 2012. Disponível em:

<http://www.ipea.gov.br/agencia/images/stories/PDFs/nota_tecnica/120904_notatecnicadisoc 09.pdf>. Acesso em: 10 nov. 2017.

CHARNES, A.; COOPER, W. W.; RHODES, E. Measuring efficiency of decision making units. European Journal of Operational Research, [S.1.], v. 2, n. 6, p. 429-44, 1978.

CHESNAIS, F. O capital portador de juros: acumulação, internacionalização, efeitos econômicos e políticos. In: CHESNAIS, F. (Org.). A finança mundializada, raízes sociais e políticas, configuração, consequências. São Paulo: Boitempo, 2005.

COBAITO, F. C. Gestão hospitalar, sob a lente da resource based view - RBV. Revista de Administração Hospitalar e Inovação em Saúde, Belo Horizonte, n. 9, p. 34-42, jan./jun. 2012.

COLLINS, C.; GREEN, A. Decentralization and primary health care: some negative implications in developing countries. International journal of health services, [S.1.], v. 24, n. 3, p. 459-475, 1994.

CONSELHO NACIONAL DE SECRETÁRIOS DA SAÚDE. O Sistema Único de Saúde. Brasília: CONASS, 2011. v. 1. Coleção para entender a gestão do SUS.

CONSELHO NACIONAL DE SECRETÁRIOS DE ADMINISTRAÇÃO. Dialogo temático: gestão financeira do SUS. 2015. Disponível em: <http://www.cosemsrn.org.br/wpcontent/uploads/2015/10/revista03.2015.pdf>. Acesso em: 17 out. 2017.

CONSELHO DE SECRETARIAS MUNICIPAIS DE SAÚDE DO ESTADO DO RIO

GRANDE DO NORTE. Assessoria parlamentar. Rio Grande do Norte, 24 ago. 2015.

DAFT, R. Organization theory and design. New York: West, 1983.

DATASUS. Estabelecimentos de Saúde. 2017. Disponível em:

<http://www2.datasus.gov.br/DATASUS/index.php?area=0204>. Acesso em: 05 maio 2017.

DATASUS. Faixa Etária I e II. 2017. Disponível em:

<http://www2.datasus.gov.br/DATASUS/index.php?area=0206\&id=6942\&VObj=http://tabne t.datasus.gov.br/cgi/deftohtm.exe?ibge/cnv/pop>. Acesso em: 05 maio 2017.

DAVID, G. C.; SHIMIZU, H. E.; SILVA, E. N. da. Atenção primária à saúde nos municípios brasileiros: eficiência e disparidades. Saúde em Debate, Rio de Janeiro, v. 39, n. esp., p. 232245, dez. 2015. 
DEBREU, G. The coefficient of resource utilisation. Econometrica, Evanston, v. 19, n. 3, p. 273-292, jul. 1951.

DEPRINS, D.; SIMAR, L.; TULKENS, H. Measuring labor efficiency in post offices. In: MARCHAND, M.; PESTIEAU, P.; TULKENS, H. (Eds.). The performance of public enterprises: concepts and measurements. Amsterdam: North-Holland, 1984. p. 345-367.

DIERICKX, I.; COOL, K. Asset stock accumulation and sustainability of competitive advantage. Management Science, [S.1.], v. 35, n. 12, p. 1504-1511, 1989.

DILLINGER, W. R.; WEBB, S. B. Fiscal management in federal democracies: Argentina and Brazil. Policy Research Working Paper 2121. Maio 1999. Disponível em: <http://documents. worldbank.org/curated/pt/927571468005477262/pdf/multi-page.pdf>. Acesso em: 10 nov. 2017.

EISENHARDT, K. M.; MARTIN, J. A. Dynamic capabilities: what are they? Strategic management journal, [S.1.], v. 21, n. 10-11, p. 1105-1121, 2000.

ESCOREL, S. et al. O Programa de Saúde da Família e a construção de um novo modelo para a atenção básica no Brasil. Revista Panamericana de Salud Pública, Washington, v. 21, n. 2, p. 164-176, 2007.

FADEL, C. B. et al. Administração pública: o pacto pela saúde como uma nova estratégia de racionalização das ações e serviços em saúde no Brasil. Revista de Administração Pública, Rio de Janeiro, v. 43, n. 2, p. 445-456, 2009.

FARIA, R. M. A territorializacão da atenção primaria a saúde no sistema único de saúde e a construção de uma perspectiva de adequação dos serviços aos perfis do território urbano.

Hygeia: Revista Brasileira de Geografia Médica e da Saúde, Uberlândia, v. 9, n. 16, p. 131-147, 2013.

FELICIANO, M.; BEZERRA, A. F. B.; SANTO, A. C. G. do E. Crescimento econômico e taxa de inflação: implicações na receita municipal e na despesa com saúde dos municípios de Pernambuco, Brasil. Ciência \& Saúde Coletiva, Rio de Janeiro, v. 22, p. 1979-1990, 2017.

FERNANDES, F. M. B.; MOREIRA, M. R.; RIBEIRO, J. M. Análise da atuação das ouvidorias estaduais do Sistema Único de Saúde como instâncias participativas. Saúde em Debate, Rio de Janeiro, v. 40, p. 201-212, 2016.

FOSS, N. J. (Ed.). Resources, firms, and strategies: a reader in the resource-based perspective. Oxford: Oxford University Press on Demand, 1997.

GADELHA, M. I. P. Funcionamento e financiamento do SUS. Revista de Doutrina da $4^{\text {a }}$ Região, Porto Alegre, n. 35, p. 1-6, abr. 2010.

GERDTHAM, U.-G.; JONSSON, B. International comparisons of health expedinture: theory, data and econometric analysis. In: CULYER, A. J.; NEWHOUSE, J. P. (Eds.). Handbook of health economics. Amsterdan: Elsevier, 2000. vol. 1A. 
GIL, C. R. R. Atenção primária, atenção básica e saúde da família: sinergias e singularidades no contex to brasileiro. Cadernos de Saúde Pública, Rio de Janeiro, v. 22, n. 6, p. 1171-1181, 2006.

GONÇALVES, C. de C. T. Práticas da gestão do SUS na atenção básica e o protagonismo dos gestores, trabalhadores de saúde e usuários: uma responsabilidade pública e exercício de cidadania? 2013. 175 f. Dissertação (Mestrado Acadêmico em Saúde Coletiva)-Universidade Estadual de Feira de Santana, Feira de Santana, 2013.

GRANT, R. M. The resource-based theory of competitive advantage: implications for strategy formulation. California management review, California, v. 33, n. 3, p. 114-135, 1991.

GUERRA, M. Modelo de alocação de recursos do Sistema Único de Saúde para organizações hospitalares: serviços de alta complexidade. 2013. 150 f. Tese (Doutorado em Administração)-Faculdade de Ciências Econômicas, Universidade de Brasília, Brasília, 2013.

HADDAD, S. Banco Mundial, OMC e FMI: o impacto nas políticas educacionais. São Paulo: Cortez, 2008.

HARTZ, Z. M. A. Institutionalizing the evaluation of health programs and policies in France: cuisine internationale over fast food and sur mesure over ready-made. Cadernos de Saúde Pública, Rio de Janeiro, v. 15, p. 229-259, 1999.

HAYES, K.; S. CHANG. The relative efficiency of city manager and mayor-councils forms of government. Southern Economic Journal, [S.1.], v. 57, v. 1, p. 167-177, 1990.

HECKMAN, J. J.; KAUTZ, T. Fostering and measuring skills interventions that improve character and cognition. In: HECKMAN, J. J.; HUMPHRIES, J. E.; KAUTZ, T. (Eds.). The GED myth: education, achievement tests, and the role of character in american life. Chicago: University of Chicago Press, 2014. Cap. 9.

INSTITUTO BRASILEIRO DE GEOGRAFIA E ESTATÍSTICA. Censo 2010. 2010. Disponível em: <https://www.ibge.gov.br/estatisticas-novoportal/sociais/populacao/2098-npcenso-demografico/9662-censo-demografico-2010.html?edicao=9673 >. Acesso em: 23 ago. 2017.

INSTITUTO BRASILEIRO DE GEOGRAFIA E ESTATÍSTICA. Densidade populacional. 2017. Disponível em: <https://cidades.ibge.gov.br/xtras/home.php?lang=>. Acesso em: 05 maio 2017.

KAY, J. Fundamentos do sucesso empresarial: como as estratégias de negócios agregam valor. Rio de Janeiro: Campus, 1996.

KOOPMANS, T. C. An analysis of production as an efficient combination of activities. In: KOOPMANS, T. C. Activity analysis of production and allocation. Cowles Commission for Research in Economics, Monograph n. 13. New York: John Wiley and Sons, 1951.

KROTH, D. C. Avaliação de impacto do "pacto pela saúde" sobre indicadores de eficiência e de vulnerabilidade de saúde municipais (2006-2013). 2017. 250 f. Tese 
(Doutorado em Desenvolvimento Econômico)-Universidade Federal do Paraná, Curitiba, 2017.

LEE, S.-Y.; WHITFORD, A. B. Assessing the effects of organizational resources on public agency performance: evidence from the US federal government. Journal of Public Administration Research and Theory, [S.1.], v. 23, n. 3, p. 687-712, 2013.

LIMA, W. G. Política pública: discussão de conceitos. Revista Interface (Porto Nacional), Porto Nacional, v. 5, n. 5, p. 49-54, nov. 2012.

MACHADO, C. V.; LIMA, L. D.; BAPTISTA, T. W. de F. Princípios organizativos e instâncias de gestão do SUS. In: GONDIM, R.; GRABOIS, V.; MENDES JUNIOR, W. V. (Orgs). Qualificação dos gestores do SUS. 2. ed. Rio de Janeiro: Fiocruz/ENSP/EAD, 2011. p. 47-72.

MAHONEY, J. T.; PANDIAN, J. R. The resource-based view within the conversation of strategic management. Strategic Management Journal, [S.1.], v. 13, p. 363-380, 1992.

MASCARENHAS, A. O.; VASCONCELOS, F. C de. Tecnologia na gestão de pessoas: estratégias de auto-atendimento para o novo RH. São Paulo: Pioneira Thomson Learning, 2004.

MATOS, E. L. M.; MUGIATTI, M. M. T. de F. Pedagogia hospitalar: a humanização integrando educação e saúde. São Paulo: Editora Vozes Limitada, 2017.

MATTA, G. C.; MOROSINI, M. V. G. Atenção primária à saúde. In: Escola Politécnica de Saúde Joaquim Venâncio (Org.). Dicionário da Educação Profissional em Saúde. Rio de Janeiro: EPSJV, 2006. vol. 1.

MATTHEWS, J.; SHULMAN, A. D. Competitive advantage in public-sector organizations: explaining the public good/sustainable competitive advantage paradox. Journal of Business Research, v. 58, n. 2, p. 232-240, 2005.

MCKEOWN, R. E. The epidemiologic transition: changing patterns of mortality and population dynamics. American Journal of Lifeestyle Medicine, [S.1.], v. 1, n. 3, p. 19-26, jul. 2009.

MEDEIROS, A. A. O olhar dos gestores públicos sobre o financiamento da saúde brasileira: gasto social ou política de investimento. 2016. 35 f. Trabalho de Conclusão de Curso (Graduação em Enfermagem)-Escola de Enfermagem, Universidade Federal do Rio Grande do Sul, Porto Alegre, 2016.

MEDINA, M. G.; AQUINO, R. Avaliando o Programa Saúde da Família. In: SOUSA, M. F. (Org.). Os sinais vermelhos do PSF. São Paulo: Editora Hucitec, 2002. p. 135-151.

MELLO, J. C. C. B. et al. Curso de Análise de Envoltória de Dados. In: SIMPÓSIO BRASILEIRO DE PESQUISA OPERACIONAL, 37., 2005, Gramado. Anais... Granado: SBPO, 2005. 
MELO, M. G. M. Estudo de dermatoses em trabalhadores de uma indústria farmacêutica. 1999. 102 f. Dissertação (Mestrado em Ciências)-Escola Nacional de Saúde Pública, Fundação Osvaldo Cruz, Rio de Janeiro, 1999.

MENDES, E. V. O cuidado das condições crônicas na atenção primária à saúde: o imperativo da consolidação da Estratégia Saúde da Família. Brasília: Organização PanAmericana da Saúde, 2012.

MENDES, E. V. Programa Mãe Curitibana: uma rede de atenção à mulher e à criança em Curitiba, Paraná, estudo de caso. Lima: Organización Panamericana de la Salud, 2009.

MENDES, Á.; MARQUES, R. M. O financiamento da atenção básica e da estratégia saúde da família no Sistema Único de Saúde. Saúde Debate, Rio de Janeiro, v. 38, n. 103, p. 900-916, out./dez. 2014.

MENDES, Á.; WEILLER, J. A. B. Renúncia fiscal (gasto tributário) em saúde: repercussões sobre o financiamento do SUS. Saúde em Debate, Rio de Janeiro, v. 39, n. 105, p. 491-505, 2015.

MENICUCCI, T. M. G. Público e privado na política de assistência à saúde no Brasil: atores, processos e trajetória. Rio de Janeiro: Editora Fiocruz, 2007.

MEZA, A. L. et al. ISYDS - Integrated System for Decision Support (SIAD - Sistema Integrado de Apoio à Decisão): a software package for data envelopment analysis model. Pesquisa Operacional, Rio de Janeiro, v. 25, n. 3, p. 493-503, set./dez. 2005.

MINISTÉRIO DA SAÚDE. Avaliação na Atenção Básica em Saúde: caminhos da institucionalização. Brasília: Ministério da Saúde, 2005. Disponível em:

<http://dab.saude.gov.br/portaldab/biblioteca.php?conteudo=publicacoes/avaliacao_ab>. Acesso em: 10 nov. 2017.

NORONHA, J.; SANTOS, I.; PEREIRA, T. Relações entre o SUS e a saúde suplementar: problemas e alternativas para o futuro do sistema universal. In: SANTOS, N. R.;

AMARANTE, P. D. C. (Orgs.). Gestão pública e relação público-privado na saúde. Rio de Janeiro: Cebes, 2012. p. 152-179.

OATES, W. E. Toward a second-generation theory of fiscal federalism. Journal of International Tax and Public Finance, [S.1.], v. 12, p. 349-373, 2005.

OCKÉ-REIS, C. O. A constituição de um modelo de atenção à saúde universal: uma promessa não cumprida pelo SUS? Texto para discussão IPEA n ${ }^{\circ}$ 1376. Rio de Janeiro: IPEA, 2009.

ORGANIZAÇÃO MUNDIAL DA SAÚDE. The world health report 2000 - Health systems: improving performance. Geneva: WHO, 2000.

ORGANIZAÇÃO MUNDIAL DA SAÚDE. The world health report 2008 - Primary health care (now more than ever). Geneva: WHO, 2008. 
ORGANIZAÇÃO PARA A COOPERAÇÃO E DESENVOLVIMENTO ECONÔMICO. Fiscal sustainability of health systems: bridging health and finance perspectives. Paris: OECD Publishing, 2015.

ORGANIZAÇÃO PARA A COOPERAÇÃO E DESENVOLVIMENTO ECONÔMICO. Value for money in health spending. Paris: OECD Health Policy Studies, 2010.

ORGANIZAÇÃO PAN-AMERICANA DA SAÚDE. A atenção à saúde coordenada pela APS: construindo as redes de atenção no SUS, contribuições para o debate. Brasília: OPAS/OMS, 2011.

PAIM, J. Modelos de atenção à saúde no Brasil. In: GIOVANELLA, L. et al. (Org.) Políticas e sistema de saúde no Brasil. 2. ed. Rio de Janeiro: Fiocruz, 2012.

PEGO, R. A.; ALMEIDA, C. M. Teoria y práctica de las reformas de los sistemas de salud: los casos de Brasil y Mexico. Cadernos de Saúde Pública, Rio de Janeiro, v. 18, n. 4, p. 971 989, 2002.

PENROSE, E. The theory of the growth of the firm. Oxford: Basil Blackwell, 1959.

PETERAF, M. A. The cornerstones of competitive advantage: a resource-based view. Strategic management journal, [S.1.], v. 14, n. 3, p. 179-191, 1993.

PIOLA, S. F. et al. Estruturas de financiamento e gasto do sistema público de saúde. Rio de Janeiro: Fiocruz/Ipea/Ministério da Saúde/Secretaria de Assuntos Estratégicos da Presidência da República, 2013. vol. 4. p. 19-70.

PIOLA, S. F. et al. Saúde no Brasil: algumas questões sobre o Sistema Único de Saúde (SUS). Texto para discussão IPEA nº 1391. Rio de Janeiro: IPEA, 2009.

PORTELA, G. Z.; RIBEIRO, J. M. A sustentabilidade econômico-financeira da estratégia saúde da família em municípios de grande porte. Ciência \& Saúde Coletiva, Rio de Janeiro, v. 16, n. 3, p. 1719-1732, mar. 2011.

PRZEWORSKI, A. A mecânica da instabilidade de regime na américa latina. Revista Novos Estudos - CEBRAP, São Paulo, n. 100, p. 27-54, 2014.

PRZEWORSKI, A. The Mechanics of regime instability in Latin America. Journal of Politics in Latin America, [S.1.], v. 1, n. 1, p. 5-36, 2009.

RAJKUMAR, A. S.; SWAROOP, V. Public spending and outcomes: does governance matter? Journal of development economics, [S.1.], v. 86, p. 96-111, 2008.

RIZZOTTO, M. L. F. et al. Força de trabalho e gestão do trabalho em saúde: revelações da Avaliação Externa do Programa Nacional de Melhoria do Acesso e da Qualidade da Atenção Básica no Paraná. Saúde em Debate, Rio de Janeiro, v. 38, p. 237-251, 2014.

RODRIGUES NETO, J. F. et al. Qualidade de vida: um instrumento para promoção de saúde. Revista Baiana de saúde pública, [S.1.], v. 32, n. 2, p. 232, 2014. 
RUBIN, D. B. The use of matched sampling and regression adjustment to remove bias in observational studies. Biometrics, [S.1.], p. 185-203, 1973.

SALTMAN, R. B.; VRANBAEK, K. Drawing lessons for policy-making. In: SALTMAN, R. B. et al (Orgs). Decentralization in Health Care: strategies and outcomes. New York: McGraw-Hill, 2007. European Observatory on Health Systems and Policies Series.

SANTOS, N. R. dos. Política pública de saúde no Brasil: encruzilhada, buscas e escolhas de rumos. Ciência \& Saúde Coletiva, Rio de Janeiro, v. 13, p. 2009-2018, 2008.

SANTOS, L. M.; GONÇALVES, M. A.; FIGUEIREDO, A. C. Avaliação do desempenho da alocação de recursos públicos na atenção básica da saúde: o caso da região sudeste do Brasil. In: ENCONTRO NACIONAL DA ASSOCIAÇÃO NACIONAL DE PÓS-GRADUAÇÃO E PESQUISA EM ADMINISTRAÇÃO, 37., 2013, Rio de Janeiro. Anais... Rio de Janeiro: EnANPAD, 2013. Disponível em:

<http://www.anpad.org.br/admin/pdf/2013_EnANPAD_APB842.pdf>. Acesso em: 10 nov. 2017.

SILVA, L. M. Conceitos, abordagens e estratégias para a avaliação em saúde. In: HARTZ, Z. M. A.; SILVA, L. M. V. da. (Orgs.). Avaliação em saúde: dos modelos teóricos à prática na avaliação de programas e sistemas de saúde. Salvador: EdUFBA e Rio de Janeiro: Editora Fiocruz, 2005. p. 15-39.

SILVA, S. F. Organização de redes regionalizadas e integradas de atenção à saúde: desafios do Sistema Único de Saúde (Brasil). Ciência \& Saúde Coletiva, Rio de Janeiro, v. 16, n. 6, p. 2753-2762, 2011.

SILVERMAN, J. Public sector decentralization: economic policy and sector investment programs. Washington: The Worl Bank, 1992.

SIMÃO, E.; ALBUQUERQUE, G. L.; ERDMANN, A. L. Atenção básica no Brasil (19802006): alguns destaques. Rev. Rene, Fortaleza, v. 8, n. 2, p. 50-59, 2007.

SISTEMA DE INFORMAÇÕES AMBULATORIAIS. Enfermagem, Médicos e Outros Profissionais. 2017. Disponível em:

<http://www2.datasus.gov.br/DATASUS/index.php?area=0202\&id=11636\&VObj=http://tabn et.datasus.gov.br/cgi/deftohtm.exe?sia/cnv/pa>. Acesso em: 14 out. 2017.

SISTEMA DE INFORMAÇÕES DA ATENÇÃO BÁSICA. Pessoas cadastradas PFS e PACS. 2017. Disponível em: <http://siab.datasus.gov.br/SIAB/index.php?area=04>. Acesso em: 10 out. 2017.

SISTEMA DE INFORMAÇÕES SOBRE ORÇAMENTOS PÚBLICOS EM SAÚDE. Despesa com atenção básica. 2017. Disponível em: <http://siopsasp.datasus.gov.br/cgi/siops/serhist/MUNICIPIO/indicadores.HTM>. Acesso em: 10 out. 2017.

SISTEMA DE INFORMAÇÕES SOBRE ORÇAMENTOS PÚBLICOS EM SAÚDE. Recursos Próprios Aplicados em Saúde. 2017. Disponível em: $<$ http://portalsaude.saude.gov.br/index.php/o-ministerio/principal/siops/mais-sobre- 
siops/6700-indicadores-municipios-consultas-fases-das-despesas>. Acesso em: 05 maio 2017.

SOARES, A.; SANTOS, N. R. dos. Financiamento do Sistema Único de Saúde nos governos FHC, Lula e Dilma. Saúde em Debate, Rio de Janeiro, v. 38, n. 100, p. 18-25, 2014.

SOUSA, M. da C. S. de; RAMOS, F. S. Eficiência técnica e retornos de escala na produção de serviços públicos municipais: o caso do Nordeste e do Sudeste brasileiros. Revista brasileira de economia, Rio de Janeiro, v. 53, n. 4, p. 433-461, 1999.

SOUZA, C. C. de et al. Classificação de risco em pronto-socorro: concordância entre um protocolo institucional brasileiro e Manchester. Revista Latino-americana de Enfermagem, Ribeirão Preto, v. 19, n. 1, p. 26-33, 2011.

STARFIELD, B. Atenção primária: equilíbrio entre necessidades de saúde, serviços e tecnologia. 2. ed. Brasília: Ministério da Saúde/Unesco/DFID, 2004.

STARFIELD, B.; SHI, L. Policy relevant determinants of health: an international perspective. Health policy, [S.1.], v. 60, p. 201-218, 2002.

STANKIEWICZ, B. Competitiviness of health resort enterprise: looking for methods of evaluating cross-border competitiviness of health resort enterprise. Economic Review, [S.1.], v. 41, n. 1, p. 31-43, 2012.

STEVENS, G. A. et al. Diretrizes para o relato preciso e transparente de estimativas de saúde: a Declaração GATHER. Epidemiologia e Serviços de Saúde, Brasília, v. 26, n. 1, p. 215-222, 2017.

SZYMANIEC-MLICKA, K. Resource-based view in strategic management of public organizations-a review of the literature. Management, [S.1.], v. 18, n. 2, p. 19-30, 2014.

VARELA, P. S.; MARTINS, G. de A.; FÁVERO, L. P. L. Desempenho dos municípios paulistas: uma avaliação de eficiência da atenção básica à saúde. Revista de Administração, São Paulo, v. 47, n. 4, p. 624-637, 2012.

VILELA, D. L. Utilização do método análise envoltório de dados para avaliação do desempenho econômico de coorporativas de crédito. 2004. 144 f. Dissertação (Mestrado em Engenharia de Produção)-Escola de Engenharia, Universidade de São Paulo, São Carlos, 2004.

WERNERFELT, B. The resource based view of the firm. Strategic Management Journal, [S.1.], v. 5, n. 2, p. 171-180, 1984.

WORTHINGTON, A. C.; DOLLERY, B. E. Efficiency measurement in the local public sector: econometric and mathematical programming frontier techniques. Queensland: Queensland University, 2000.

XIA, J.; LI, S. The divestitude of acquired subunits: a resource dependence approach. Strategic Management Journal, [S.1.], v. 34, n. 2, p. 131-148, 2013. 
XU, K.; SAKSENA, P.; HOLLY, A. The determinants of health expenditure: a countrylevel panel data analysis. Geneva: WHO, 2011. 


\section{APÊNDICE A - DMUs Eficiente}

Equação 1: Equação da Regressão para as DMUs eficientes

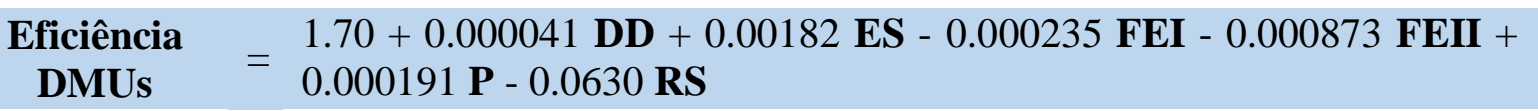

Figura 5 - Pressupostos do modelo de regressão para as 17 DMUS eficientes - normalidade dos resíduos e homocedasticidade

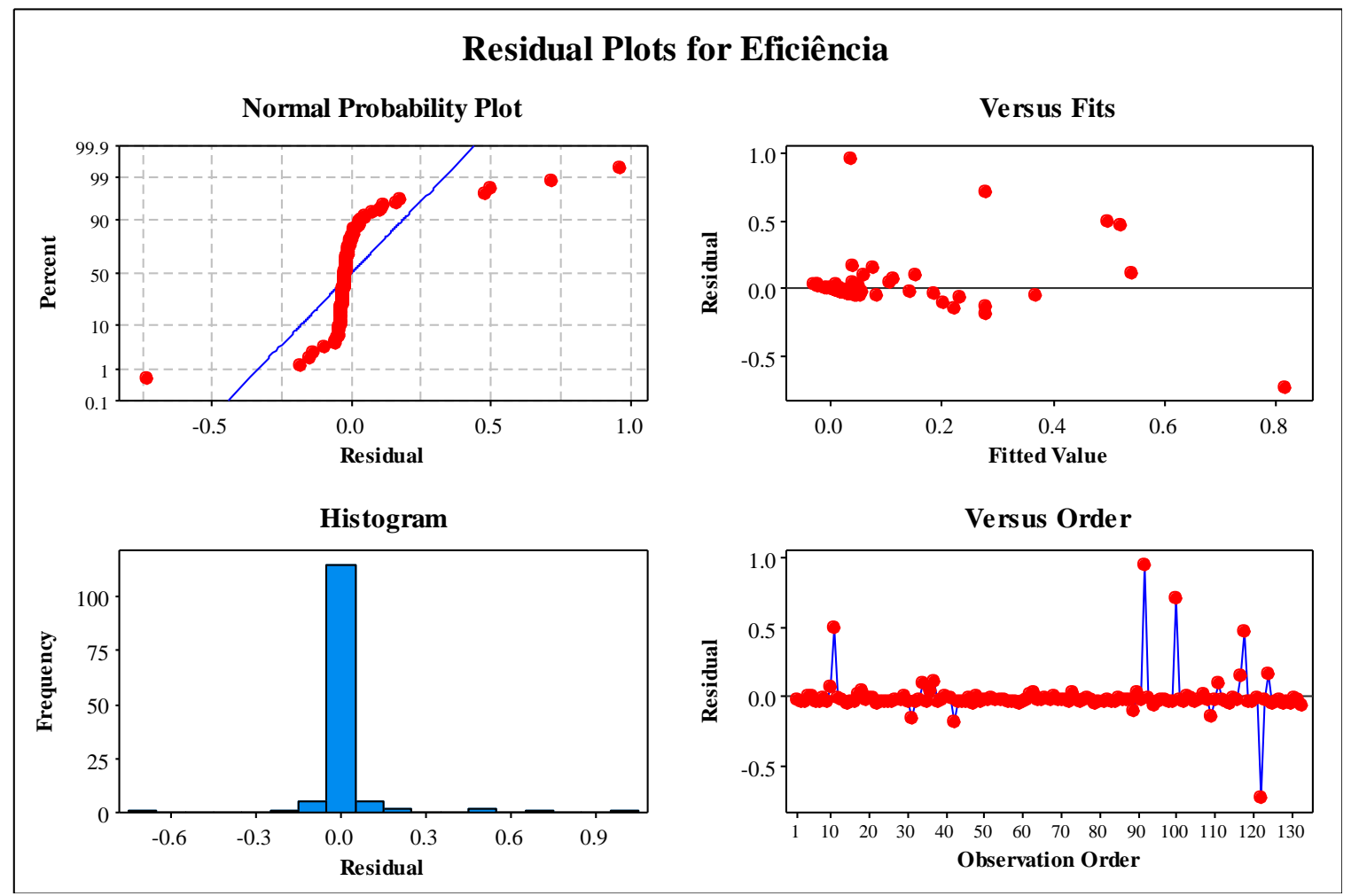

Fonte: Dados da pesquisa.

Tabela 5 - Modelo de Regressão Múltipla utilizando todas as variáveis não controláveis, para as DMUs eficientes

\begin{tabular}{|c|c|c|c|c|c|}
\hline \multicolumn{6}{|c|}{ Analysis of Variance (ANOVA) } \\
\hline Source & DF & SS & MS & $\mathbf{F}$ & $\mathbf{P}^{(\mathbf{1})}$ \\
\hline Regression & 1 & 3,159 & 3,159 & 29.190 & $<0.0001 * *$ \\
\hline Residual Error & 16 & 1,731 & 0,108 & & \\
\hline Total & 17 & 4,890 & & & \\
\hline
\end{tabular}




\section{APÊNDICE B - DMUs Ineficientes}

Equação 2 - Modelo de Regressão para as 116 DMUs ineficientes

$$
\begin{aligned}
& \text { Eficiência } \\
& \text { DMUs }
\end{aligned}=\begin{aligned}
& 0.0179+0.000009 \text { DD }+0.000180 \text { ES }+0.000000 \text { FEI }-0.000001 \text { FEII } \\
& -0.000000 \mathbf{P}-0.000601 \text { RS }
\end{aligned}
$$

Tabela 6 - ANOVA do modelo de Regressão Múltipla para os 116 municípios ineficientes

\begin{tabular}{lccccc}
\hline \hline & \multicolumn{5}{c}{ Analysis of Variance (ANOVA) } \\
\hline Source & DF & SS & MS & F & $\mathbf{P}^{(\mathbf{1})}$ \\
\hline Regression & 6 & 0.0167816 & 0.0027969 & 13.51 & $0.000^{* *}$ \\
Residual Error & 109 & 0.0225590 & 0.0002070 & & \\
\hline Total & $\mathbf{1 1 5}$ & $\mathbf{0 . 0 3 9 3 4 0 6}$ & & & \\
\hline \hline
\end{tabular}

Fonte: Dados da pesquisa.

(1) Teste ANOVA (p-valor <0.05).

** Valores Altamente significativos; *Valores Significativos; ${ }^{N S}$ Valores Não Significativos.

$\mathrm{H}_{1}$ : O modelo é adequado para explicar a variação da ineficiência do município $(\mathrm{p}<0.05)$.

Figura 6 - Pressupostos do modelo de regressão - normalidade dos resíduos e homocedasticidade utilizando todas as variáveis não controláveis, para as DMUs ineficientes

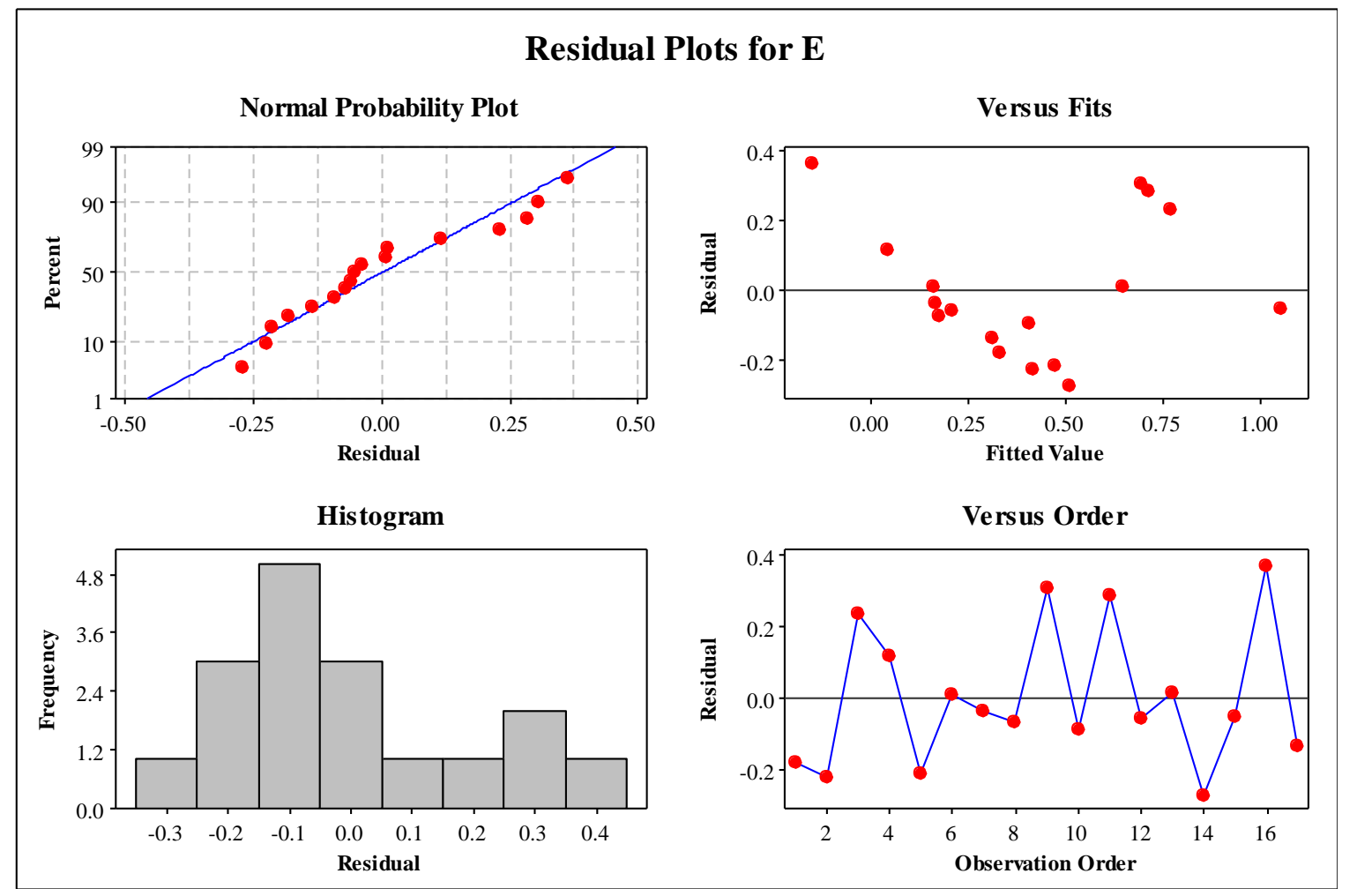

Fonte: Dados da pesquisa.

Figura 7 - Pressupostos do modelo de regressão - normalidade dos resíduos e 
homocedasticidade utilizando todas as variáveis não controláveis, para as DMUs ineficientes resultantes do Primeiro Estágio

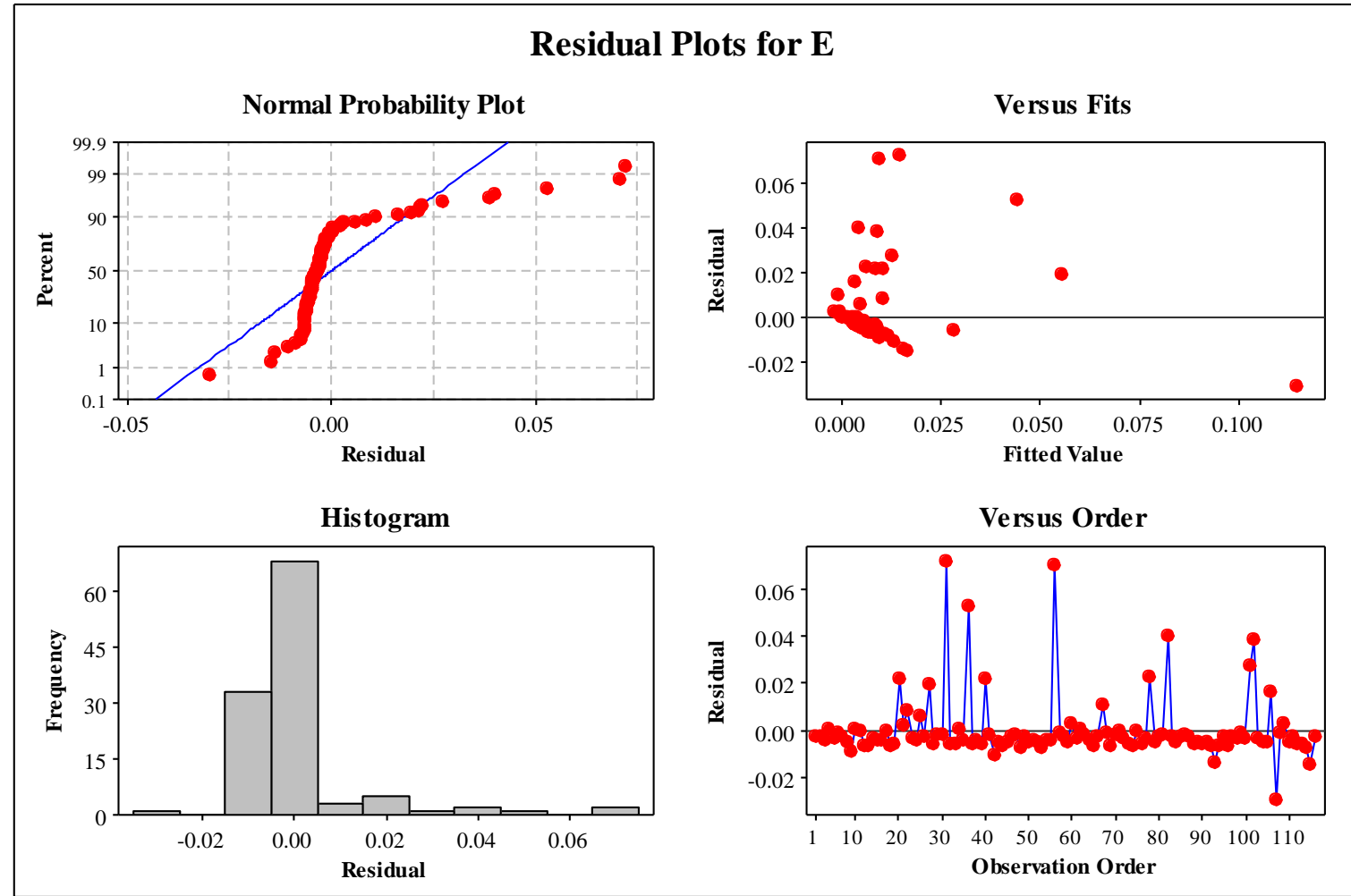

Fonte: Dados da pesquisa. 
Figura 8 - Intervalo de Confiança variável DD no modelo de Regressão para os 116 municípios ineficientes

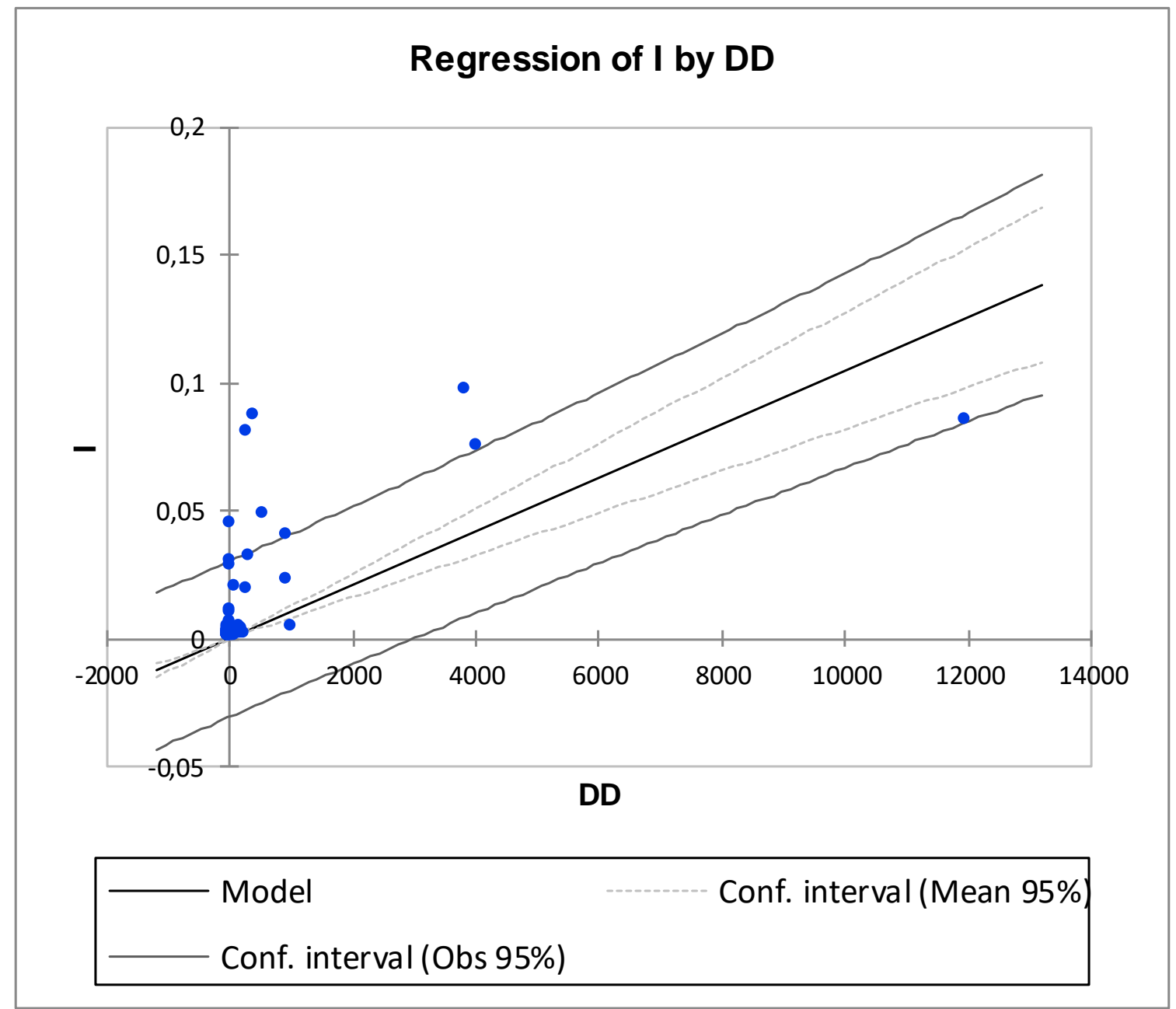

Fonte: Dados da pesquisa. 
Figura 9 - Intervalo de Confiança da variável RS no modelo de Regressão para os 116

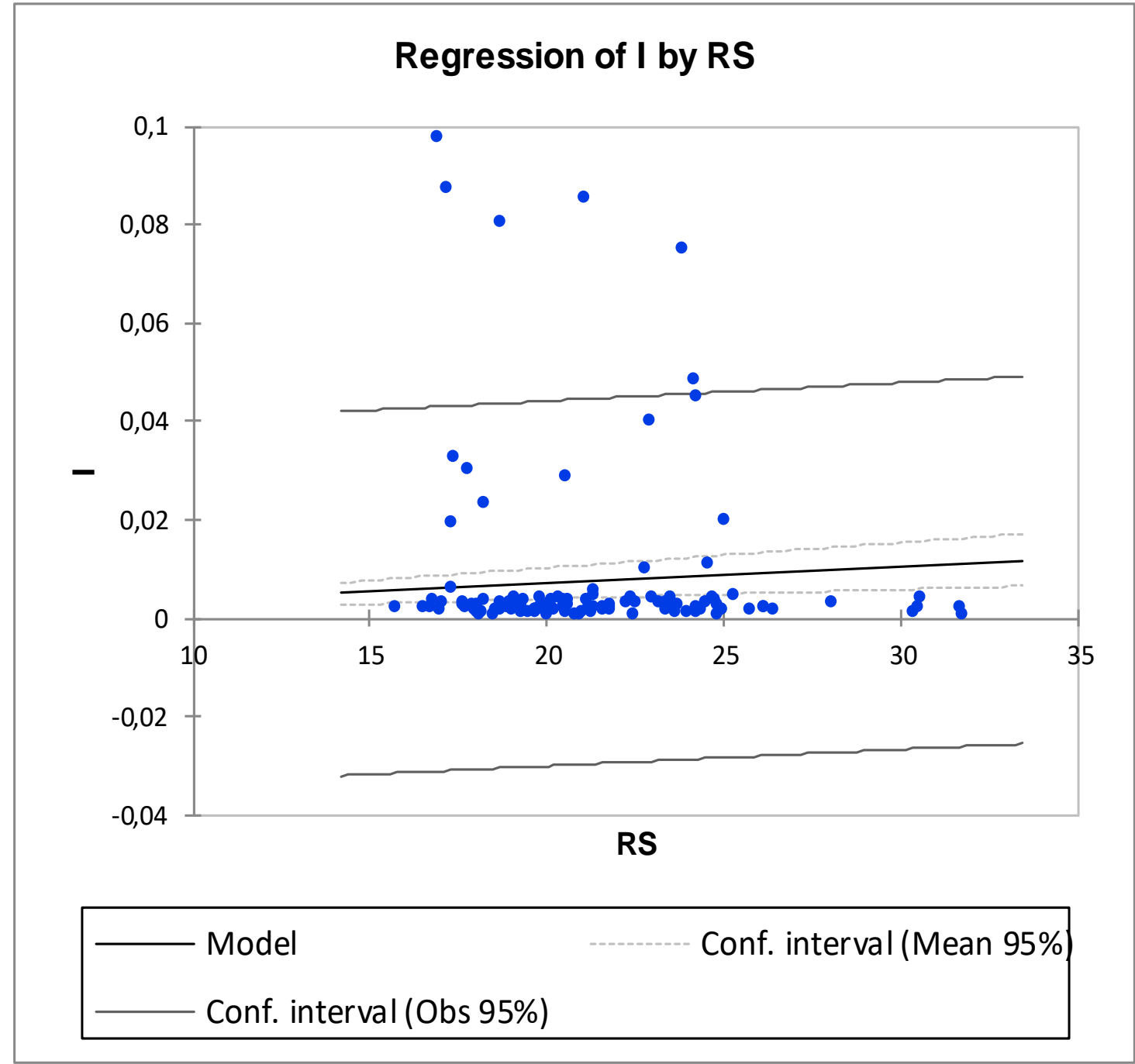

Fonte: Dados da pesquisa.

A Figura 9 mostra que o conjunto de DMUs manteve a previsão da ineficiência dentro do intervalo de confiança de $95 \%$, indicando que o modelo possui capacidade significativa $(\mathrm{p}<0.05)$ de predição. 
Figura 10 - Valores preditivos com base modelo de regressão para os 16 municípios ineficientes

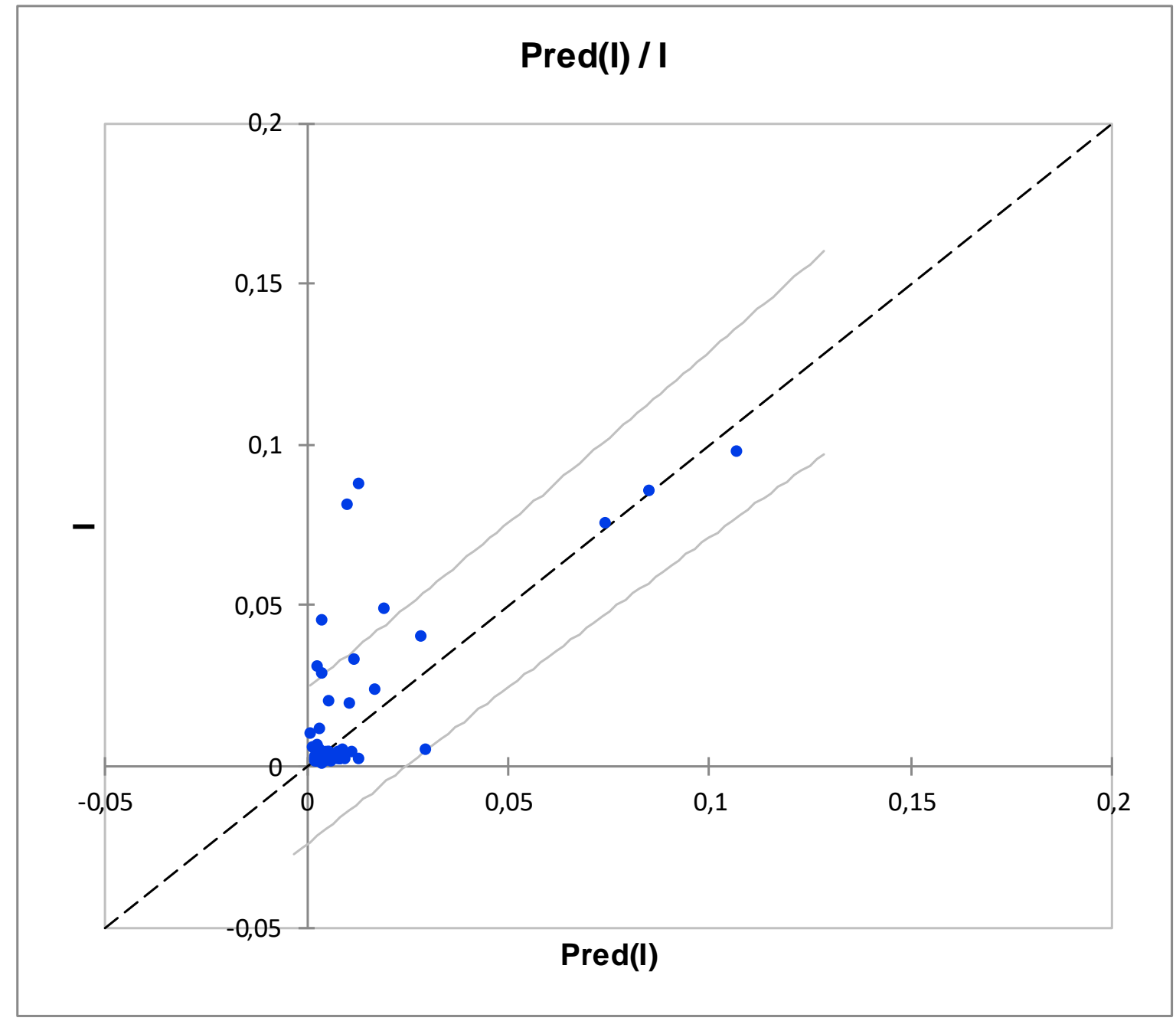

Fonte: Dados da pesquisa. 


\section{APÊNDICE C - Gasto Per Capita}

Tabela 7 - Gasto Per Capita por municípios considerados eficientes

\begin{tabular}{|c|c|c|c|c|c|}
\hline $\begin{array}{c}\text { Classificação } \\
\text { DEA }\end{array}$ & DMU & Município & $\begin{array}{l}\text { Número de } \\
\text { Habitante }\end{array}$ & Despesa Total & $\begin{array}{c}\text { Gasto Per } \\
\text { Capita }\end{array}$ \\
\hline $1^{\circ}$ & DMU74 & Salvador & 2.675 .000 & $1.109 .429 .500,00$ & 414,74 \\
\hline $2^{\circ}$ & DMU79 & Belo Horizonte & 1.433 .000 & $1.825 .570 .350,00$ & $1.273,95$ \\
\hline $3^{\circ}$ & DMU109 & São Paulo & 12.043 .000 & $9.154 .968 .170,00$ & 760,19 \\
\hline $4^{\circ}$ & DMU124 & Restinga Seca & 15.850 & $8.241 .207,50$ & 519,95 \\
\hline $5^{\circ}$ & DMU27 & Fortaleza & 862.750 & $700.846 .335,00$ & 812,34 \\
\hline $6^{\circ}$ & DMU94 & Rio de Janeiro & 6.032 .000 & $4.349 .916 .480,00$ & 721,14 \\
\hline $7^{\circ}$ & DMU91 & Duque de Caxias & 341.304 & $216.513 .018,48$ & 634,37 \\
\hline $8^{\circ}$ & DMU24 & São Luís & 958.545 & 757.164.280,95 & 789,91 \\
\hline $9^{\circ}$ & DMU25 & Teresina & 767.559 & $502.160 .124,57$ & 654,23 \\
\hline $10^{\circ}$ & DMU8 & Belém & 143.474 & $84.523 .402,88$ & 589,12 \\
\hline $11^{\circ}$ & DMU90 & Vitória & 211.529 & $143.456 .852,51$ & 678,19 \\
\hline $12^{\circ}$ & DMU106 & São Bernardo do Campo & 736.466 & $772.619 .115,94$ & $1.049,09$ \\
\hline $13^{\circ}$ & DMU95 & Campinas & 952.659 & $954.812 .009,34$ & $1.002,26$ \\
\hline $14^{\circ}$ & DMU7 & Ananindeua & 470.819 & $306.507 .877,19$ & 651,01 \\
\hline $15^{\circ}$ & DMU105 & Santo André & 568.538 & $387.572 .354,60$ & 681,7 \\
\hline $16^{\circ}$ & DMU93 & Nova Iguaçu & 787.563 & $447.249 .152,07$ & 567,89 \\
\hline $17^{\circ}$ & DMU123 & Porto Alegre & 1.409 .00 & $110.200 .708,89$ & 782,12 \\
\hline
\end{tabular}

Fonte: Dados da pesquisa.

Tabela 8 - Gasto Per Capita por municípios considerados ineficientes

\begin{tabular}{|c|l|l|l|r|r|}
\cline { 1 - 3 } Classificação & \multicolumn{1}{|c|}{ Município } & \multicolumn{1}{|c|}{ DMU } & \multicolumn{1}{|c|}{$\begin{array}{c}\text { Número de } \\
\text { Habitante }\end{array}$} & Despesa Total & \multicolumn{1}{c|}{$\begin{array}{c}\text { Gasto Per } \\
\text { Capita }\end{array}$} \\
\cline { 1 - 4 } $1^{\circ}$ & Guarulhos & DMU96 & 784.971 & $550.303 .919,55$ & 701,05 \\
\hline $2^{\circ}$ & Feira de Santana & DMU59 & 495.516 & $251.409 .952,92$ & 507,37 \\
\hline $3^{\circ}$ & Taboão da Serra & DMU110 & 244.528 & $154.546 .586,56$ & 632,02 \\
\hline $4^{\circ}$ & Londrina & DMU114 & 485.822 & $351.317 .321,08$ & 723,14 \\
\hline $5^{\circ}$ & Curitiba & DMU113 & 1.752 .000 & $1.203 .834 .240,00$ & 687,12 \\
\hline $6^{\circ}$ & São José dos Campos & DMU108 & 533.501 & $468.669 .958,48$ & 878,48 \\
\hline $7^{\circ}$ & Praia Grande & DMU100 & 201.259 & $141.549 .479,88$ & 703,32 \\
\hline $8^{\circ}$ & São José do Rio Preto & DMU107 & 372.492 & $251.260 .753,68$ & 674,54 \\
\hline $9^{\circ}$ & Caruaru & DMU39 & 277.982 & $145.201 .117,88$ & 522,34 \\
\hline $10^{\circ}$ & Ibirubá & DMU122 & 19.310 & $7.959 .968,20$ & 412,22 \\
\hline $11^{\circ}$ & Pilar do Sul & DMU99 & 28.309 & $15.032 .362,09$ & 531,01 \\
\hline $12^{\circ}$ & Ribeirão Preto & DMU102 & 590.593 & $423.927 .655,40$ & 717,8 \\
\hline $13^{\circ}$ & Sobral & DMU32 & 147.353 & $101.266 .875,72$ & 687,24 \\
\hline $14^{\circ}$ & Chapecó & DMU115 & 166.040 & $90.787 .351,20$ & 546,78 \\
\hline $15^{\circ}$ & Condeúba & DMU56 & 18.312 & $8.311 .816,80$ & 453,9 \\
\hline
\end{tabular}




\begin{tabular}{|c|c|c|c|c|c|}
\hline $16^{\circ}$ & Monte Carmelo & DMU83 & 48.096 & $27.756 .201,60$ & 577,1 \\
\hline $17^{\circ}$ & Mocajuba & DMU12 & 30.277 & $15.646 .548,06$ & 516,78 \\
\hline $18^{\circ}$ & Caldas Novas & DMU133 & 70.474 & $33.695 .028,88$ & 478,12 \\
\hline $19^{\circ}$ & Tailândia & DMU19 & 100.300 & $67.346 .435,00$ & 671,45 \\
\hline $20^{\circ}$ & São Cristóvão & DMU55 & 84.620 & $45.977 .430,80$ & 543,34 \\
\hline $21^{\circ}$ & Açu & DMU33 & 56.829 & $40.468 .499,19$ & 712,11 \\
\hline $22^{\circ}$ & Vargem Grande Paulista & DMU111 & 48.720 & $34.408 .987,20$ & 706,26 \\
\hline $23^{\circ}$ & Santana do Araguaia & DMU17 & 55.033 & $24.704 .864,03$ & 448,91 \\
\hline $24^{\circ}$ & Bom Conselho & DMU37 & 47.991 & $26.054 .313,90$ & 542,9 \\
\hline $25^{\circ}$ & Salinópolis & DMU16 & 39.569 & $26.562 .669,70$ & 671,3 \\
\hline $26^{\circ}$ & Bom Jardim & DMU38 & 26.126 & $15.077 .314,60$ & 577,1 \\
\hline $27^{\circ}$ & Cianorte & DMU112 & 100.269 & $78.210 .822,69$ & 780,01 \\
\hline $28^{\circ}$ & Rio do Sul & DMU116 & 66.255 & $27.836 .375,70$ & 420,14 \\
\hline $29^{\circ}$ & Curaçá & DMU57 & 32.165 & $18.269 .076,70$ & 567,98 \\
\hline $30^{\circ}$ & Jaru & DMU1 & 51.883 & $31.758 .103,13$ & 612,11 \\
\hline $31^{\circ}$ & Ipirá & DMU60 & 62.631 & $20.543 .594,31$ & 328,01 \\
\hline $32^{\circ}$ & Videira & DMU118 & 47.510 & $20.363 .736,20$ & 428,62 \\
\hline $33^{\circ}$ & Palmares & DMU44 & 62.300 & $22.941 .352,00$ & 368,24 \\
\hline $34^{\circ}$ & São Lourenço do Sul & DMU127 & 44.935 & $15.374 .060,90$ & 342,14 \\
\hline $35^{\circ}$ & Jacundá & DMU11 & 52.993 & $24.224 .160,16$ & 457,12 \\
\hline $36^{\circ}$ & Presidente Epitácio & DMU101 & 43.718 & $21.939 .441,12$ & 501,84 \\
\hline $37^{\circ}$ & Araxá & DMU78 & 102.238 & $68.273 .514,02$ & 667,79 \\
\hline $38^{\circ}$ & Mauriti & DMU30 & 44.240 & $20.178 .748,80$ & 456,12 \\
\hline $39^{\circ}$ & Guaporé & DMU120 & 22.810 & $16.701 .253,90$ & 732,19 \\
\hline $40^{\circ}$ & Itabaianinha & DMU54 & 40.821 & $17.510 .984,37$ & 428,97 \\
\hline $41^{\circ}$ & Jaguaquara & DMU65 & 51.019 & $16.502 .095,55$ & 323,45 \\
\hline $42^{\circ}$ & Nova Ubiratã & DMU131 & 11.074 & $4.286 .966,88$ & 387,12 \\
\hline $43^{\circ}$ & Guaxupé & DMU82 & 180.008 & $130.169 .185,04$ & 723,13 \\
\hline $44^{\circ}$ & Nazaré da Mata & DMU43 & 30.647 & $19.372 .581,64$ & 632,12 \\
\hline $45^{\circ}$ & União dos Palmares & DMU52 & 65.764 & $34.402 .463,68$ & 523,12 \\
\hline $46^{\circ}$ & Morro do Chapéu & DMU71 & 35.164 & $15.851 .931,20$ & 450,8 \\
\hline $47^{\circ}$ & Candelária & DMU119 & 30.176 & $17.113 .413,12$ & 567,12 \\
\hline $48^{\circ}$ & Itapetinga & DMU63 & 123.439 & $58.628 .587,44$ & 474,96 \\
\hline $49^{\circ}$ & Tracuateua & DMU20 & 25.857 & $13.991 .739,84$ & 541,12 \\
\hline $50^{\circ}$ & Itaocara & DMU92 & 22.824 & $14.954 .056,56$ & 655,19 \\
\hline $51^{\circ}$ & Santana do Acaraú & DMU31 & 29.977 & $17.608 .190,03$ & 587,39 \\
\hline $52^{\circ}$ & São Francisco do Sul & DMU117 & 42.569 & $33.246 .814,69$ & 781,01 \\
\hline $53^{\circ}$ & Domingos Martins & DMU87 & 32.304 & $14.611 .745,28$ & 452,32 \\
\hline $54^{\circ}$ & Aliança & DMU35 & 38.248 & $25.027 .196,32$ & 654,34 \\
\hline $55^{\circ}$ & Francisco Sá & DMU81 & 25.983 & $16.684 .203,96$ & 642,12 \\
\hline $56^{\circ}$ & Mirador & DMU23 & 20.956 & $9.481 .542,20$ & 452,45 \\
\hline $57^{\circ}$ & Itiúba & DMU64 & 36.112 & $19.986 .186,40$ & 553,45 \\
\hline $58^{\circ}$ & Luís Eduardo Magalhães & DMU67 & 83.557 & $56.661 .672,84$ & 678,12 \\
\hline $59^{\circ}$ & Itararé & DMU97 & 50.243 & $27.231 .203,57$ & 541,99 \\
\hline $60^{\circ}$ & Tucumã & DMU21 & 37.920 & $23.706 .446,40$ & 625,17 \\
\hline
\end{tabular}




\begin{tabular}{|c|c|c|c|c|c|}
\hline $61^{\circ}$ & Santa Bárbara & DMU85 & 178.596 & $113.856 .735,96$ & 637,51 \\
\hline $62^{\circ}$ & \begin{tabular}{|lll} 
Santa Cruz & das \\
Palmeiras & & \\
\end{tabular} & DMU103 & 29.974 & $15.678 .200,44$ & 523,06 \\
\hline $63^{\circ}$ & $\begin{array}{|cccc|}\text { Santa } & \text { Maria } & \text { da } & \text { Boa } \\
\text { Vista } & & & \\
\end{array}$ & DMU46 & 40.980 & $20.071 .184,40$ & 489,78 \\
\hline $64^{\circ}$ & Juquiá & DMU98 & 19.446 & $10.915 .039,80$ & 561,3 \\
\hline $65^{\circ}$ & Marco & DMU29 & 26.738 & $21.098 .153,66$ & 789,07 \\
\hline $66^{\circ}$ & Pinheiros & DMU89 & 81.924 & $51.624 .408,60$ & 630,15 \\
\hline $67^{\circ}$ & Glória do Goitá & DMU40 & 29.675 & $21.820 .621,00$ & 735,32 \\
\hline $68^{\circ}$ & Ubatã & DMU76 & 25.004 & $21.905 .254,28$ & 876,07 \\
\hline $69^{\circ}$ & Curuçá & DMU10 & 38.391 & $22.342 .026,36$ & 581,96 \\
\hline $70^{\circ}$ & Ibiapina & DMU28 & 24.555 & $16.020 .173,10$ & 652,42 \\
\hline $71^{\circ}$ & Jitaúna & DMU66 & 14.115 & $11.915 .036,10$ & 844,14 \\
\hline $72^{\circ}$ & Passira & DMU45 & 29.031 & $22.301 .033,58$ & 768,18 \\
\hline $73^{\circ}$ & Maracás & DMU69 & 26.613 & $19.744 .450,83$ & 741,91 \\
\hline $74^{\circ}$ & Codajás & DMU4 & 27.303 & $16.451 .968,71$ & 602,57 \\
\hline $75^{\circ}$ & Barra de Guabiraba & DMU36 & 13.808 & $6.111 .558,88$ & 442,61 \\
\hline $76^{\circ}$ & Pombal & DMU34 & 31.524 & $16.968 .738,72$ & 538,28 \\
\hline $77^{\circ}$ & Carnaubal & DMU26 & 16.755 & $9.512 .986,35$ & 567,77 \\
\hline $78^{\circ}$ & Viçosa & DMU53 & 77.863 & $56.232 .658,60$ & 722,2 \\
\hline $79^{\circ}$ & Água Branca & DMU47 & 16.869 & $12.718 .382,55$ & 753,95 \\
\hline $80^{\circ}$ & Guarani das Missões & DMU121 & 8.114 & $4.244 .595,68$ & 523,12 \\
\hline $81^{\circ}$ & Pacajá & DMU13 & 45.596 & $21.794 .888,00$ & 478 \\
\hline $82^{\circ}$ & Miguel Calmon & DMU70 & 26.466 & $9.442 .804,14$ & 356,79 \\
\hline $83^{\circ}$ & Santa Fé do Sul & DMU104 & 30.872 & $10.714 .127,60$ & 347,05 \\
\hline $84^{\circ}$ & Campo Novo do Parecis & DMU129 & 31.171 & $7.965 .749,05$ & 255,55 \\
\hline $85^{\circ}$ & Macaparana & DMU42 & 24.904 & $9.044 .385,68$ & 363,17 \\
\hline $86^{\circ}$ & Fátima & DMU58 & 19.524 & $8.069 .659,68$ & 413,32 \\
\hline $87^{\circ}$ & Rosário Oeste & DMU132 & 17.682 & $7.782 .909,12$ & 440,16 \\
\hline $88^{\circ}$ & Itacaré & DMU61 & 28.013 & $14.008 .741,04$ & 500,08 \\
\hline $89^{\circ}$ & Carandaí & DMU80 & 23.341 & $16.571 .876,59$ & 709,99 \\
\hline $90^{\circ}$ & Rio Maria & DMU15 & 17.721 & $6.514 .594,02$ & 367,62 \\
\hline $91^{\circ}$ & Pão de Açúcar & DMU51 & 23.809 & $11.567 .602,65$ & 485,85 \\
\hline $92^{\circ}$ & São Sepé & DMU128 & 24.465 & $11.592 .006,30$ & 473,82 \\
\hline $93^{\circ}$ & Valente & DMU77 & 27.162 & $12.077 .854,92$ & 444,66 \\
\hline $94^{\circ}$ & Rorainópolis & DMU6 & 25.714 & $13.230 .881,56$ & 514,54 \\
\hline $95^{\circ}$ & Serra Dourada & DMU75 & 18.389 & $7.864 .607,52$ & 427,68 \\
\hline $96^{\circ}$ & Chapada dos Guimarães & DMU130 & 19.049 & $7.638 .839,49$ & 401,01 \\
\hline $97^{\circ}$ & Cacimbinhas & DMU48 & 10.197 & $4.235 .323,95$ & 415,35 \\
\hline $98^{\circ}$ & Canapi & DMU49 & 12.250 & $6.751 .097,50$ & 551,11 \\
\hline $99^{\circ}$ & Brasil Novo & DMU9 & 14.834 & $7.087 .685,20$ & 477,8 \\
\hline $100^{\circ}$ & Atílio Vivacqua & DMU86 & 9.840 & $4.123 .353,60$ & 419,04 \\
\hline $101^{\circ}$ & Ibiraçu & DMU88 & 12.358 & $5.182 .821,62$ & 419,39 \\
\hline $102^{\circ}$ & Jurema & DMU41 & 14.760 & $5.060 .613,60$ & 342,86 \\
\hline $103^{\circ}$ & Peçanha & DMU84 & 17.817 & $9.011 .482,26$ & 505,78 \\
\hline $104^{\circ}$ & Japaratinga & DMU50 & 7.752 & $3.378 .399,12$ & 435,81 \\
\hline
\end{tabular}




\begin{tabular}{|l|l|l|l|r|r|}
$105^{\circ}$ & Maraã & DMU5 & 18.477 & $8.564 .089,50$ & 463,5 \\
\hline $106^{\circ}$ & Benjamin Constant & DMU3 & 40.417 & $19.847 .172,02$ & 491,06 \\
\hline $107^{\circ}$ & Itajuípe & DMU62 & 21.094 & $12.076 .104,06$ & 572,49 \\
\hline $108^{\circ}$ & Palmeiras & DMU72 & 26.855 & $8.027 .496,60$ & 298,92 \\
\hline $109^{\circ}$ & Peixe-Boi & DMU14 & 7.867 & $2.573 .925,06$ & 327,18 \\
\hline $110^{\circ}$ & Malhada de Pedras & DMU68 & 8.468 & $3.622 .949,12$ & 427,84 \\
\hline $111^{\circ}$ & Santa Bárbara do Sul & DMU125 & 8.829 & $3.391 .130,61$ & 384,09 \\
\hline $112^{\circ}$ & Alto Parnaíba & DMU22 & 10.765 & $3.634 .156,35$ & 337,59 \\
\hline $113^{\circ}$ & Amaturá & DMU2 & 11.242 & $4.108 .726,16$ & 365,48 \\
\hline $114^{\circ}$ & Planaltino & DMU73 & 8.822 & $4.324 .897,28$ & 490,24 \\
\hline $115^{\circ}$ & Santarém Novo & DMU18 & 6.842 & $2.321 .216,92$ & 339,26 \\
\hline $116^{\circ}$ & Santo Augusto & DMU126 & 13.910 & $7.161 .980,80$ & 514,88 \\
\hline
\end{tabular}

Fonte: Dados da pesquisa. 


\section{MODELO DE REGRESSÃO LINEAR MÚLTIPLA}

A regressão linear múltipla é uma técnica multivariada cuja finalidade principal é obter uma relação matemática entre uma das variáveis estudadas (variável dependente ou resposta) e o restante das variáveis que descrevem o sistema (variáveis independentes ou explicativas), e reduzir um grande número de variáveis para poucas dimensões com o mínimo de perda de informação, permitindo a detecção dos principais padrões de similaridade, associação e correlação entre as variáveis. Sua principal aplicação, após encontrar a relação matemática, é produzir valores para a variável dependente quando se têm as variáveis independentes (cálculo dos valores preditos). Ou seja, ela pode ser usada na predição de resultados, por meio da regra estatística dos mínimos quadrados.

$X$ - Variável explicativa ou independente medida sem erro (não aleatória);

E - Variável aleatória residual na qual se procuram incluir todas as influencias no comportamento da variável $\mathrm{Y}$ que não podem ser explicadas linearmente pelo comportamento da variável $\mathrm{X}$;

$\beta_{0}$ e $\beta_{1}$ - parâmetros desconhecidos do modelo (a estimar);

Y - Variável explicada ou dependente (aleatória).

Temos $n$ observações da variável $\mathrm{X}: \mathrm{x}_{1}, \mathrm{x}_{2}, \ldots, \mathrm{x}_{\mathrm{n}}$ (assume-se que estas observações são medidas sem erro).

A inclusão de novas variáveis na equação de ajuste pode ser feita para aumentar o grau de correlação entre os dados teóricos e reais. Tal modelo apresenta a seguinte equação:

$$
Y=\beta_{0}+\beta_{1} X_{1}+\cdots+\beta_{p} X_{p}+e
$$

Sendo $X_{p}$ a $p$-ésima variável observada, $\beta_{p}$ o coeficiente associado à $p$-ésima variável e $e=$ $Y-\widehat{Y}=Y-\beta_{0}-\beta_{1} X_{1}-\cdots-\beta_{p} X_{p}$ o erro que apresenta distribuição normal com média zero e variância $\sigma^{2}$.

O resultado do modelo (1) é um único valor que representa uma combinação do conjunto inteiro de variáveis que melhor atinge o objetivo da análise multivariada específica. A solução de ajuste de reta pode ser generalizada a um conjunto de pontos $\left(x_{1}, y_{1}\right), \ldots,\left(x_{\mathrm{n}}, y_{\mathrm{n}}\right)$, pelo método de mínimos quadrados (MMQ), para que modelos de regressão múltipla possam ser utilizados. Em notação matricial, tem-se que:

$$
\boldsymbol{Y}=\left[\begin{array}{l}
y_{1} \\
y_{2} \\
\mathrm{M} \\
y_{n}
\end{array}\right], \boldsymbol{X}=\left[\begin{array}{ccccc}
1 & x_{11} & x_{12} & \cdot & x_{1 p} \\
1 & x_{21} & x_{22} & \cdot & x_{2 p} \\
\cdot & \cdot & \cdot & \cdot & \cdot \\
1 & x_{n 1} & x_{n 2} & \cdot & x_{n p}
\end{array}\right] \quad \text { e } \boldsymbol{\beta}=\begin{array}{r}
\beta_{0} \\
\beta_{1} \\
\mathrm{M} \\
\beta_{P}
\end{array}
$$


e, assim, pode-se escrever:

$$
\boldsymbol{Y}=X \beta+e
$$

Sendo $\boldsymbol{y}$ um vetor $n \times 1, \mathrm{X}$ uma matriz $n \times(p+1), \boldsymbol{\beta}$ um vetor $p \times 1$ e $\boldsymbol{e}$ um vetor $n \times 1$.

Para obter a solução de ajuste da função linear em $\beta$ a um conjunto de pontos $\left(\mathrm{y}_{1}, \mathrm{x}_{11}, \mathrm{x}_{12}\right.$, $\mathrm{x}_{13}, \ldots, \mathrm{x}_{1 p}$ ), pelo MMQ, deve-se minimizar a expressão:

$$
\sum_{i=1}^{n}\left[y_{i}-\left(\beta_{0}+\beta_{1} X_{i 1}+\beta_{2} X_{i 2}+\cdots+\beta_{p} X_{i p}\right)\right]^{2}=(y-X \beta)^{\prime}(y-X \beta) .
$$

Derivando simultaneamente em termos de $\boldsymbol{\beta}$, tem-se:

$$
\frac{\partial \boldsymbol{y}^{\prime} \boldsymbol{y}}{\partial \boldsymbol{\beta}}-2 \frac{\partial \boldsymbol{y}^{\prime} \boldsymbol{X} \boldsymbol{\beta}}{\partial \boldsymbol{\beta}}+\frac{\partial \boldsymbol{\beta}^{\prime} \boldsymbol{X}^{\prime} \boldsymbol{X} \boldsymbol{\beta}}{\partial \boldsymbol{\beta}}=0-2\left(\boldsymbol{y}^{\prime} X\right)^{\prime}+2 X^{\prime} X \boldsymbol{\beta},
$$

no qual o vetor de dimensão $p+1$ resulta na expressão:

$$
\left(X^{\prime} X\right)^{-1} X^{\prime} y=\widehat{\boldsymbol{\beta}}
$$

Onde $\widehat{\boldsymbol{\beta}}$ é o estimador não viciado do modelo, desde que $\left(X^{\prime} X\right)^{-1}$ exista.

Portanto, o modelo de regressão ajustado e o vetor de resíduos são dados, respectivamente, por:

$$
\widehat{\boldsymbol{y}}=X \widehat{\boldsymbol{\beta}} \text { e } e=\boldsymbol{y}-\widehat{\boldsymbol{y}}=\boldsymbol{y}-X \widehat{\boldsymbol{\beta}}
$$

